\title{
Data quality of collocated portable broadband seismometers using direct burial and vault emplacement
}

Kasey Aderhold ${ }^{1}$, Katherine E. Anderson ${ }^{2}$, Angela M. Reusch ${ }^{2}$, Mary C. Pfeifer ${ }^{2}$, Richard C. Aster $^{3}$, and Tim Parker ${ }^{2}$

Corresponding author: Kasey Aderhold, Department of Earth and Environment, Boston University, 685 Commonwealth Avenue, Room 130, Boston, MA 02215, USA. (kasey@bu.edu)

${ }^{1}$ Department of Earth and Environment, Boston University, Boston, Massachusetts, USA.

${ }^{2}$ Incorporated Research Institutions for Seismology Program for Array Seismic Studies of the Continental Lithosphere Instrument Center, Socorro, New Mexico, USA.

${ }^{3}$ Geosciences Department, Colorado State University, Fort Collins, Colorado, USA.

An edited version of this paper was published by SSA.

Copyright (2015) Seismological Society of America.

Kasey Aderhold, Katherine E. Anderson, Angela M. Reusch, Mary C. Pfeifer, Richard C. Aster, Tim Parker; Data Quality of Collocated Portable Broadband Seismometers Using Direct Burial and Vault Emplacement. Bulletin of the Seismological Society of America; 105 (5): 2420-2432. doi: https://doi.org/10.1785/0120140352 


\section{Data quality of co-located portable broadband seismometers using}

\section{2 direct burial and vault emplacement}

4 Kasey Aderhold ${ }^{1}$, Katherine E. Anderson ${ }^{2}$, Angela M. Reusch ${ }^{2}$, Mary C. Pfeifer ${ }^{2}$, Richard C.

$5 \quad$ Aster $^{3}$, and Tim Parker ${ }^{2}$

6

7 Corresponding author: Kasey Aderhold, Department of Earth and Environment, Boston

8 University, 685 Commonwealth Avenue, Room 130, Boston, MA 02215, USA. (kasey@bu.edu)

$10{ }^{1}$ Department of Earth and Environment, Boston University, Boston, Massachusetts, USA.

$12{ }^{2}$ Incorporated Research Institutions for Seismology Program for Array Seismic Studies of the 13 Continental Lithosphere Instrument Center, Socorro, New Mexico, USA.

$15{ }^{3}$ Geosciences Department, Colorado State University, Fort Collins, Colorado, USA.

17 Electronic Supplement:

18 The supplementary material for this paper contains figures of the daily median noise levels in the

19 microseism band, monthly probability density functions for the magnitude squared coherence

20 between the six station couplings [Direct Burial 1 to Direct Burial 2, Vault 1 to Direct Burial 1,

21 Vault 1 to Direct Burial 2, Vault 1 to Vault 2, Vault 2 to Direct Burial 1, Vault 2 to Direct Burial

22 2] for all three components [BHE, BHN, BHZ], results of the coherency self-noise analysis, and

23 the recordings of the teleseismic and local earthquakes used for the signal-to-noise analysis. 
Aderhold et al.: Data quality of portable broadband seismometers using direct burial and

\section{Abstract}

25 Temporary broadband sensor deployments have traditionally been predominantly emplaced

26 using shallow vaults that require more materials, personnel, and time than direct burial.

27 However, new developments in seismometer and seismograph technology are increasingly

28 facilitating systems that can be directly buried in earth or snow without vault enclosures. We

29 analyze data from two identical shallow vaults installed adjacent to two identical direct burial

30 sites in soft flood plain alluvial and shallow water table conditions near Socorro, New Mexico.

31 Data recorded from these four sensors over eight months in 2012 were assessed to determine if

32 the emplacement type had a significant and systematic effect on data quality. We used metrics

33 derived from power spectral density analysis to examine temporal trends in noise [instrument,

34 installation, and site noise], signal-to-noise ratio for teleseismic and local earthquakes, and

35 magnitude squared coherence of both noise and earthquake signal recordings. We found that

36 noise on the vault sensors is higher during the transition from spring to summer than for the

37 direct burial sensors. This difference is especially evident on the horizontal components at long

38 periods between $20-170$ seconds with an average of $5.3 \mathrm{~dB}$ more noise on the vaults than the

39 direct burials from April to June, indicating enhanced tilt susceptibility for vault emplaced

40 sensors. However, most variability in data quality is comparable between sensors with differing

41 emplacement methods and between sensors with the same emplacement method in this four-

42 station experiment. We conclude that the direct burial emplaced sensors at this test site

43 performed as well as the vault emplaced sensors, and that direct burial is preferable when

44 considering data quality and ease of installation. 
Aderhold et al.: Data quality of portable broadband seismometers using direct burial and

\section{Introduction}

48 Temporary broadband seismic deployments have been driving advancements in seismological

49 investigation into seismic sources and earth structure for decades (e.g., Aster et al., 2005). The

50 emplacement method of choice for temporary broadband deployments has overwhelmingly been

51 a shallow vault-style design, where a hole that is substantially larger than the seismometer is

52 excavated to accommodate bulky installation materials. The vault is designed to protect the

53 sensor from the elements, insulate it from temperature and surface noise, and to couple the

54 sensor stably with the ground (Trnkoczy et al., 2002). Vault-style sensor emplacement often

55 requires significant manpower, installation times of hours to days, and materials that cost

56 hundreds of dollars or more per site. Direct burial emplacement, in contrast, requires an augered

57 or otherwise excavated hole that is only slightly larger than the instrument itself and

58 approximately one hour or less to install a station, while utilizing a fraction of the manpower,

59 tools, and materials. To assess if direct burial is a feasible cost- and time-attractive emplacement

60 alternative to vaults while not compromising data quality, we present a quantitative comparison

61 between data recorded by co-located sensors using the two emplacement types. Four identical

62 broadband sensors were installed in two identical shallow vaults and two identical direct burial

63 sites in close proximity at an alluvial high soil moisture location near Socorro, New Mexico.

64 Eight months of data recorded during 2012 from these four sensors were intercompared to

65 determine any systematic quality differences using metrics derived from power spectral density

66 analysis, signal-to-noise ratios, and magnitude squared coherence. These data quality metrics

67 were also monitored with time, given that sudden but inevitable seasonal changes such as freeze-

68 thaw, soil moisture levels, and high winds are likely to have different effects on sensors installed

69 in different emplacement conditions. 
Aderhold et al.: Data quality of portable broadband seismometers using direct burial and

\section{Site Selection}

71 The installation location $\left[33.96^{\circ} \mathrm{N}, 106.85^{\circ} \mathrm{W}\right]$ is a "soft" site characterized by $\sim 1.2$ meters of

72 recent mud and silt floodplain deposits overlying deeper alluvial fill of the central Rio Grande

73 rift (Cather, 2002). This area is prone to flooding from the river and from adjacent arroyos, and

74 the water table is shallow, varying from many centimeters to several meters deep, depending on

75 the season. Sources of local seismographic noise are likely to include wind, variations in

76 precipitation and soil moisture, temperature cycles, nearby riparian (cottonwood and tamarisk)

77 vegetation, a natural gas pipeline within $2 \mathrm{~km}$, as well as seismic and tilt coupling from

78 vegetation and grazing cattle that may sporadically come within meters of the site (Anderson et

79 al., 2012). Two Program for Array Seismic Studies of the Continental Lithosphere (PASSCAL)-

80 style shallow vaults and two direct burial deployments were co-located within a 4 m-square area,

81 Figure 1a-b. All deployments used Güralp CMG-3T sensors with a long-period corner frequency

82 of $120 \mathrm{~s}$ and a gain of $1500 \mathrm{~V} / \mathrm{m} / \mathrm{s}$. CMG-3Ts are not designed for direct burial, but the two

83 directly buried sensors in this experiment were retrofitted with waterproof cable connectors and

84 cables. Data were collected on two 6-channel Quanterra Q330 digitizers with $1 \mathrm{~Hz}$ and $40 \mathrm{~Hz}$

85 sampling and telemetered to the nearby PASSCAL Instrument Center at New Mexico Tech in

86 Socorro. Data were subsequently archived at the Incorporated Research Institutions for

87 Seismology (IRIS) Data Management Center under the YE temporary network code. The site

88 was powered with four 65-W solar panels and two 100-A-Hr lead acid batteries contained, along

89 with the dataloggers, charge controllers and cell modem, in a very small aperture terminal

90 (VSAT) box sited next to the sensors. A posthole sensor was also installed within the site during

91 the study, but recordings from this station are not analyzed here. 
Aderhold et al.: Data quality of portable broadband seismometers using direct burial and

The PASSCAL-style shallow vaults (Figure 1a) consisted of concentric plastic barrels: an

93 inner 15-gallon with an open bottom for housing the sensor and an outer 55-gallon with a locking

94 lid. Both barrels were installed in the ground over a $20 \mathrm{~cm}$ high cement pier with open-cell foam

95 and styrofoam disks for thermal insulation and air circulation buffering. The direct burial

96 emplaced sensors were contained in a heavy plastic bag and installed on top of $5 \mathrm{~cm}$ of

97 compacted all-purpose sand with fine sand gently tamped around the sensor. The plastic bag

98 covering the direct burial sensors was later removed after it was deemed not necessary for

99 protection. Additional dirt was mounded on top of the sensor installations to provide further

100 insulation and thermal mass to minimize temperature fluctuations. The installation was then

101 covered with a tarp for protection from rain. The vault and the direct burial sensors were both

102 situated at a depth of about $1 \mathrm{~m}$ from the top of the mounded dirt to the sensor base. Sensor

103 specifications are reported in Table 1.

\section{Data Return}

105 There were two sensor failures that occurred during this study, with Direct Burial 2 (Table 1)

106 performing poorly beginning on 22 September 2012, and continuing through November, as well

107 as a failure with the BHE component of Direct Burial 1 on 18 November 2012. A conclusive

108 reason for the failure of the direct burial sensors during this study could not be determined,

109 though both instruments failed most significantly on the BHE component. Lightning strikes were

110 investigated as a possible cause, however there were no storm cells or lightning strikes reported

111 within three days of either failure (U.S. National Lightning Detection Network ${ }^{\mathrm{TM}}$ and NEXRAD,

112 accessed 8 April 2014). A compromised power source may be the cause of a failure. Data

113 recorded during the eight-month period from 1 January 2012 to 31 August 2012, excluding a 
Aderhold et al.: Data quality of portable broadband seismometers using direct burial and

114 telemetry gap on 17 January 2012, was chosen for the analysis to utilize periods of time when all

115 sensors were functioning properly.

116

\section{Data Quality Analysis}

118 Eight months of data from January to August 2012 recorded on all four emplaced sensors were

119 compared to determine if the two emplacement methods showed a systematic effect on data

120 quality. To do this we calculated power spectral density, signal-to-noise ratio for teleseismic and

121 local earthquakes, coherence of the sensors for both noise and earthquake signal recordings, and

122 also monitored and accounted for any discrepancies in data return. This analysis was focused on

123 assessing use of such data in research, as well as examining relevant temporal trends in data

124 quality at scales from seconds to seasons.

\section{Power Spectral Density}

126 To characterize seismic noise levels, we used the method of McNamara et al. (2009) to compare

127 baseline data qualities through power spectral density (PSD) probability density function (PDF)

128 analysis. PSDs were calculated using PQLX software (McNamara and Boaz, 2011) using

129 continuous one-hour time series segments of data overlapping by 50\%, resulting in 48 PSDs per

130 day per sensor. The instrument response was deconvolved from the signal to allow comparison

131 of the calculated PSDs to the New Low Noise Model (NLNM) and New High Noise Model

132 (NHNM) (Peterson, 1993), baselines for seismic station performance that remain widely used

133 despite more recent proposed models (McNamara and Buland, 2004; Berger et al., 2004;

134 Castellaro and Mulargia, 2012). Earthquake and most other signals are highly sporadic, so

135 robust central tendency estimates for the background noise at a seismic station are best 
Aderhold et al.: Data quality of portable broadband seismometers using direct burial and

136 characterized using the median of the PDFs at each frequency interval without resorting to event 137 culling.

138 Median PSD PDFs from eight months of data for each sensor are reported in Figure 2a.

139 There was not a perceptible difference between the overall trends of the $10^{\text {th }}$ and $90^{\text {th }}$ percentiles

140 of the PDFs and the medians of the PDFs. The site may be generally characterized, relative to the

141 Peterson noise models, as being high noise at shorter periods. The high horizontal/vertical noise

142 ratio observed here is typical of shallow vaults (e.g., Anthony et al., 2015), and reflects the

143 coupling of local tilt into horizontal component signals (e.g., Wielandt and Frobriger, 1999). As

144 is often observed, long-period vertical site noise is more coherent than the long-period horizontal

145 site noise. The median PSD PDFs of all eight months of data show that the direct burial sites had

146 highly comparable noise levels to the vaults except for the horizontal components at long periods

$147[15 \mathrm{~s} \leq \mathrm{T}]$ where the east component of both of the direct burials had less noise than the vaults.

148 To highlight differences between the recorded noise levels more clearly, the mean was

149 taken of the four median PSDs of the direct burial and vault sensors for each respective

150 component at each frequency to calculate an average comparison PSD of all stations. The

151 difference between this all-station average PSD and the median PSD of each sensor was then

152 calculated at each frequency, with negative values showing a higher probability of less noise

153 power than the average and positive values showing a higher probability of more noise power

154 than the average (Figure 2b). This analysis shows that the predominant difference in noise level

155 is on the east component where the median power levels of both direct burial stations at periods

156 greater than $15 \mathrm{~s}$ are at least $2 \mathrm{~dB}$ lower than both vault stations. Between the highest noise vault

157 station and the lowest noise direct burial station on the east component this performance

158 difference grows to about $9 \mathrm{~dB}$ at $100 \mathrm{~s}$. The north component does not show this effect, with 
Aderhold et al.: Data quality of portable broadband seismometers using direct burial and

159 Direct Burial 1 performing similarly to the vault stations and only Direct Burial 2 having lower

160 noise. There is some separation in station performance at longer periods on the vertical

161 component, but all station medians stay within a $4 \mathrm{~dB}$ spread of each other at all periods. At

162 periods less than $10 \mathrm{~s}$ on all three components, all four stations stay within $1 \mathrm{~dB}$ of the ensemble

163 mean.

164 Temporal trends in background noise are also an important metric of consistent station

165 performance. Daily temperature cycles and weather patterns change strongly with the season in

166 central New Mexico, with winter months potentially bringing the effects of ground freeze and

167 thaw, spring months characterized by high winds, and summer months heralded by monsoon

168 rains. To explore how these seasonal changes affect the data quality of the differing

169 emplacement types at this site, median PSD PDFs were taken for each day and divided into three

170 useful period bands: short period [0.1-1 s], microseism [2-20 s], and long period [20-172 s].

171 Dividing the result into separate frequency bands is valuable, as there is a strong frequency-

172 dependence on sources of noise and the performance of these stations. These differing

173 bandwidths are also distinctly important to a variety of research applications. Median daily PSD

174 PDFs were interpolated, and the difference between the PSD and the NLNM was calculated at

175 each frequency from 0.1 to $172 \mathrm{~s}$. This difference between daily PSD PDFs and the NLNM was

176 then averaged across each band to create basic seasonal noise level metrics. Since all sensors are

177 compared to the same baseline noise model, these differences can then be compared to one

178 another and provide an accurate average power, or power difference, of the noise for each day.

179 This analysis was performed on all three components of the four sensors in the study and the

180 results of the microseism and long period band are reported in Figure S1 of the electronic

181 supplement to this article and Figure 3 respectively. 
Aderhold et al.: Data quality of portable broadband seismometers using direct burial and

It is well known that teleseismic body waves have a contribution to ambient seismic

183 background through extended coda and aftershock signals that confer small amplitude motion to

184 the surface over a long period of time, and it is possible that this phenomenon is measurable in

185 this analysis (Boué et al., 2013). Days on which a $M_{\mathrm{W}} \geq 7$ earthquake occurred are indicated and

186 while every $M_{\mathrm{W}} \geq 7$ earthquake does not mark a day of higher than average noise, many high

187 noise days do line up with an $M_{\mathrm{W}} \geq 7$ earthquake and we disregard these days to concentrate on

188 locally- or regionally-generated background power trends.

189 The vertical component is ubiquitously the lowest noise component usually with a

190 separation from the horizontals of at least $20 \mathrm{~dB}$, while the noisier east and north components

191 overlap one another (Figure 3). Some of the distinct trends on the vertical component of Direct

192 Burial 2 may be due to the drift of the sensor's mass position, which can add long-period noise

193 on the vertical component of CMG-3T sensors. This prompts a mass re-center command from

194 the data logger and a corresponding abrupt decrease in vertical noise after the sensor settles. If a

195 gradual increase in vertical long-period noise follows the trend of vertical mass-position drift and

196 an abrupt decrease in vertical long-period noise coincides with a mass re-center and mass voltage

197 decrease, then the long-period vertical noise is almost certainly related to mass position. Mass re-

198 centers were triggered by the horizontals of Direct Burial 2 on 8 March and 10 June 2012,

199 coinciding with a drop in the vertical long-period noise of the station. An additional mass re-

200 center on 1 August 2012 does not show a clear drop in long-period noise.

201 The horizontal components of all four sensors show a decrease in noise in the microseism

202 band from April through August in Figure S1 available in the electronic supplement to this

203 paper, reflective of a typical seasonal decrease in Northern Pacific storms during that time period

204 (e.g., Aster et al., 2008; Given, 1990; Hasselmann, 1963). The horizontal components of the 
Aderhold et al.: Data quality of portable broadband seismometers using direct burial and

205 direct burials showed an average decrease of $3.6 \mathrm{~dB}$ from January-March to April-June on the 206 horizontal components compared with an average decrease of only $1.9 \mathrm{~dB}$ on the vault sensors.

207 On the long period band the two direct burial sensors display fairly consistent noise levels with a 208 decrease of noise from April to June on the horizontal components consistent with this scenario.

209 The vaults, however, show a general increase in noise beginning in April in the long period band,

210 which tapers off through August. On average the horizontal components of the vaults have 5.3

$211 \mathrm{~dB}$ more noise from April to June than the direct burials at long periods. The source of this noise

212 is likely local environmental effects occurring in the spring months. Average maximum-

213 minimum temperature differentials are highest during April, May, and June with a $36^{\circ} \mathrm{F}$ monthly

214 average differential during this time period, $4^{\circ} \mathrm{F}$ greater than the average temperature differential

215 of all other months (Arguez et al., 2012). The experimental site is also very near the Rio Grande,

216 with clay-rich alluvium and a variable and shallow water table. Discharge is mainly driven by

217 snowmelt and is recorded on two United States Geological Survey (USGS) water data sites near

218 the sensors, one $18.2 \mathrm{~km}$ directly north and one $3.7 \mathrm{~km}$ directly south. These sites show identical

219 trends, with a relatively steady daily discharge of $700 \mathrm{ft}^{3} / \mathrm{s}$ from January through March,

220 disrupted on 4 April 2012 by the largest spike to over $2000 \mathrm{ft}^{3} / \mathrm{s}$ followed by lesser spikes of

2211500,1000 , and $700 \mathrm{ft}^{3} / \mathrm{s}$ before decreasing to zero flow by the end of July (USGS New Mexico

222 Water Science Center National Water Information System, last accessed 19 February 2015).

223 During demobilization we observed evidence of repeated flooding from the interior floor of the

224 vaults, with water levels to within $15 \mathrm{~cm}$ of the top of the cement pier. Residue of previous

225 moisture beads on the interior top of the inner barrel of the vaults and moisture on the inside of

226 the open-cell foam was also found, but there was no evidence of water flowing in from the top of

227 the vault so we concluded that water must have entered through the base. The direct burial 
Aderhold et al.: Data quality of portable broadband seismometers using direct burial and

228 sensors were above this inferred maximum water table. Repeated wetting and drying of the clay-

229 heavy sediment from changes in the average discharge of the Rio Grande could be responsible

230 for the increase in observed long-period noise observed on the vault sensors in the spring

231 months.

\section{Magnitude Squared Coherence}

233 A useful metric for intercomparing the similarity of signals at co-located seismic stations is to

234 calculate their coherency, a fundamental measure of how similar the phase and amplitude

235 structure of time series data are as a function of frequency. Values of coherency between two

236 time series range from near 0 , indicating incoherence and 1 indicating perfect resemblance. The

237 complex coherency function is the cross-spectral power density function normalized by the

238 square root of the product of the power spectral density functions of the two time series to be

239 compared. The cross spectrum is the discrete Fourier transform of the cross correlation function

240 between two time series $\mathrm{X}$ and $\mathrm{Y}$, where the cross correlation is:

$$
R_{x y}(n)=\sum_{t=-\infty}^{\infty} X(t) Y(t-n)
$$

242 and the cross spectrum is the Fourier transform of the cross correlation at a specific angular

243 frequency $\omega$ :

$$
P_{x y}(\omega)=\sum_{k=-\infty}^{\infty} R_{x y}(m) e^{-j \omega k}
$$

245 The angular frequency $\omega$ can be converted to frequency $f$ by the simple relation:

$$
\omega=2 * \pi * f
$$

247 Magnitude squared coherence $C_{x y}(f)$ (MSC) is calculated in this study given by: 
Aderhold et al.: Data quality of portable broadband seismometers using direct burial and

$$
C_{x y}(f)=\frac{\left|P_{x y}(f)\right|^{2}}{P_{x x}(f) P_{y y}(f)}
$$

249 where $P_{x y}(f)$ is the cross spectrum of the two equally sampled time series $\mathrm{X}$ and $\mathrm{Y}$, and their

250 associated power spectral densities are noted by $P_{x x}(f)$ and $P_{y y}(f)$ respectively. MSC was

251 calculated for each hour of data recorded from January through August of 2012, using the

252 Welch's overlapped averaged periodogram method (Welch, 1967) with 1-hour windows, an

253 overlap of 30 minutes, and a standard Hamming window. With three components [BHE, BHN,

254 BHZ] and three station couplings [Vault 1 to Vault 2, Direct Burial 1 to Direct Burial 2, and

255 Vault 1 to Direct Burial 1] there were 9 interstation same-component comparisons.

256 Probability density functions of MSC were produced from the ensemble of hourly MSC

257 estimates for each station/channel comparison, for each month. The median of this PDF was then

258 evaluated as a representative MSC metric as a function of frequency (Figure 4). Figures for all

259 six station couplings of the monthly probability density functions for MSC are available in the

260 electronic supplement to this article and allow the temporal changes to be observed.

\section{Effect of Orientation Error on MSC}

262 Seismic sensors are typically installed with great precision and care, however orientation errors

263 occur in the field and can be up to $10^{\circ}$ (Ekström and Busby, 2008). Sensor alignment errors can

264 add a significant amount of uncorrelated noise on the horizontal components, and slight

265 variations from the vertical allow noise to leak onto the vertical component particularly in the

266 microseism band (Ringler et al., 2011). In order to determine the relative orientation of the four

267 sensors in this study, we use a modified version of the coherency analysis method by Sleeman et

268 al. (2006). Vault 1 was used as the reference station and hourly data segments from 1 - 31

269 December 2011 were used to minimize both noise and temperature fluctuations (Ringler et al., 
Aderhold et al.: Data quality of portable broadband seismometers using direct burial and

270 2011). Data from the other vaults were rotated in the horizontal plane by increments of $0.1^{\circ}$ until

271 the uncorrelated instrument and site noise in the microseism band [ $3 \mathrm{~s}$ to $30 \mathrm{~s}$ ] median power

272 across all hourly segments was minimized for each individual sensor relative to the data

273 collected at Vault 1. The optimal rotations for each sensor in the clockwise direction relative to

274 Vault 1 were $-4.4^{\circ}, 3.1^{\circ}$, and $-2.4^{\circ}$ for Vault 2, Direct Burial 1, and Direct Burial 2 respectively.

275 These orientation errors are similar to those found for many Advanced National Seismic System

276 stations prior to 2011, and are attributed to uncertainties arising from the use of a magnetic

277 compass to estimate horizontal orientation during sensor deployment (Ringler et al., 2013). The

278 remaining uncorrelated noise levels of the direct burial sensors were within a few decibels of the

279 vaults sensors, with an improvement over the vault sensors in the long periods of 10 seconds or

280 greater on the BHE component.

A significant amount of uncorrelated noise remained in the microseism band on the BHZ

282 component after the rotation in the horizontal plane, prompting a further rotation of the data to

283 minimize uncorrelated noise in the vertical plane using the same methodology as for the

284 horizontal components. The vertical rotation was done iteratively for dip and azimuth with

285 increments of $0.05^{\circ}$ and $1^{\circ}$ respectively. The rotations that minimized the uncorrelated

286 microseism noise were dips and azimuths of $0.2^{\circ} / 10^{\circ}, 0.35^{\circ} / 175^{\circ}, 0.4^{\circ} / 20^{\circ}$, and $0.3^{\circ} / 125^{\circ}$ for the

287 Vault 1, Vault 2, Direct Burial 1, and Direct Burial 2 respectively. Any tilt noise from off-

288 vertical alignment on this scale is negligible for the previous temporal noise analysis due to these

289 small angles. The uncorrelated noise that remained in the microseism was higher in the direct

290 burials and the noise that remained in the long periods was higher in the vaults. This incoherent

291 noise can come from additional sources other than the seismic wavefield alone, such as non- 
Aderhold et al.: Data quality of portable broadband seismometers using direct burial and

292 seismic vault-localized ground strains in a relatively high noise site (Ringler et al., 2011). Other

293 results from this analysis are available in the electronic supplement to this article.

294 To ensure that our results are not affected by calculating the MSC of misaligned stations, 295 we tested the effect of orientation errors on MSC in a controlled way. We took the recorded data

296 of the BHE component of Vault 1 for the month of December 2011 and rotated it in the

297 horizontal plane by $1^{\circ}, 2^{\circ}, 3^{\circ}, 4^{\circ}, 5^{\circ}, 10^{\circ}$, and $20^{\circ}$ to simulate a misalignment. We took each

298 rotated recording and performed the same MSC analysis outlined previously on the original

299 Vault 1 data (Figure 5a-b). Calculating the coherence of the original signal to the slightly rotated

300 signal is a method that fully isolates the effects from a misaligned sensor. Misalignment of the

301 vertical plane was also tested for eastward dips of $0.2^{\circ}, 0.4^{\circ}, 0.8^{\circ}, 1.6^{\circ}$, and $3.2^{\circ}$ from the vertical

302 (Figure 5c-d). The effects in MSC for rotations of the horizontal plane from $1^{\mathrm{o}}-5^{\mathrm{o}}$ were minimal

303 with a maximum 0.01 decrease in MSC at frequencies of 0.3 and $2 \mathrm{~Hz}$. Similarly, MSC was only

304 reduced by a maximum of $\sim 0.015$ with a $0.4^{\circ}$ rotation of the vertical plane and only at the

305 longest frequencies. With larger rotations in both the horizontal and vertical plane, reductions of

$306 \mathrm{MSC}$ are more significant. The maximum orientation errors of the sensors are less than $5^{\circ}$ in the

307 horizontal and $0.4^{\circ}$ in the vertical, which equates to an indiscernible effect on MSC based on our

308 calculation above. We conclude that any uncorrected misalignment between sensors will not

309 impact the results of our calculations, but it should be a consideration for stations with larger

310 orientation errors.

\section{Same-emplacement MSC}

312 For all months the vertical components of the direct burial sensors are more consistently coherent

313 with one another than any other component/station pair at longer periods to about $10 \mathrm{~s}$, past

314 which MSC drops off rapidly, Figure 4. This is in contrast to the vertical component of the 
Aderhold et al.: Data quality of portable broadband seismometers using direct burial and

315 vaults, which are less consistently coherent but show higher levels of vertical component

316 coherence at longer periods to approximately $100 \mathrm{~s}$. The direct burial vertical components also

317 show consistently higher MSC through the microseism band than the vaults. Both horizontal

318 components show comparable MSC between vault-vault and direct burial-direct burial

319 comparisons during all months at periods above $10 \mathrm{~s}$, excluding a dip at $1 \mathrm{~Hz}$. The $1 \mathrm{~Hz}$

320 frequency is often associated with cultural noise, but this decrease in coherency may also be due

321 to wind noise (Wilson et al., 2002; Given, 1990). Temporal trends of MSC can be best observed

322 in the animated plots available in the electronic supplement to this article in Figures S2-S4. From

323 June to August, the coherence of direct burial-to-direct burial horizontal components stay steady

324 at $1 \mathrm{~Hz}$ while the vault-to-vault decrease in coherence. This difference could be due to the

325 additional $30+\mathrm{cm}$ of thermal mass above the direct buried sensors, providing more protection

326 from temperature changes in the summer months. At periods longer than $10 \mathrm{~s}$, the coherence of

327 direct burial-to-direct burial horizontal components vary up to 0.3 in MSC while the vaults vary

328 up to 0.6 in MSC between January and June.

\section{Dissimilar-emplacement MSC}

330 When dissimilar emplacement type sensors are compared, we find that MSC is comparable to the

331 analysis done in the previous section with similar emplacement types at periods higher than $10 \mathrm{~s}$

332 for all three components, Figure 4. The one exception is a drop around $1 \mathrm{~s}$ in MSC between

333 Vault 1 and Direct Burial 1 on the BHE component during August. On the vertical component at

334 periods longer than $50 \mathrm{~s}$, the MSC is higher between Vault 1 and Direct Burial 1 than MSC

335 between Direct Burial 1 and Direct Burial 2. Thus, MSC in recorded signals can be lower

336 between two sensors with the same emplacement than two sensors with different emplacement in 337 this experiment. 
Aderhold et al.: Data quality of portable broadband seismometers using direct burial and

338

339

340

341 Figure 6a. These integrated values were normalized by the ideal magnitude squared coherence to

342 compare the three bands to one another (Anderson et al., 2012). Coherence values of zero

343 indicate the data gaps on 17 January 2012. The short period and long period bands are much less

344 coherent than the microseism band, rarely dipping below 0.8 coherence in both vault-to-vault

345 and direct burial-to-direct burial over all months and all three components. Short period

346 coherence typically falls around 0.7 for all stations and all components. The BHE components

347 show the most temporal change in behavior in the long period band with a range in coherency of

348 1.0-0.6 coherence in January at both station pairings increasing to a range of 1.0-0.5 for direct

349 burial-direct burial and 1.0-0.3 for vault-vault coherence in June. These temporal changes in

350 coherence are well-above the uncorrelated noise of the sensors from misalignment, suggesting

351 that these sensors are recording a source of noise that changes in coherence temporally and is

352 recorded differently based on emplacement type.

353

To investigate temporal cycling of coherence, each month of hourly coherences was

354 converted to the frequency domain by taking the fast Fourier transform for each band and for all

355 six vault and direct burial station pairings (Figure 6b). A distinct diurnal cycle can be identified

356 at the $0-0.2 \mathrm{~Hz}$ band, evident in the sinusoidal pattern of the lowest frequency plots on both the

357 direct burial and vault in June, Figure 6a. The strongest cycle appears in the lowest frequency

358 band for all components, with the highest amplitude corresponding to a daily cycle on the east

359 component (Figure 6b). The vertical component (not shown) displays only a slight diurnal peak

360 on the lowest frequency band, less than one third the amplitude of the east component. The 
Aderhold et al.: Data quality of portable broadband seismometers using direct burial and

361 amplitude of the daily cycle increases in the later months with the highest amplitude in August.

362 This daily cycle of long period noise could be explained by temperature and atmospheric

363 pressure, both diurnally varying factors known to cause uncorrelated noise on sensors (Custódio

364 et al., 2014; Sleeman and Melichar, 2012; Given, 1990). We believe that the decline in MSC of

365 the direct burial sites in June at long periods is due to wind driven spatially variable strain such

366 as ground tilt from tree roots. Relationships between environmental factors, emplacement type,

367 and noise require further analysis.

368 Signal-to-Noise (SNR)

369 The ratio of earthquake signal-to-noise (SNR) recorded by sensors is included in this study

370 because the most common use of PASSCAL seismic stations is to record earthquakes.

371 Teleseismic earthquakes were taken from the National Earthquake Information Center (NEIC)

372 global earthquake search and were selected for $M_{\mathrm{W}} \geq 6$ and within distances of $30^{\circ}$ to $90^{\circ}$ from

373 the installation site. 23 teleseismic earthquakes representing a wide range of depths and faulting

374 styles were used in this analysis, evident from their global Centroid Moment Tensor mechanisms

375 (Ekström et al., 2012). Local earthquakes were taken from the New Mexico Tech Seismological

376 Observatory earthquake archives with distances up to $10 \mathrm{~km}$ from the site, representing

377 magnitudes of $1.1 \geq M_{\mathrm{L}} \geq 0.1$. Six of these local earthquakes had a clear onset to distinguish the

378 event signal from the noise and were included in the analysis. The vertical waveforms were

379 filtered with a second-order, single-pass band-pass filter between $0.5 \mathrm{~Hz}$ and $3 \mathrm{~Hz}$ for teleseismic

380 events and a second-order, single-pass high-pass filter with a corner of $1 \mathrm{~Hz}$ for local events. $P$

381 wave arrivals were calculated to first-order using the TauP Toolkit (Crotwell et al., 1999) with

382 the IASP91 1D earth model (Kennett and Engdahl, 1991) and then were manually repicked. Two

383 windows of data were selected before and after the manually picked arrival for the noise and 
Aderhold et al.: Data quality of portable broadband seismometers using direct burial and

384 signal windows, each with lengths of 40 seconds for teleseismic and 1 second for local 385 earthquakes. The signal-to-noise ratio (SNR) was defined as the ratio of the root-mean-square 386 (RMS) of the signal over the RMS of the noise.

All stations have a median SNR of 17 or above and a mean SNR of greater than 26 for 388 teleseismic earthquakes occurring between 1 January and 31 August 2014, recorded on the

389 vertical component (Table 2). Both mean and median are shown, but the median SNR is less

390 biased by the greater signal of the largest earthquakes. The differences of SNR between sensors

391 for these strong teleseisms, not surprisingly, are insignificant for the frequency range of $0.5-3$

392 Hz. Both direct burial stations had slightly higher SNR than both vault stations for all six of the

393 local earthquakes but the differences were not significant (Table 3). Recordings of the

394 teleseismic and local earthquakes can be found in Figure S7 and S8 available in the electronic 395 supplement to this paper.

396 Coherency of pre-event noise and coherency of earthquake signal between the four 397 sensors was compared using the largest event that occurred during the study period, the $M_{\mathrm{W}} 7.7$

398 earthquake near Japan on 14 August 2012. The MSC, as defined in the previous section, was

399 taken on the pre-event noise and a signal window defined by 15 minutes of unfiltered data

400 windowed on either side of the $P$ arrival, Figure 7 . The signal portion is always more coherent

401 than the noise particularly at low frequencies of less than $0.1 \mathrm{~Hz}$ but also at high frequencies of

402 about $10 \mathrm{~Hz}$. Signal coherency is of comparable magnitude between all stations pairings, with

403 the dissimilar pairing of Vault 1 and DB 1 showing the highest values. This suggests that

404 emplacement type does not have a detectable impact on the coherence of recorded events

405 between adjacent sensors. 
Aderhold et al.: Data quality of portable broadband seismometers using direct burial and

\section{Conclusions}

408 We conclude that in this high-noise and soft-soil site broadband sensors with direct burial

409 emplacement have very similar data quality to co-located sensors with vault emplacement over

410 an eight-month record. Power spectral density (PSD) probability density function (PDF) analysis

411 shows that all components of directly buried sensors have comparable noise levels to sensors

412 emplaced in vaults. However, the sites show differing responses to seasonal changes that we

413 attribute to the soil column, with horizontal components of the direct burial sensors at long

414 periods showing less noise beginning in early April while the vault sensors show increased noise, 415 with these trends continuing into mid-July. This represents an improvement of $5.3 \mathrm{~dB}$ in mean

416 noise levels on horizontal components of the direct burial sensors over the vault sensors at long

417 periods during the spring transition, when these moist soils are undergoing vadose zone drying

418 and/or shallow freeze thaw, and indicating that direct burial sensors were in this case more

419 resistant to tilt-coupled noise from these processes.

420 Diurnal cycling of magnitude squared coherence (MSC) is apparent in both vault and

421 direct burial comparisons, and is most obvious in the long period band of all components starting

422 in mid-July. August shows the widest range of MSC in both emplacement type comparisons,

423 cycling from 0.1 to 1 . The MSC probability density functions show that the direct burial-to-direct

424 burial comparisons have a smaller range of coherence values around $1 \mathrm{~Hz}$ than the vault-to-vault

425 coherency. This could be explained by atmospheric pressure induced tilt known to produce

426 incoherent signals even at sensors co-located to within 1 meter, as well as increased incoherency

427 due to the vault void space (Ringler et al., 2011).

428 The signal-to-noise analysis shows similar values for high signal/noise teleseismic events

429 recorded at all four stations as well as for lower signal/noise local events down to $M_{\mathrm{L}}$ of 0.1 . 
Aderhold et al.: Data quality of portable broadband seismometers using direct burial and

430 Coherence of the largest recorded earthquake $\left[M_{\mathrm{W}} 7.7\right]$ during the field experiment did not 431 appreciably differ between like and dislike emplacement types.

432 We compare data quality between vault-sited and shallow directly buried sensors to show

433 that the time and cost advantages of direct burial do not appreciably degrade data quality in a soft

434 soil environment. Noise recorded by vault-sited sensors is generally higher in amplitude during

435 the transition from spring to summer as compared to the direct burials. This increase is especially

436 evident on the tilt-coupled horizontal components at long periods between 20-170 s. Levels of

437 noise, and diurnal changes in the levels, are similar at all sensors from cultural activity, wind

438 noise, local tilting, and temperature fluctuations. We conclude that direct burial broadband

439 sensors in this environment were essentially equivalent in data quality to the shallow vaults, and

440 can be superior.

441 Although this was a closely monitored and maintained site, two directly buried sensors

442 failed on separate occasions. While this does not necessarily indicate that these standard 3T were

443 ill suited for the direct burial environment, we do not endorse directly burying broadband sensors

444 that are not purpose-built for direct burial. This work thus suggests that the community would be

445 well served by developing and deploying robust broadband sensors that can be routinely installed

446 via direct burial using the methods discussed in this paper.

447 To improve data quality for similar portable broadband sites, we suggest employing a

448 similar augured direct burial technique over vault installation to reduce the cargo load for each

449 installation and to reduce noise from non-seismic sources. Augered posthole design has been

450 utilized for seismic emplacement in icy environments, and includes an "all in one" datalogger

451 and sensor design to further reduce installation materials (Bernsen et al., 2014). Streckeisen STS-

452 4B and Trillium 120PH sensors installed in deeper posthole/borehole systems show 
Aderhold et al.: Data quality of portable broadband seismometers using direct burial and

453 improvement over deeper Transportable Array style vaults in the long period band on the

454 horizontal components, and methods for securing the cables and sensors within these

455 configurations have been developed to further improve station performance (Frassetto et al.,

456 2014). These techniques will soon be deployed on a large scale in EarthScope USArray

457 Transportable Array activities in Alaska and Canada (Busby et al., 2013).

458

459 Data and Resources

460 All data used in this study can be obtained under the network code YE from the IRIS Data

461 Management Center at www.iris.edu [last accessed February 2015].

462

\section{Acknowledgements}

464 The seismic instruments were provided by IRIS through the PASSCAL Instrument Center at

465 New Mexico Tech. The facilities of the IRIS Consortium are supported by the National Science

466 Foundation under Cooperative Agreement EAR-1261681 and the DOE National Nuclear

467 Security Administration. The authors appreciate the valuable comments of two anonymous

468 reviewers that helped to improve this article. Thank you to the numerous researchers and

469 students who contributed to all stages of this long-term project, and especially to the entire staff

470 at IRIS PASSCAL Instrument Center including Noel Barstow, Pnina Miller, George Slad, and

471 Bruce Beaudoin.

472

473

474

475 
Aderhold et al.: Data quality of portable broadband seismometers using direct burial and

\section{References}

477 Anderson, K. E., S. Azevedo, N. Barstow, B. Beaudoin, L. Carothers, J. Gridley, M. Love, P.

478 Miller, T. Parker, C. Pfeifer, A. M. Reusch, G. Slad, and D. Thomas (2013). Preliminary report:

479 PASSCAL sensor emplacement testing at Poker Flats, Alaska, EarthScope National Meeting,

480 Raleigh, USA.

481

482 Anderson, K. E., J. F. Anderson, R. E. Anthony, J. Chaput, N. D. McMahon, E. A. Morton, C.

483 Pfeifer, M. E. Templeton, J. M. Tarnowski, T. Parker, and R. C. Aster (2012). A site comparison

484 of shallow vault-deployed and direct burial broadband sensors, Incorporated Research

485 Institutions for Seismology Workshop, Boise, USA.

486

487 Anthony, R., R. Aster, D. Wiens, A. Nyblade, S. Anandakrishnan, A. Huerta, J. P. Winberry, T.

488 Wilson, and C. Rowe (2015). The seismic noise environment of Antarctica, Seismol. Res. Lett., $4898612 \mathrm{p}$.

490

491 Arguez, A., I. Durre, S. Applequist, R. S. Vose, M. F. Squires, X. Yin, R. R. Heim, and T. W.

492 Owen (2012), NOAA's 1981-2010 U.S. climate normals: An overview. Bull. Amer. Meteor.

493 Soc., 93 1687-1697.

494

495 Aster, R., B. Beaudoin, J. Hole, M. Fouch, J. Fowler, and D. James (2005). IRIS seismology

496 program marks 20 years of discovery, EOS Trans. AGU, 86 171-172. 
Aderhold et al.: Data quality of portable broadband seismometers using direct burial and

498 Aster, R. C., D. E. McNamara, and P. D. Bromirski (2008). Multidecadal climate-induced 499 variability in microseisms, Seismol. Res. Lett., 79, 194-202.

500

501 Berger, J., P. Davis, and G. Ekström (2004). Ambient Earth noise: A survey of the Global

502 Seismographic Network, J. Geophys. Res, 109 1-10.

503

504 Bernsen, S., P. Winberry, A. Huerta, R. Aster, R. Woodward, P. Carpenter, B. Beaudoin, and J.

505 Gridley (2014). Development of new seismological observing capabilities for ice covered 506 environments, American Geological Union Fall Meeting, San Francisco, USA.

508 Boué, P., P. Poli, M. Campillo, H. Pedersen, X. Briand, and P. Roux (2013). Teleseismic 509 correlations of ambient seismic noise for deep global imaging of the Earth, Geophys. J. Int., 194 $510 \quad 844-848$.

511

512 Busby, R., K. Hafner, and R. Woodward (2013). Transportable Array plans for Alaska and 513 Yukon, EarthScope National Meeting, Raleigh, USA.

514

515 Castellaro, S., and F. Mulargia (2012). A statistical low noise model of the earth, Seismol. Res. 516 Lett., 83 39-48.

517

518 Cather, S. M. (2002). Preliminary geologic map of the San Antonio 7.5 minute quadrangle,

519 Socorro County, New Mexico. New Mexico Bureau of Geology and Mineral Resources, Open-

520 File Geologic Map OF-GM-58, scale 1:24,000. 
Aderhold et al.: Data quality of portable broadband seismometers using direct burial and

522 Crotwell, H. P., T. J. Owens, and J. Ritsema (1999). The TauP Toolkit: Flexible seismic travel-

523 time and ray-path utilities, Seismol. Res. Lett., 70 154-160.

524

525 Custódio, S., N. A. Dias, B. Caldeira, F. Carrilho, S. Carvalho, C. Corela, J. Díaz, J. Narciso, D.

526 Madureira, L. Matias, C. Haberland, and WILAS Team (2014). Ambient noise recorded by a

527 dense broadband seismic deployment in western Iberia, Bull. Seism. Soc. Am., 104 2985-3007.

528

529 Ekström, G., M. Nettles, and A. M. Dziewonski (2012). The global CMT project 2004-2010:

530 Centroid-moment tensors for 13,017 earthquakes, Phys. Earth Planet. In., 200 1-9.

531

532 Esktröm, G., and R. W. Busby (2008). Measurements of seismometer orientation at USArray

533 transportable array and backbone stations, Seismol. Res. Lett., 79 554-561.

534

535 Frassetto, A., B. Busby, K. Hafner, A. Sauter, and R. Woodward (2014). Posthole sensor

536 performance in the USArray Transportable Array - results from testing and initial deployments

537 in Alaska and Canada, American Geophysical Union Fall Meeting, San Francisco, CA.

538

539 Given, H. K. (1990). Variations in broadband seismic noise at IRIS/IDA stations in the USSR

540 with implications for event detection, Bull. Seismol. Soc. Am., 80 2072-2088.

541

542 Hasselmann, K. (1963). A statistical analysis of the generation of microseisms, Rev. Geophs. 1

$543 \quad 177-210$. 
Aderhold et al.: Data quality of portable broadband seismometers using direct burial and

545 Kennett, B. L. N., and E. R. Engdahl (1991). Traveltimes for global earthquake location and 546 phase identification, Geophys. J. Int., 105 429-465.

547

548 McNamara, D. E., and R. I. Boaz (2011). PQLX: A seismic data quality control system

549 description, applications and users manual, U.S. Geological Survey Open-File Report 2010$5501292,41 \mathrm{p}$.

551

552 McNamara, D. E., C. R. Hutt, R. P. Buland, L. S. Gee, H. Bolton, and H. M Benz (2009). A

553 method to establish seismic noise baselines for automated station assessment, Seismol. Res. Lett.,

$55480628-637$.

555

556 McNamara, D. E., and R. P. Buland (2004). Ambient noise levels in the continental United

557 States, Bull. Seism. Soc. Am., 94 1517-1527.

558

559 National Earthquake Information Center (2013). Global earthquake search.

560 [www.earthquake.usgs.gov/earthquakes/search].

561

562 New Mexico Tech Seismological Observatory (2013). Earthquake archives.

563 [www.ees.nmt.edu/outside/NMTSO/archives.html].

564

565 Peterson, J. (1993). Observations and modeling of seismic background noise, U.S. Geological 566 Survey Open-File Report 93-322, 41 p. 
Aderhold et al.: Data quality of portable broadband seismometers using direct burial and

568 Ringler, A. T., C. R. Hutt, J. R. Evans, and L. D. Sandoval (2011). A comparison of seismic

569 instrument noise coherence analysis techniques, Bull. Seism. Soc. Am., 101 558-567.

570

571 Ringler, A. T., C. R. Hutt, K. Persefield, and L. S. Gee (2013). Seismic stations installation

572 orientation errors at ANSS and IRIS/USGS stations, Seismol. Res. Lett., 84 926-931.

573

574 Sleeman, R., A. van Wettum, and J. Trampert (2006). Three-channel correlation analysis: a new

575 technique to measure instrumental noise of digitizers and seismic sensors, Bull. Seism. Soc. Am.,

$57696,258-271$.

577

578 Sleeman, R., and P. Melichar (2012). PDF representation of the STS-2 self-noise obtained from

579 one year of data recorded in the Conrad Observatory, Austria, Bull. Seism. Soc. Am., 102 587-

580597.

581

582 Trnkoczy, A., P. Bormann, W. Hanka, L. G. Holcomb, and R. L. Nigbor (2002). Site selection,

583 preparation and installation of seismic stations, in IASPEI New Manual of Seismological

584 Observatory Practice, vol. 1, edited by P. Bormann, chap. 7, 1-106, GeoForschungsZentrum,

585 Potsdam.

586

587 Welch, P. D. (1967). The use of the fast Fourier transform for the estimation of power spectra: a

588 method based on time averaging over short, modified periodograms, IEEE Transactions on

589 Audio and Electroacoustics, 15 70-73. 
Aderhold et al.: Data quality of portable broadband seismometers using direct burial and

591 Wielandt, E., and T. Forbriger (1999). Near-field seismic displacement and tilt associated with

592 the explosive activity of Stromboli, Ann. Geofis., 42 407-416.

593

594 Wilson, D., J. Leon, R. Aster, J. Ni, J. Schlue, S. Grand, S. Semken, S. Baldridge, and W. Gao

595 (2002). Broadband seismic background noise at temporary seismic stations observed on a

596 regional scale in the southwestern United States, Bull. Seism. Soc. Am., 92 3335-3341.

597

598 List of Figure Captions

599 Figure 1 a) Cross-section schematic of vault and direct burial emplacement. b) Map view

600 schematic of experimental setup at the installation site, after Anderson et al. (2012).

601

602 Figure 2 a) Medians of PDFs for each station from January to August 2012. Vault stations are in 603 darker shades and direct burials are in lighter shades. Dashed lines are the NLNM and NHNM.

604 b) Deviation from the mean of the median noise levels from the four stations over the same time 605 period, with positive values for a higher power than the mean and negatives values for a lower 606 power than the mean.

607

608 Figure 3) Daily median noise levels at long periods (20-172 seconds) with respect to the NLNM 609 for eight months of study, 1 January through 31 August 2012, on all four stations. Vertical 610 dashed lines indicate days on which a $M_{\mathrm{W}} \geq 7$ earthquake occurred. Vertical solid lines indicate a 611 mass re-center on Direct Burial 2. 
Aderhold et al.: Data quality of portable broadband seismometers using direct burial and

613 Figure 4) Median probability density functions of hourly MSC for each month between January

614 to August 2012 on the BHE, BHN, and BHZ components of Direct Burial 1 vs. Direct Burial 2,

615 Vault 1 vs. Vault 2 and Direct Burial 1 vs. Vault 1.

616

617 Figure 5) Results of MSC analysis of original data and rotated data from the BHE component of

618 Vault 1 during the month of December 2011. a) PDF of magnitude squared coherence of Vault 1

619 station and Vault 1 station rotated by $20^{\circ}$ in the horizontal plane. White lines show median PDF

620 of $1-20^{\circ}$ rotations. b) Median probability density functions for $1^{\circ}, 2^{\circ}, 3^{\circ}, 4^{\circ}, 5^{\circ}, 10^{\circ}$, and $20^{\circ}$

621 rotations in the horizontal plane. c) PDF of MSC of Vault 1 station and Vault 1 station with $3.2^{\circ}$

622 rotation of the vertical plane. White lines show median PDF of 0.2-3.2 ${ }^{\circ}$ rotations. d) Median

623 PDFs for $0.2^{\circ}, 0.4^{\circ}, 0.8^{\circ}, 1.6^{\circ}$, and $3.2^{\circ}$ rotations in the horizontal plane.

624

625 Figure 6 a) Hourly integrated and normalized MSC between stations of the same emplacement.

626 Four plots show the hourly MSC between direct burial stations and vault stations on the BHE

627 component for the representative months of January and June at three different frequency bands.

628 The diurnal behavior becomes more apparent in June, along with an overall decrease in

629 coherence in the vault stations. b) Eight months of hourly MSC values recorded on the BHE

630 component converted to the frequency domain. There is a strong diurnal signal on both sets of

631 stations in the long periods, increasing in amplitude through the year. Similar behavior is found

632 on the BHE and BHN components of all other pairings between direct burial and vault stations.

633

634 Figure 7) MSC of a $M_{\mathrm{W}} 7.7$ earthquake near Japan on 14 August 2012 recorded on the vertical

635 component with noise windows on the left and signal windows on the right. 
Aderhold et al.: Data quality of portable broadband seismometers using direct burial and

636 Kasey Aderhold

637 Department of Earth and Environment

638 Boston University

639685 Commonwealth Avenue, Room 130

640 Boston, MA 02215

641

642 Katherine E. Anderson

643 IRIS PASSCAL Instrument Center

644 New Mexico Tech

645100 East Road

646 Socorro, NM 87801

647

648 Angela M. Reusch

649 IRIS PASSCAL Instrument Center

650 New Mexico Tech

$651 \quad 100$ East Road

652 Socorro, NM 87801

653

654 Mary C. Pfeifer

655 IRIS PASSCAL Instrument Center

656 New Mexico Tech

$657 \quad 100$ East Road

658 Socorro, NM 87801 
Aderhold et al.: Data quality of portable broadband seismometers using direct burial and

659

660 Richard C. Aster

661 Geosciences Department

662 322E NR Building

663 Warner College of Natural Resources

664 Colorado State University

665 Fort Collins, CO 80523

666

667 Tim Parker

668 IRIS PASSCAL Instrument Center

669 New Mexico Tech

$670 \quad 100$ East Road

671 Socorro, NM 87801 
a)

\section{Vault}

\section{Direct Burial}

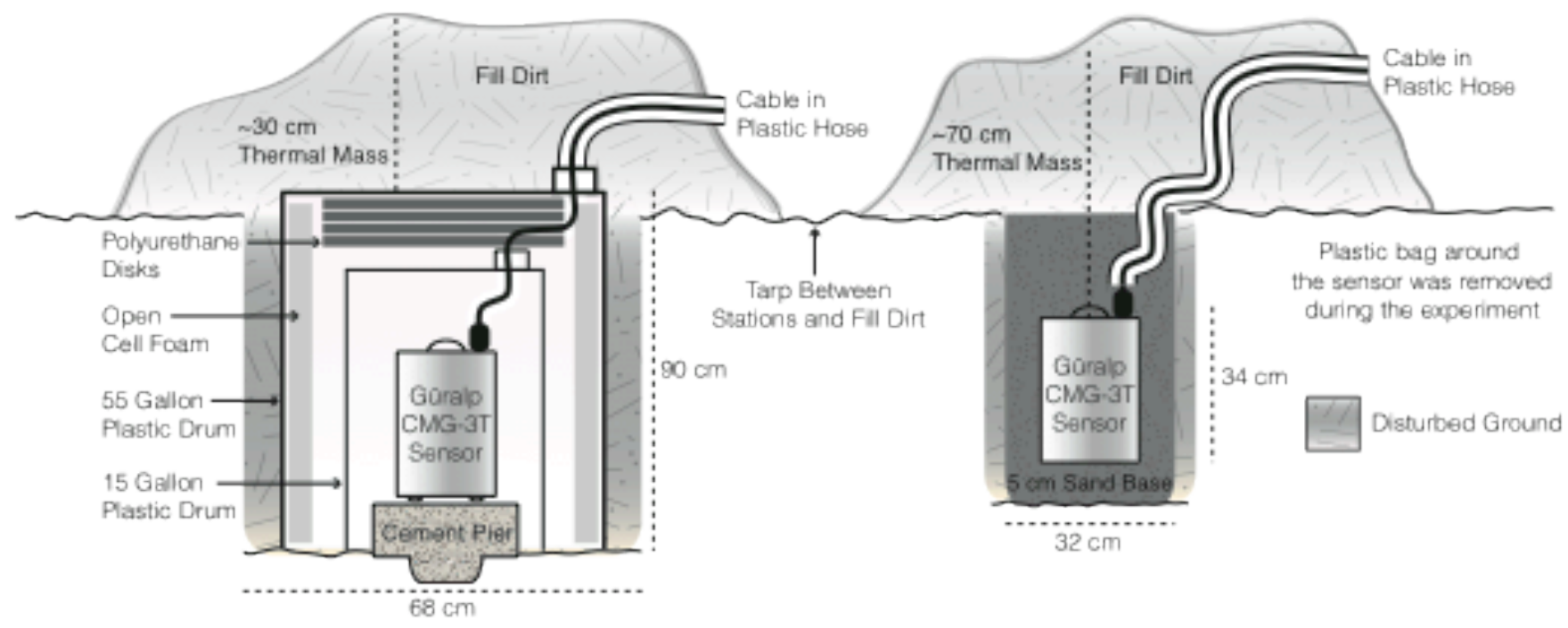

b)

\section{9}

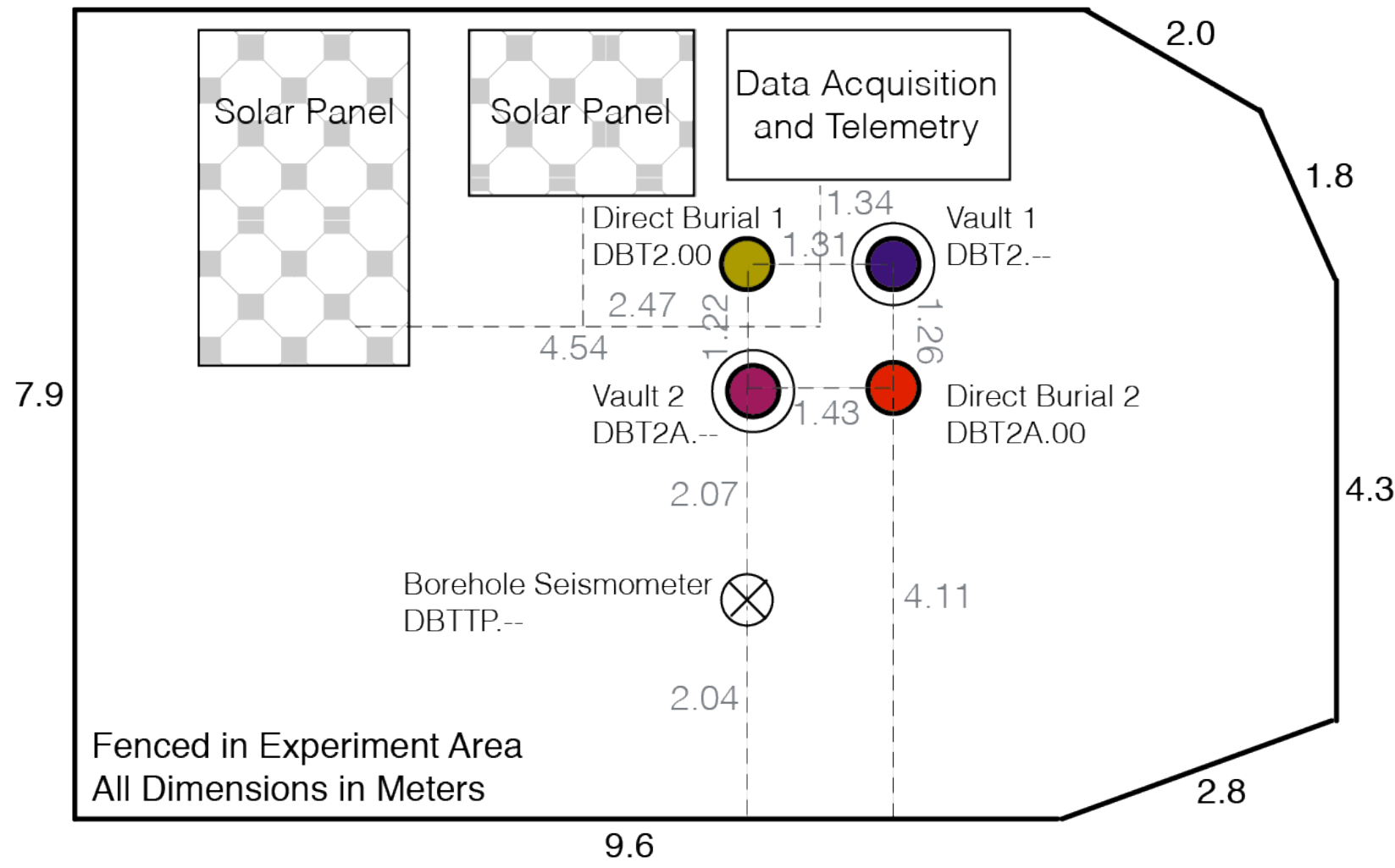

Figure 1 a) Cross-section schematic of vault and direct burial emplacement, after Anderson et al. (2012). b) Map view schematic of experimental setup at the installation site, after Anderson et al. (2012). 
a)
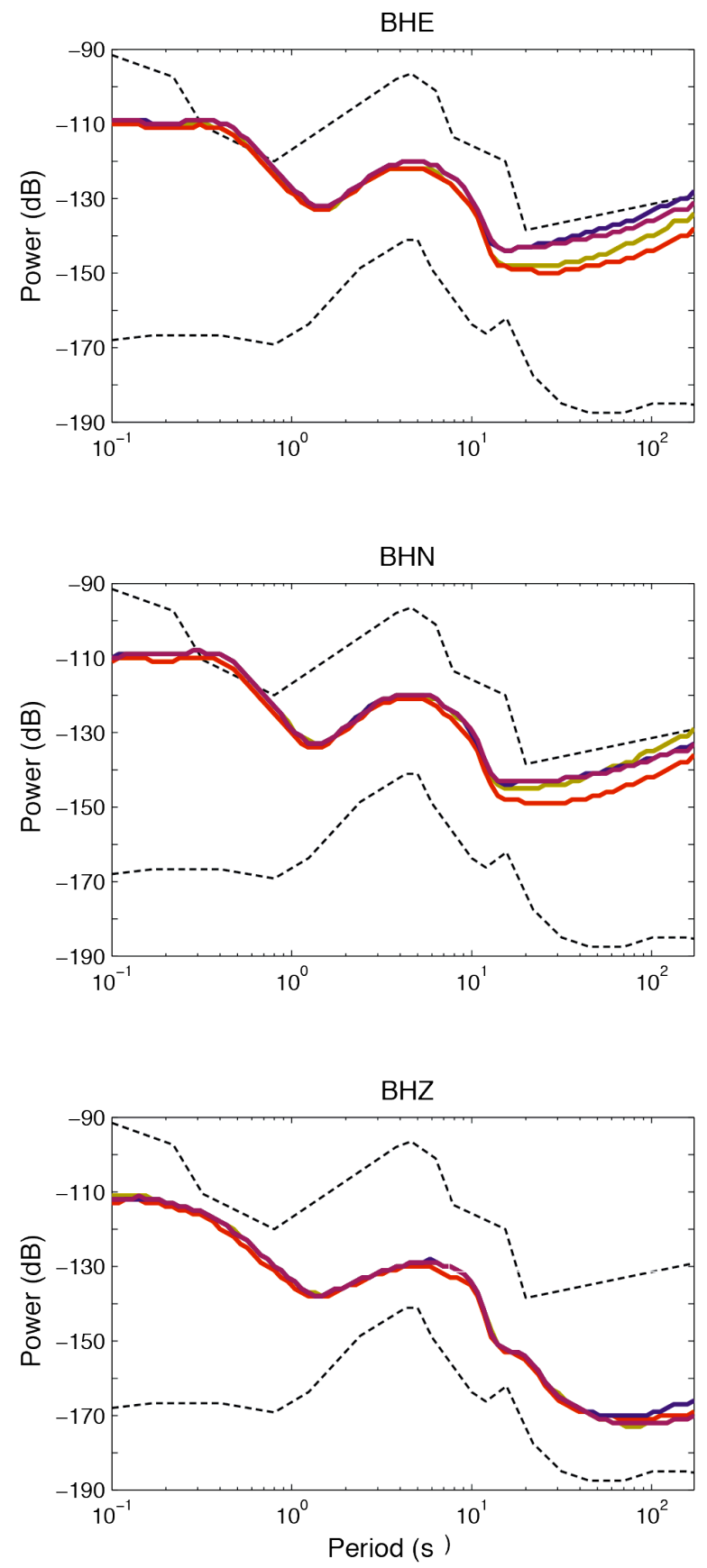

b)

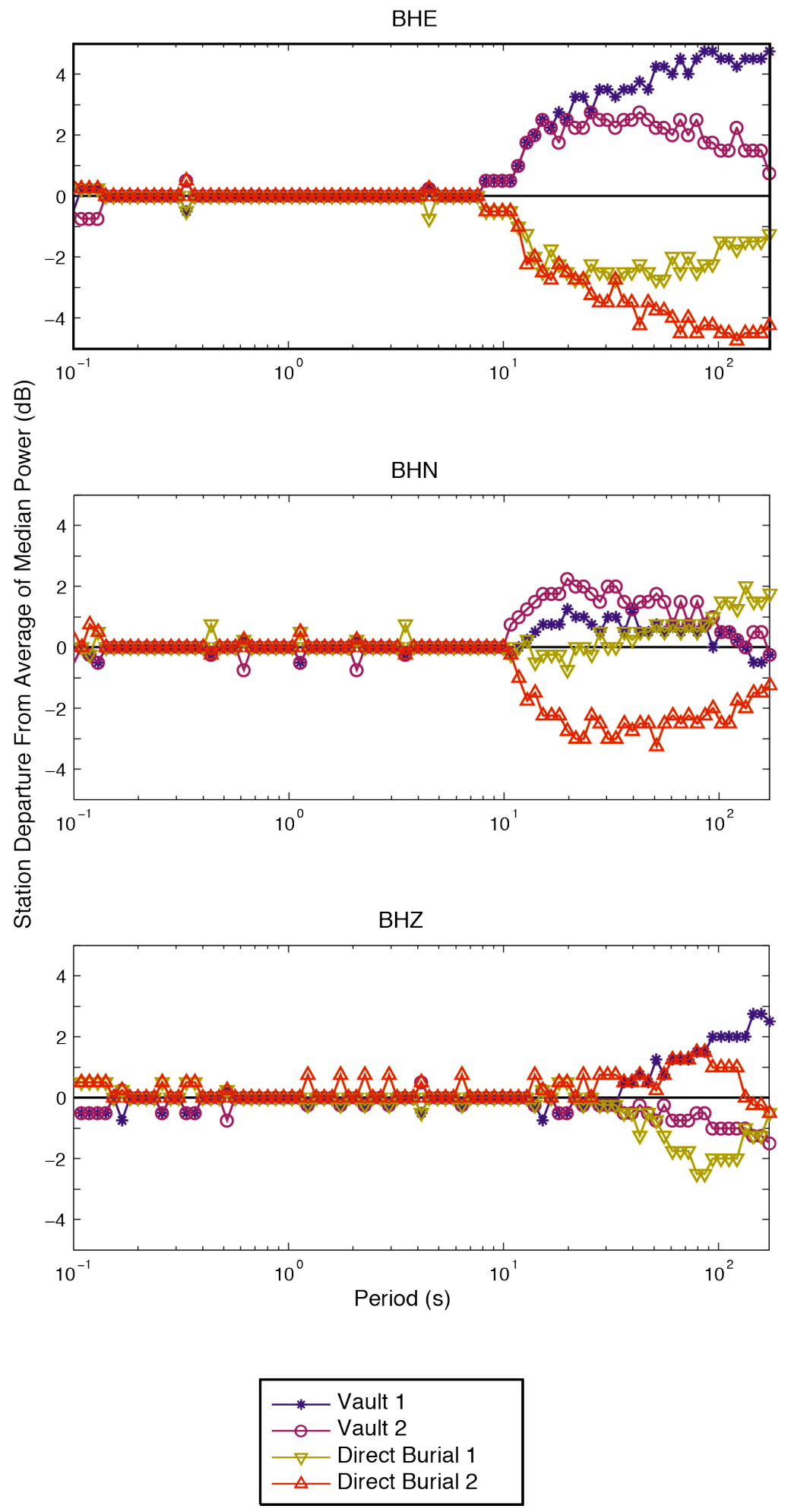

Figure 2 a) Medians of PDFs for each station from January to August 2012. Vault stations are in darker shades and direct burials are in lighter shades. Dashed lines are the NLNM and NHNM. b) Deviation from the mean of the median noise levels from the four stations over the same time period, with positive values for a higher power than the mean and negatives values for a lower power than the mean. 
Figure 3
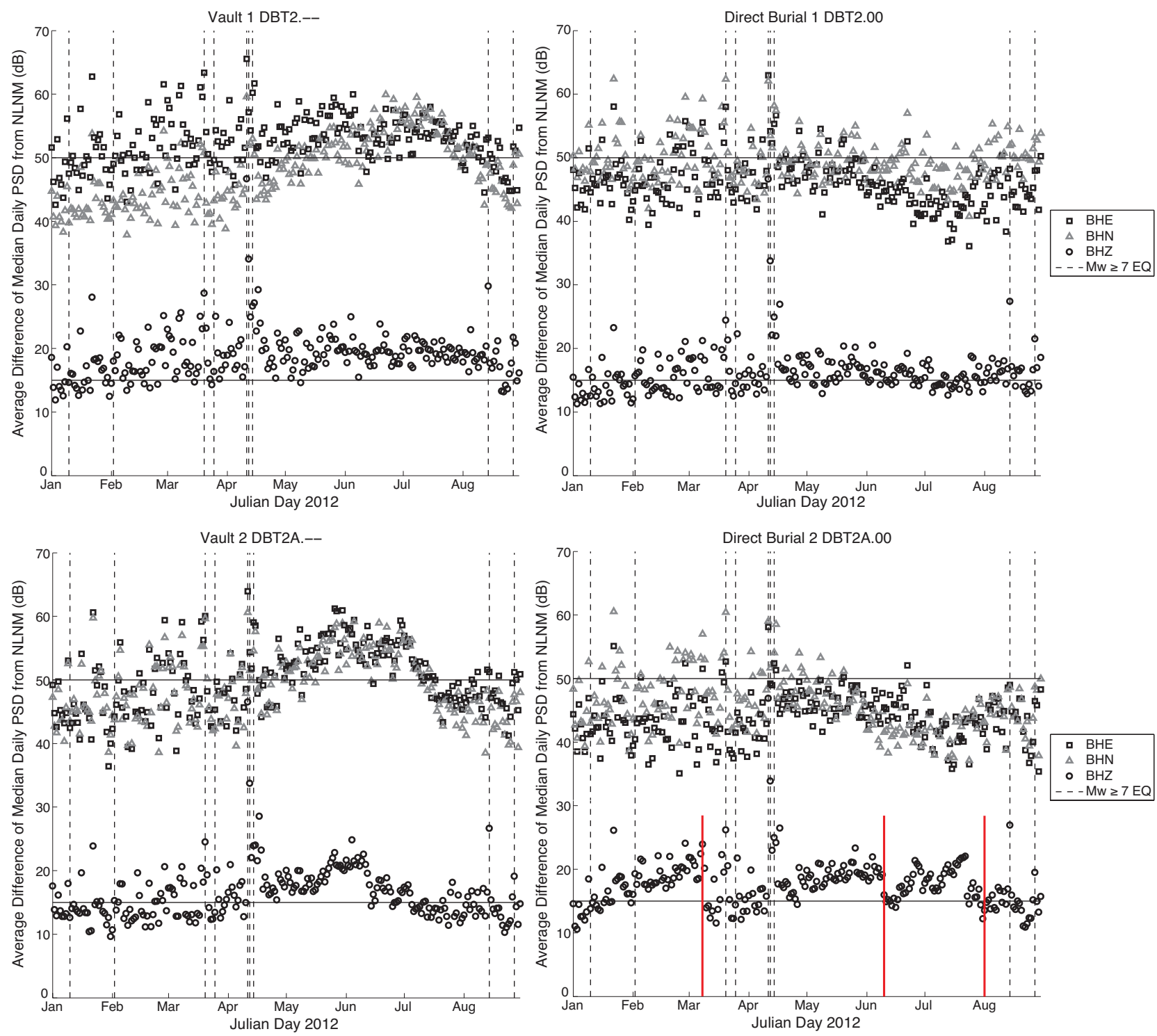

Figure 3) Daily median noise levels at long periods (20-172 seconds) with respect to the NLNM for eight months of study, 1 January through 31 August 2012, on all four stations. Vertical dashed lines indicate days on which a $M_{W} \geq 7$ earthquake occurred. Vertical solid lines indicate a mass recenter on Direct Burial 2. 


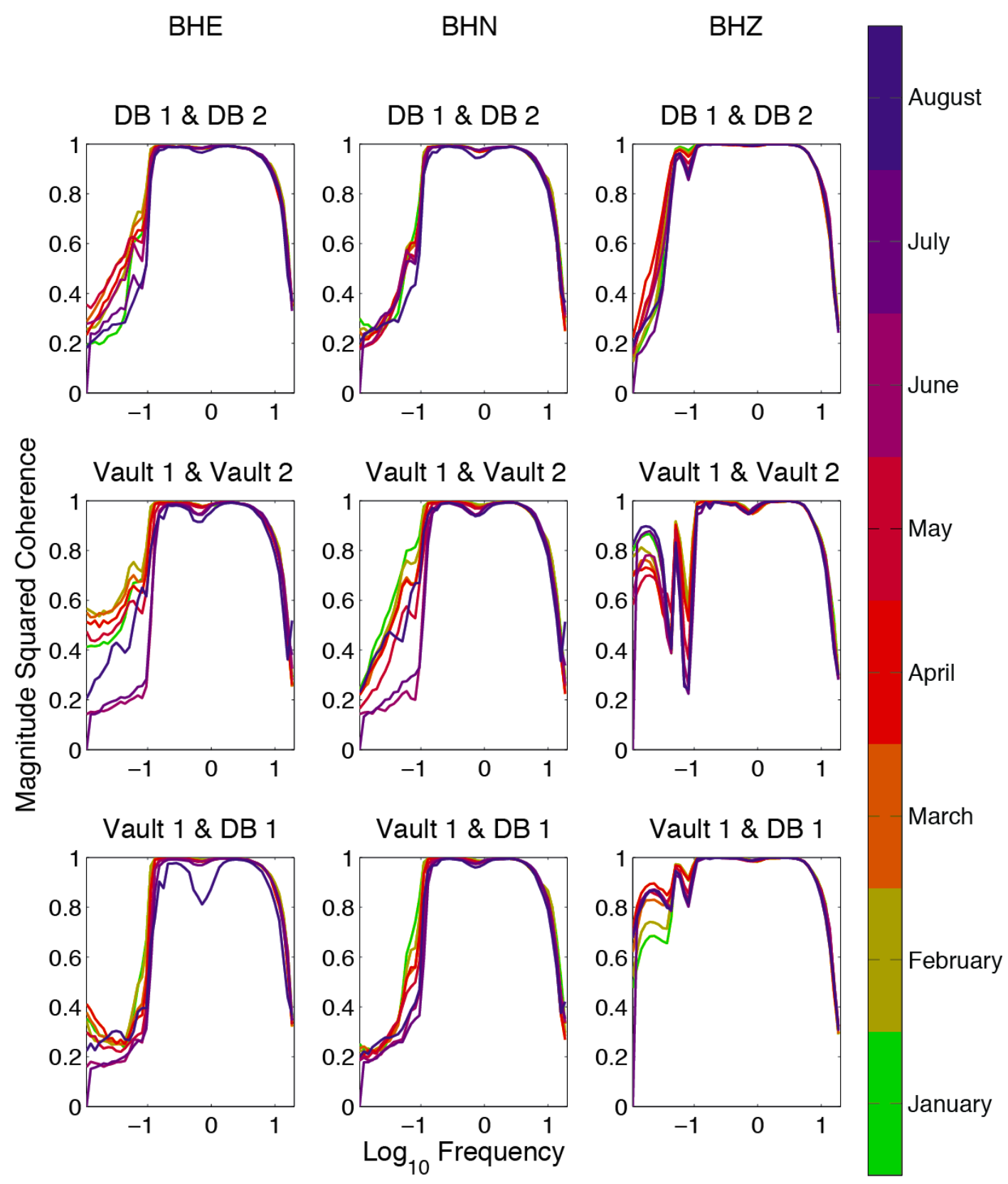

Figure 4) Median probability density functions of hourly MSC for each month between January to August 2012 on the BHE, BHN, and BHZ components of Direct Burial 1 vs. Direct Burial 2, Vault 1 vs. Vault 2 and Direct Burial 1 vs. Vault 1. 
a)

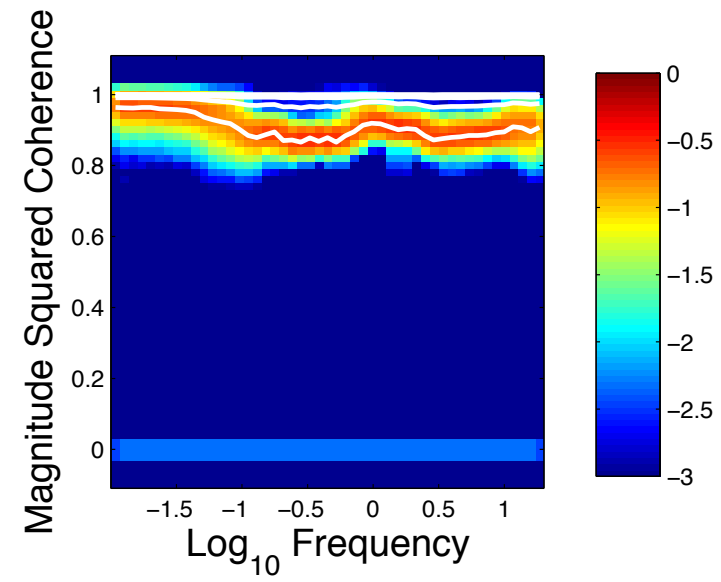

c)

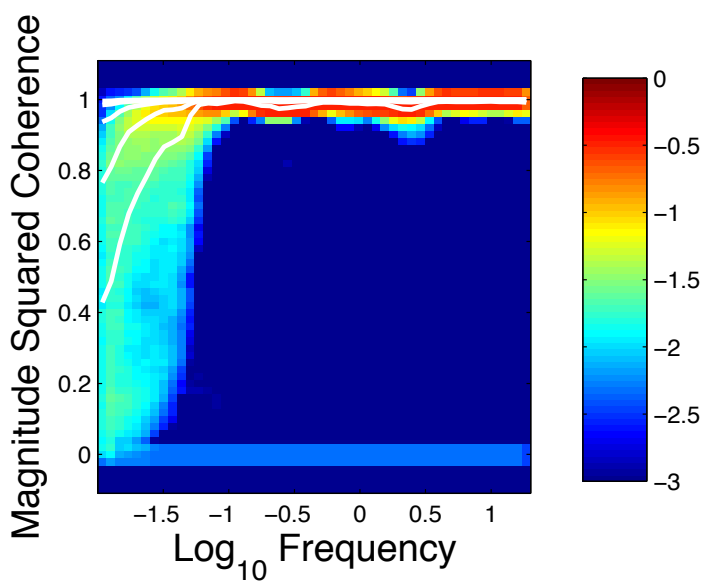

b)

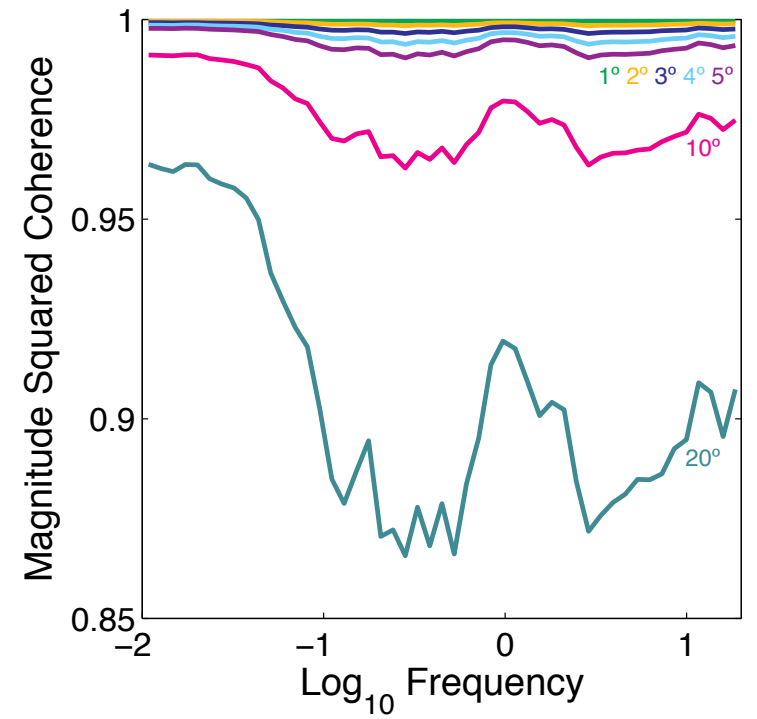

d)

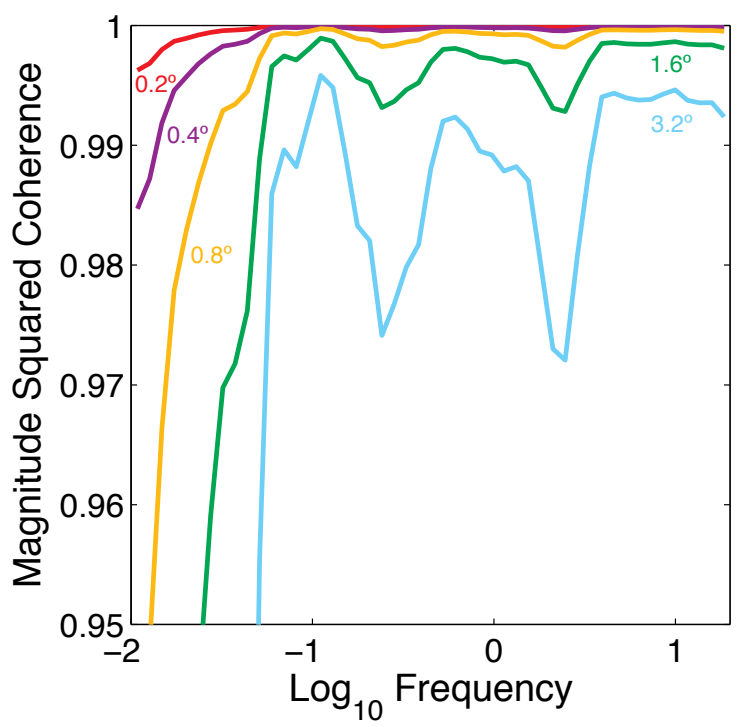

Figure 5) Results of MSC analysis of original data and rotated data from the BHE component of Vault 1 during the month of December 2011. a) PDF of magnitude squared coherence of Vault 1 station and Vault 1 station rotated by 200 in the horizontal plane. White lines show median PDF

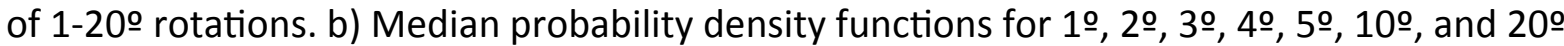
rotations in the horizontal plane. c) PDF of MSC of Vault 1 station and Vault 1 station with 3.20 rotation of the vertical plane. White lines show median PDF of 0.2-3.2을 rotations. d) Median PDFs for $0.2^{\circ}, 0.4^{\circ}, 0.8^{\circ}, 1.6^{\circ}$, and $3.2^{\circ}$ rotations in the horizontal plane. 
a)
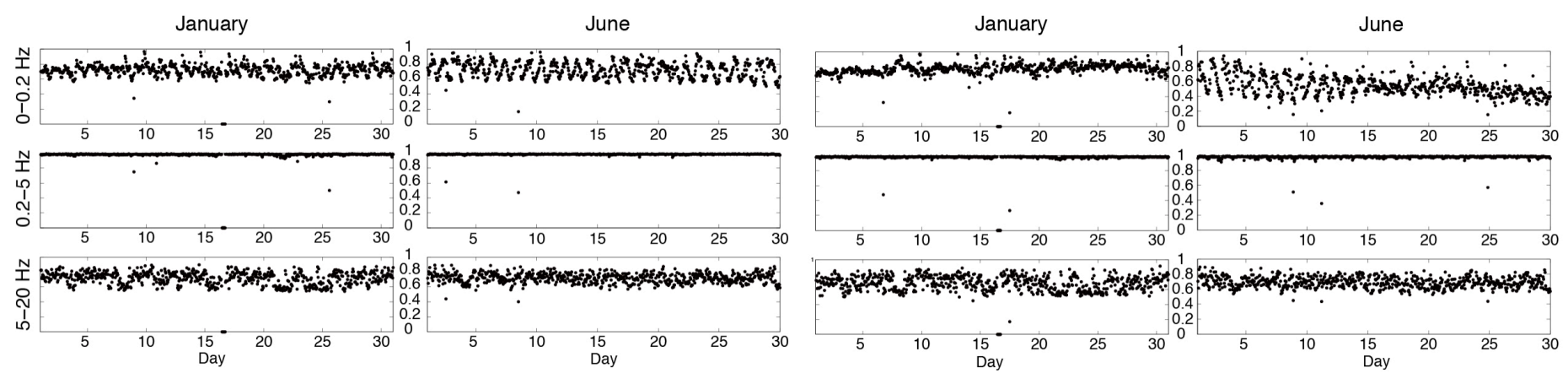

b)
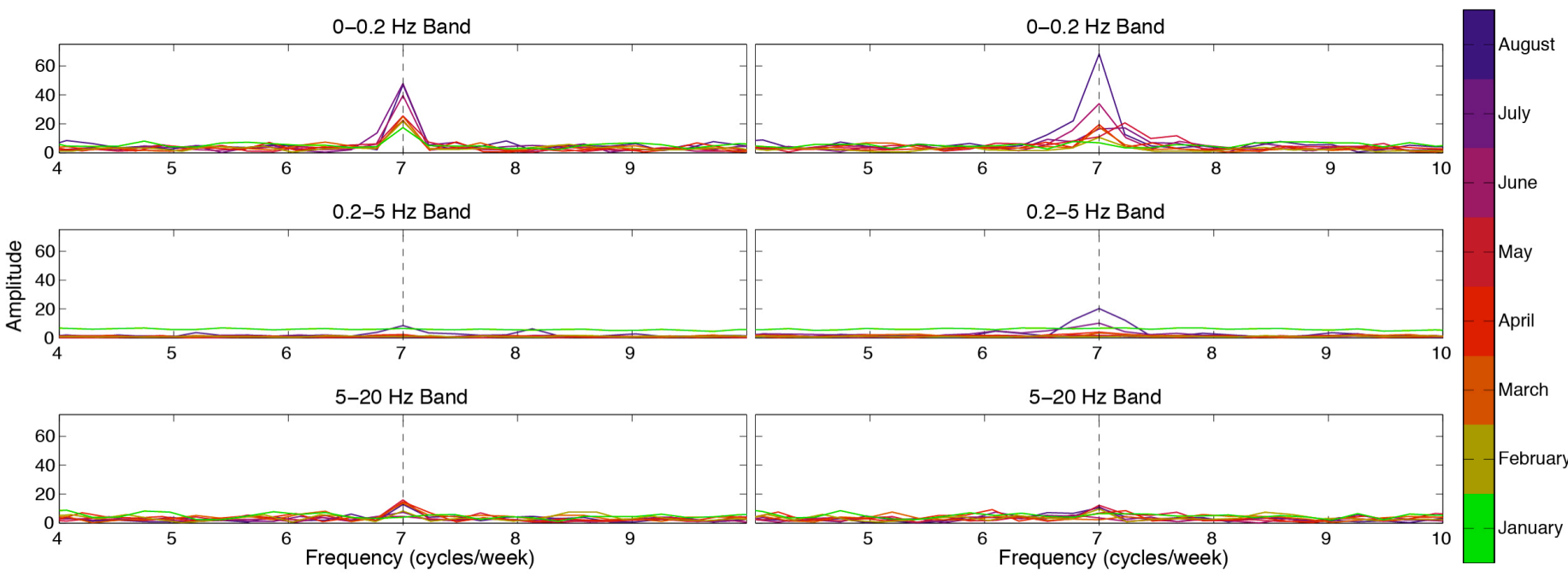

Figure 6 a) Hourly integrated and normalized MSC between stations of the same emplacement. Four plots show the hourly MSC between direct burial stations and vault stations on the BHE component for the representative months of January and June at three different frequency bands. The diurnal behavior becomes more apparent in June, along with an overall decrease in coherence in the vault stations. b) Eight months of hourly MSC values recorded on the BHE component converted to the frequency domain. There is a strong diurnal signal on both sets of stations in the long periods, increasing in amplitude through the year. Similar behavior is found on the BHE and BHN components of all other pairings between direct burial and vault stations. 
Noise
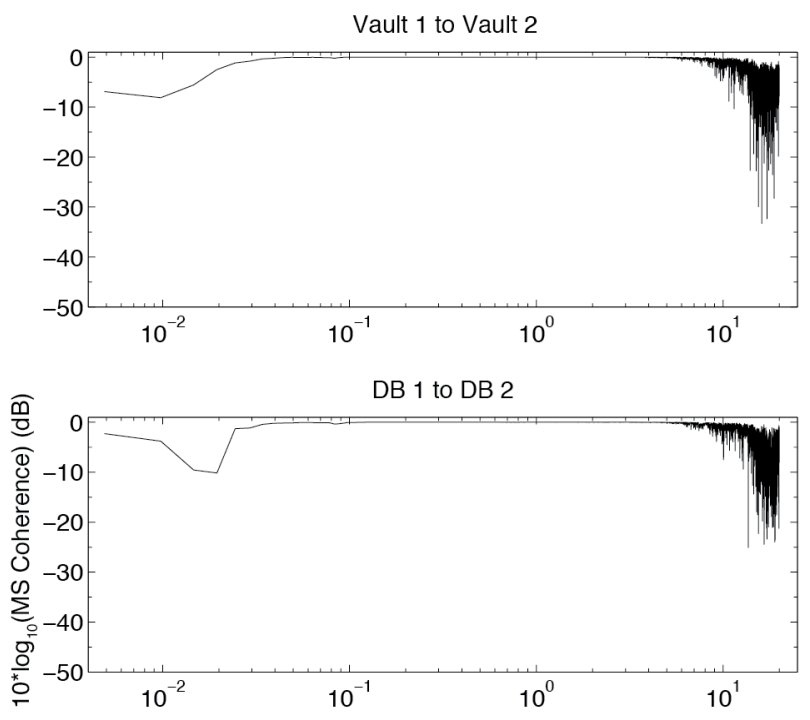

Vault 1 to DB 1

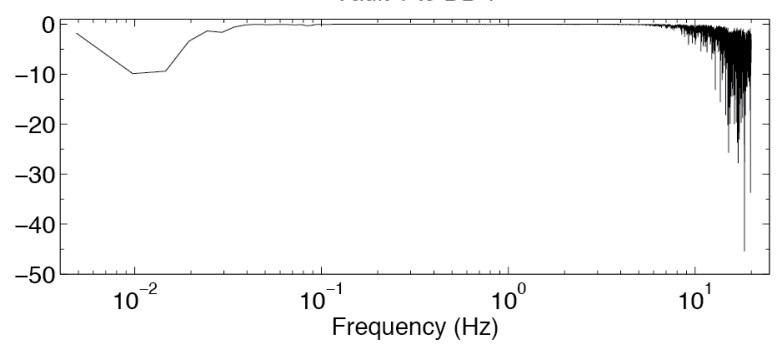

Signal
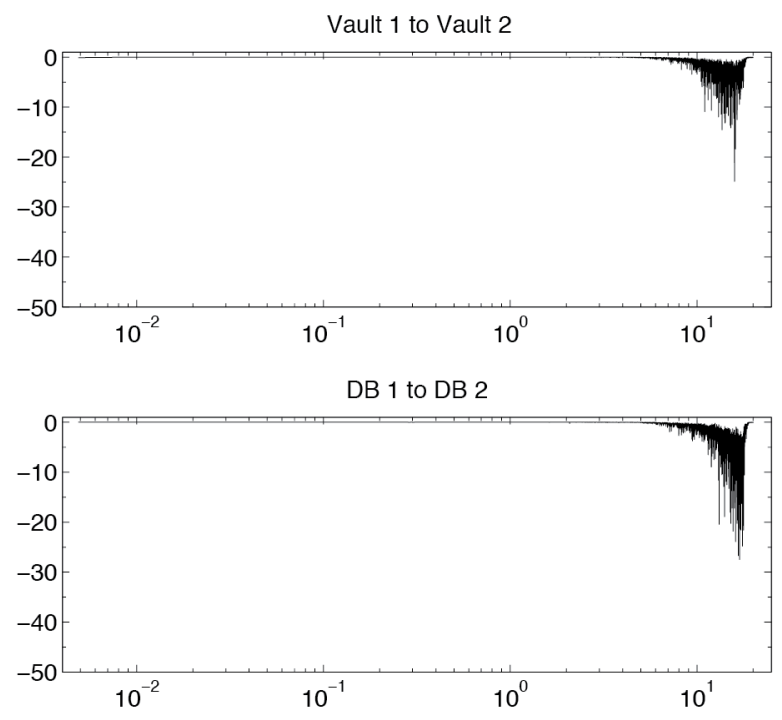

Vault 1 to DB 1

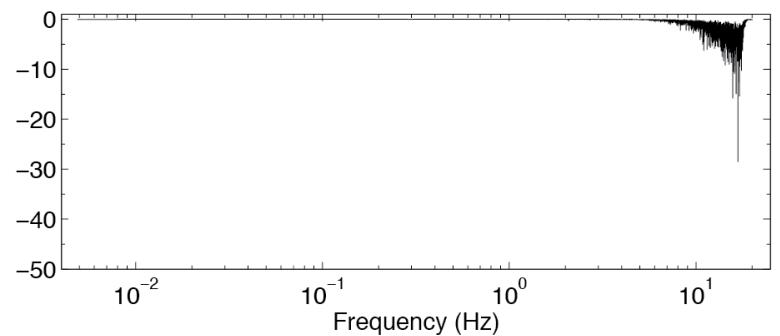

Figure 7) MSC of a $M_{w} 7.7$ earthquake near Japan on 14 August 2012 recorded on the vertical component with noise windows on the left and signal windows on the right. 
Table 1) Station abbreviations used in the paper and their attributes during the experiment.

\begin{tabular}{lllll}
\hline Station Name & Station Code & Thickness of Thermal Mass & Failure & Evidence of Water \\
\hline Vault 1 & DBT2.-- & $30 \mathrm{~cm}$ & None & $10-13 \mathrm{~cm}$ mark on pier \\
Vault 2 & DBT2A.-- & $30 \mathrm{~cm}$ & None & $10 \mathrm{~cm}$ mark on pier \\
Direct Burial 1 & DBT2.00 & $60 \mathrm{~cm}$ & $11 / 18 / 12$ & Water in cable housing \\
Direct Burial 2 & DBT2A.00 & $76 \mathrm{~cm}$ & $9 / 22 / 12$ & None \\
\hline
\end{tabular}


1 Table 2) Signal-to-noise ratios for all $23 M_{W} \geq 6.0$ earthquakes at distances of $30^{\circ}$ to $90^{\circ}$

2 from the stations. ${ }^{1,2}$

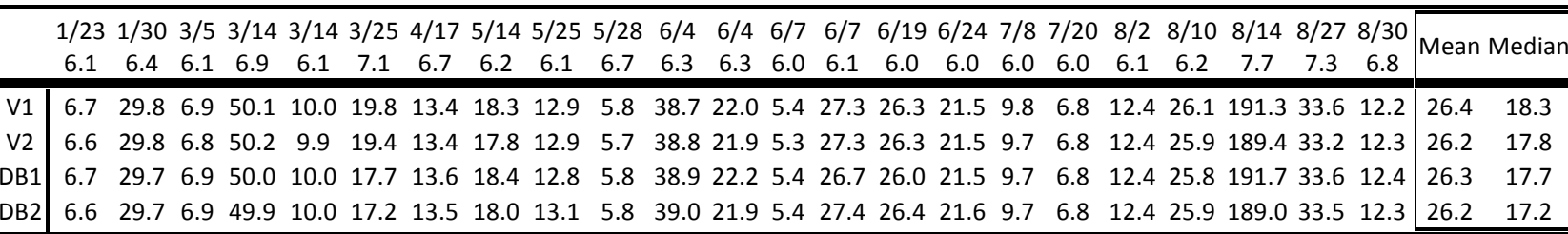

4

${ }^{1}$ The date of the earthquake is on top with the moment magnitude $\left(M_{W}\right)$ on the bottom.

${ }^{2}$ V1 and V2 stand for Vault 1 and Vault 2. DB1 and DB2 stand for Direct Burial 1 and Direct Burial 2. 
1 Table 3) Signal-to-noise ratios for six $1.1 \geq \mathrm{M}_{\mathrm{L}} \geq 0.1$ earthquakes at distances within $10 \mathrm{~km}$

2 from the stations. ${ }^{1,2}$

3

\begin{tabular}{|c|c|c|c|c|c|c|c|c|}
\hline \multirow{2}{*}{4} & $4 / 26$ & & $6 / 4$ & $6 / 4$ & $6 / 10$ & $8 / 04$ & \multirow{2}{*}{\multicolumn{2}{|c|}{ Mean Mediar }} \\
\hline & & & & & & & & \\
\hline V1 & 3.179 & 2.03 & 1.81 & 1.72 & 2.66 & 2.59 & 2.33 & 2.31 \\
\hline V2 & 3.226 & 1.97 & 1.73 & 1.76 & 2.59 & 2.56 & 2.31 & 2.26 \\
\hline DB1 & 3.481 & 2.05 & 1.92 & 1.81 & 2.83 & 2.77 & 2.48 & 2.41 \\
\hline DB2 & 3.228 & 2.12 & 1.98 & 1.83 & 2.89 & 2.77 & 2.47 & 2.44 \\
\hline
\end{tabular}

4

${ }^{1}$ The date of the earthquake is on top with the local magnitude from the New Mexico Tech Seismological Observatory $\left(\mathrm{M}_{\mathrm{L}}\right)$ on the bottom.

2 V1 and V2 stand for Vault 1 and Vault 2. DB1 and DB2 stand for Direct Burial 1 and Direct Burial 2. 


\section{Data quality of co-located portable broadband seismometers using direct burial and vault emplacement}

Kasey Aderhold, Katherine E. Anderson, Angela M. Reusch, Mary C. Pfeifer, Richard Aster, and Tim Parker

\section{Electronic Supplement:}

The supplementary material for this paper contains figures of the daily median noise levels in the microseism band, monthly probability density functions for the magnitude squared coherence between the six station couplings (Direct Burial 1 to Direct Burial 2, Vault 1 to Direct Burial 1, Vault 1 to Direct Burial 2, Vault 1 to Vault 2, Vault 2 to Direct Burial 1, Vault 2 to Direct Burial 2) for all three components (BHE, BHN, BHZ), results of the coherency self-noise analysis, and the recordings of the teleseismic and local earthquakes used for the signal-to-noise analysis.

Figure S1) Daily median noise levels on the microseism band (2-20 seconds) with respect to the NLNM for eight months of study, 1 January through 31 August 2012, on all four stations. Vertical dashed lines indicate days on which a $M_{W} \geq 7$ earthquake occurred.

Figure S2) Probability density function of magnitude squared coherence on the BHZ component. Probability density function is taken of the hourly magnitude squared coherences for each month from January to August 2012 for each of the six station pairings (First column from top to bottom: Direct Burial 1 to Direct Burial 2, Vault 1 to Direct Burial 1, Vault 1 to Direct Burial 2; second column from top to bottom: Vault 1 to Vault 2, Vault 2 to Direct Burial 1, Vault 2 to 
Direct Burial 2). The $x$-axis is the $\log _{10}$ of frequency, the $y$-axis is magnitude squared coherence, and the black line is the median of the PDF.

Figure S3) Probability density function of magnitude squared coherence on the BHE component. Probability density function is taken of the hourly magnitude squared coherences for each month from January to August 2012 for each of the six station pairings (First column from top to bottom: Direct Burial 1 to Direct Burial 2, Vault 1 to Direct Burial 1, Vault 1 to Direct Burial 2; second column from top to bottom: Vault 1 to Vault 2, Vault 2 to Direct Burial 1, Vault 2 to Direct Burial 2). The $\mathrm{x}$-axis is the $\log _{10}$ of frequency, the $\mathrm{y}$-axis is magnitude squared coherence, and the black line is the median of the PDF.

Figure S4) Probability density function of magnitude squared coherence on the BHN component. Probability density function is taken of the hourly magnitude squared coherences for each month from January to August 2012 for each of the six station pairings (First column from top to bottom: Direct Burial 1 to Direct Burial 2, Vault 1 to Direct Burial 1, Vault 1 to Direct Burial 2; second column from top to bottom: Vault 1 to Vault 2, Vault 2 to Direct Burial 1, Vault 2 to Direct Burial 2). The $\mathrm{x}$-axis is the $\log _{10}$ of frequency, the $\mathrm{y}$-axis is magnitude squared coherence, and the black line is the median of the PDF.

Figure S5) Results from horizontal rotations in the North-East plane relative to Vault 1 to correct for orientation errors using recorded data from the entire month of December 2011. Rotations were $3.1^{\circ}$ for Direct Burial 1, $-2.4^{\circ}$ for Direct Burial 2, and $-4.4^{\circ}$ for Vault 2 clockwise from 
north. Median PSDs of all noise are in solid lines and median PSDs of uncorrelated installation/instrument noise are in dashed lines.

Figure S6) Results from dip and azimuth vertical rotation for the four stations to correct for nonparallel vertical components using recorded data from the entire month of December 2011. Rotations were $0.2^{\circ} / 10^{\circ}$ for Vault $1,0.35^{\circ} / 175^{\circ}$ for Vault $2,0.4^{\circ} / 20^{\circ}$ for Direct Burial 1 , and $0.3^{\circ} / 125^{\circ}$ for Direct Burial 2 for dip and azimuth (clockwise from north) respectively. Median PSDs of all noise are in solid lines and median PSDs of uncorrelated installation/instrument noise are in dashed lines.

Figure S7) a) Normalized and band-pass filtered teleseismic seismograms on BHZ component at the four stations for all $23 \mathrm{M}_{\mathrm{W}} \geq 6.0$ earthquakes between $30^{\circ}$ and $90^{\circ}$ distance from the study site. The black vertical line shows the $P$ arrival picks with the noise window to the left and the signal window to the right, and date of the event on the bottom left. b) Map of gCMT (Esktröm et al., 2012) moment tensors for earthquake of $\mathrm{M}_{\mathrm{W}} \geq 6.0$ from January to August 2012. Black mechanisms were used for the signal to noise calculations and grey were not.

Figure S8) Normalized and high-pass filtered seismograms for the six $1.1 \geq \mathrm{M}_{\mathrm{L}} \geq 0.1$ local earthquakes recorded on the four stations. The handpicked first arrival is indicated by the solid line and the 1 second noise and signal windows are shown with the dashed lines. The date of the event is indicated in the lower left corner. For magnitudes, refer to Table 3 in the paper. 

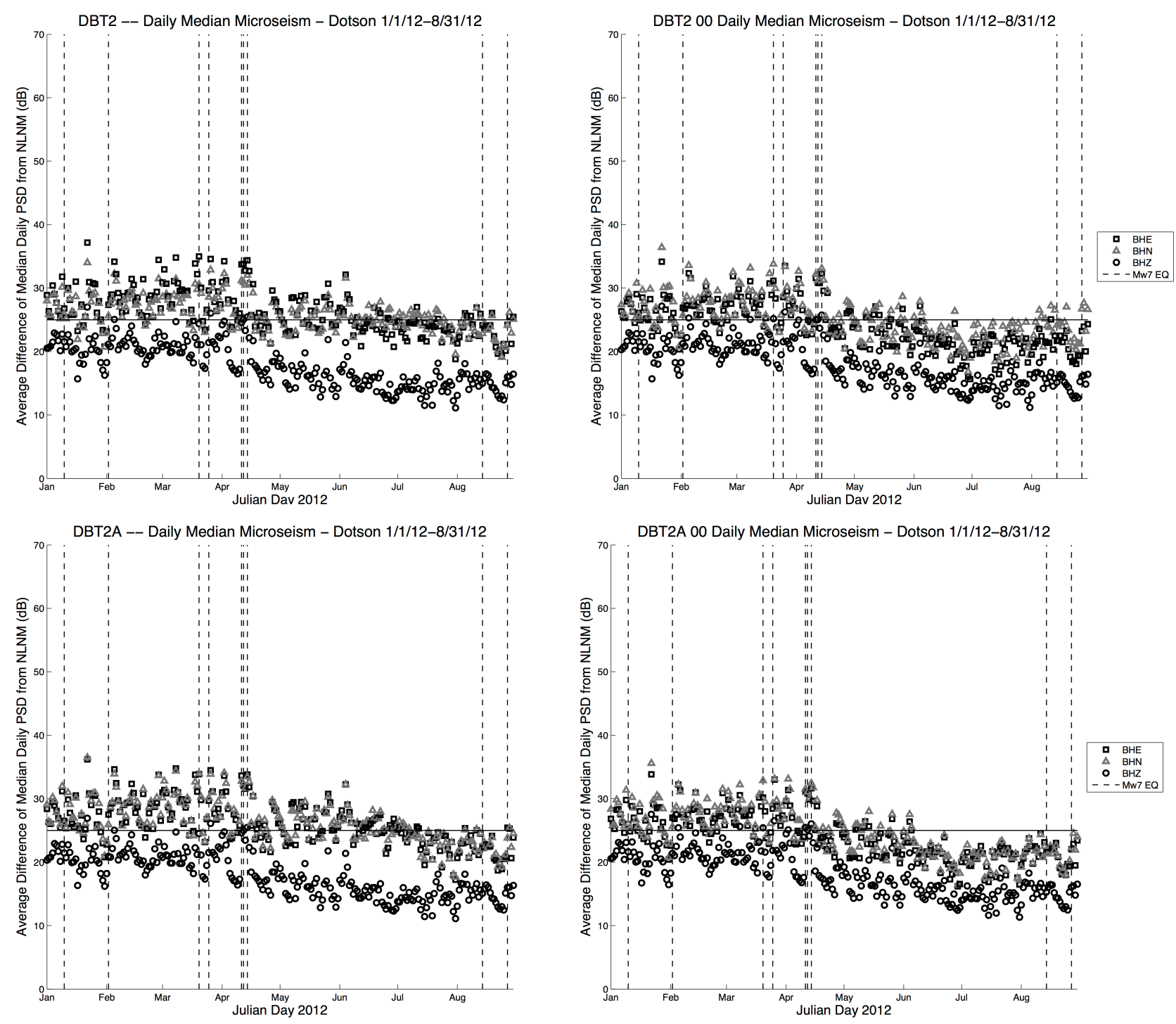

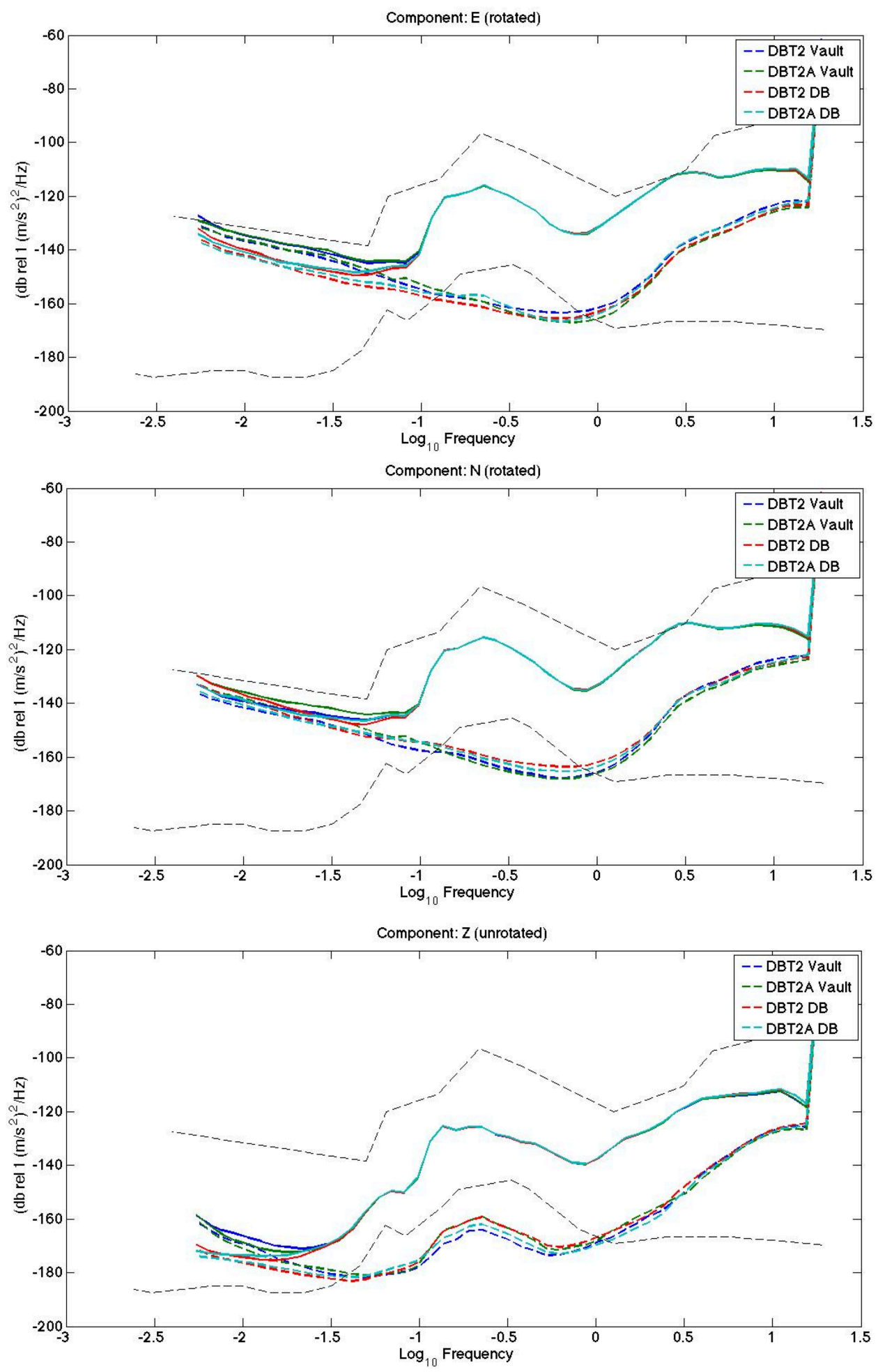


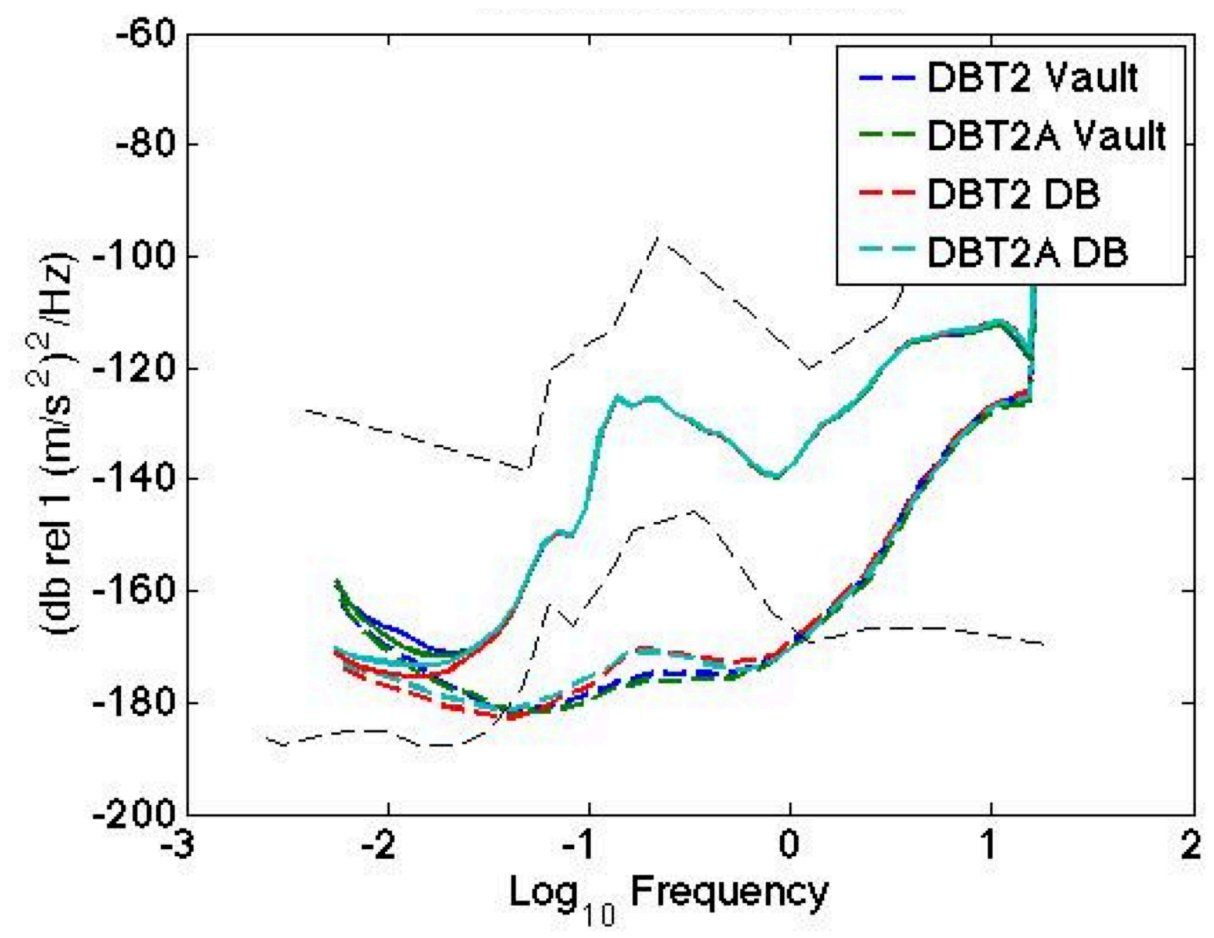



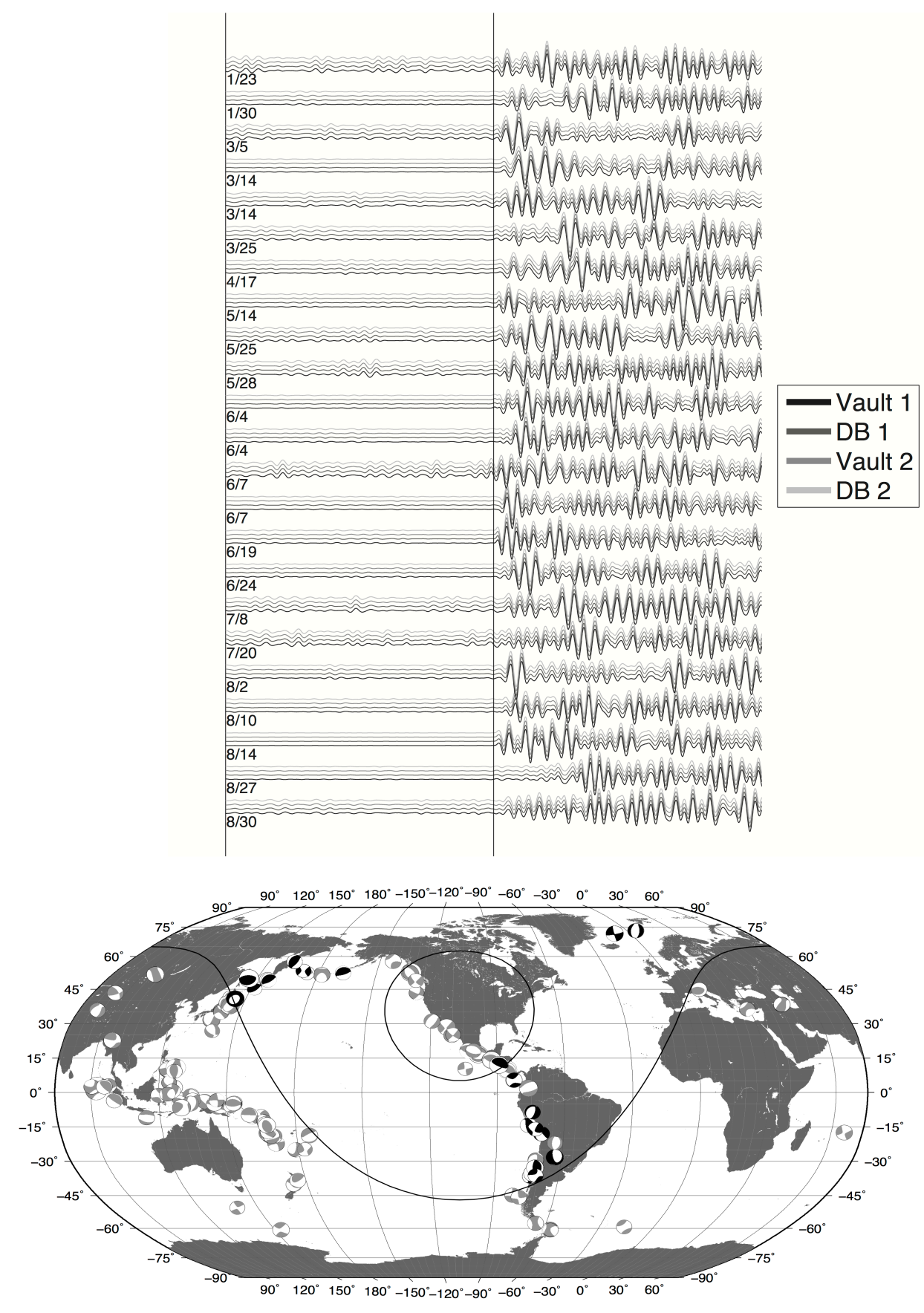


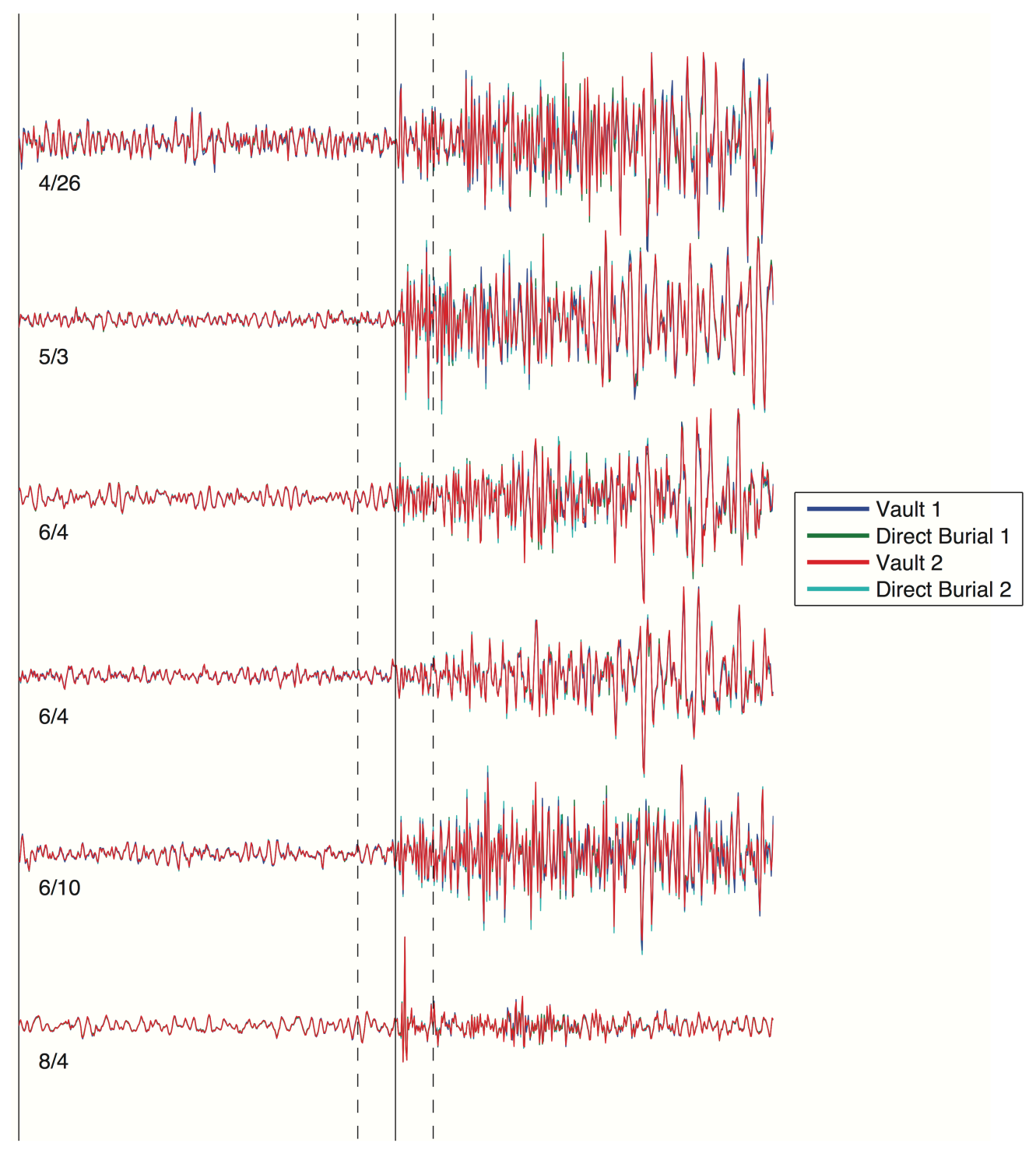



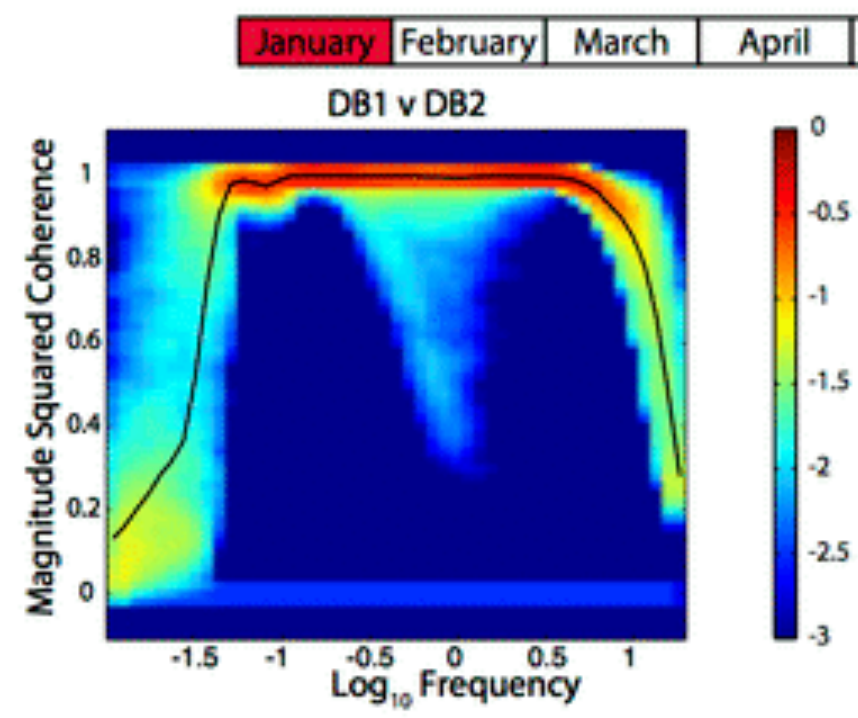

\begin{tabular}{|l|l|l|l|}
\hline May & June & July & August \\
\hline
\end{tabular}

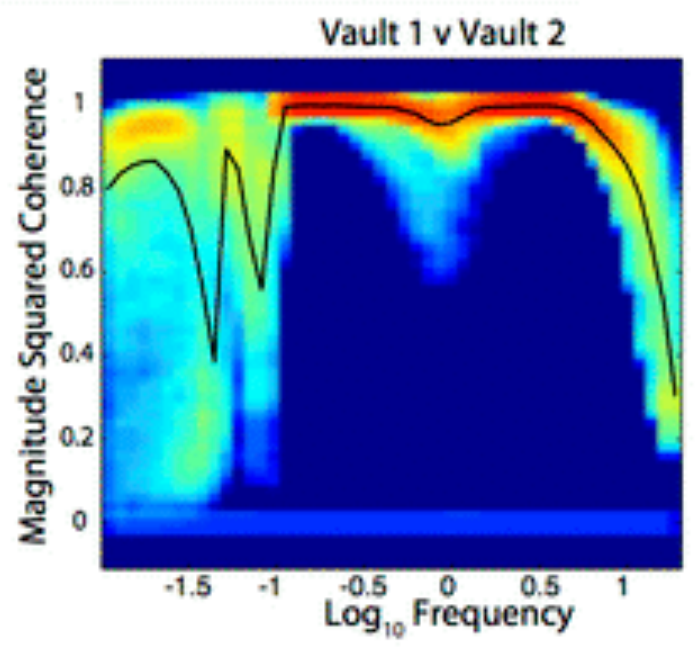

\section{$\mathrm{BHZ}$}
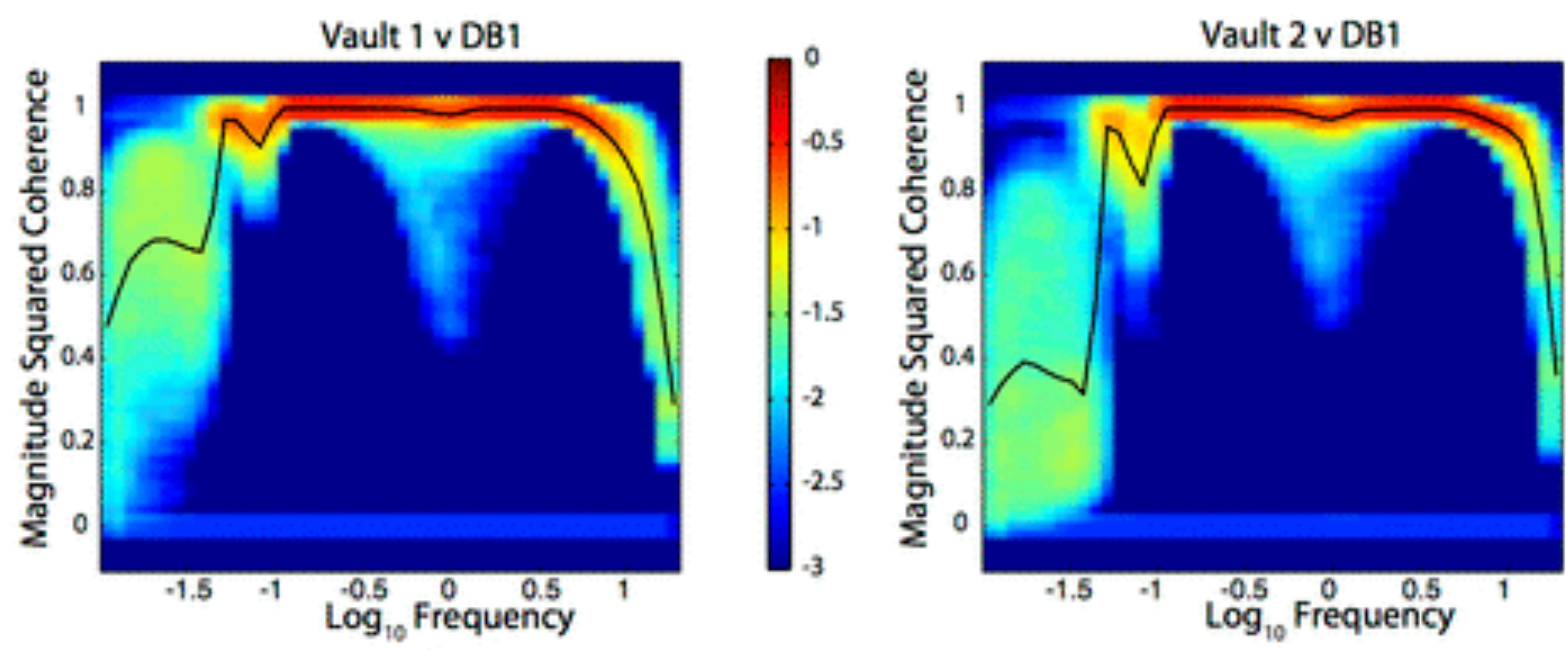

\section{$\mathrm{BHZ}$}
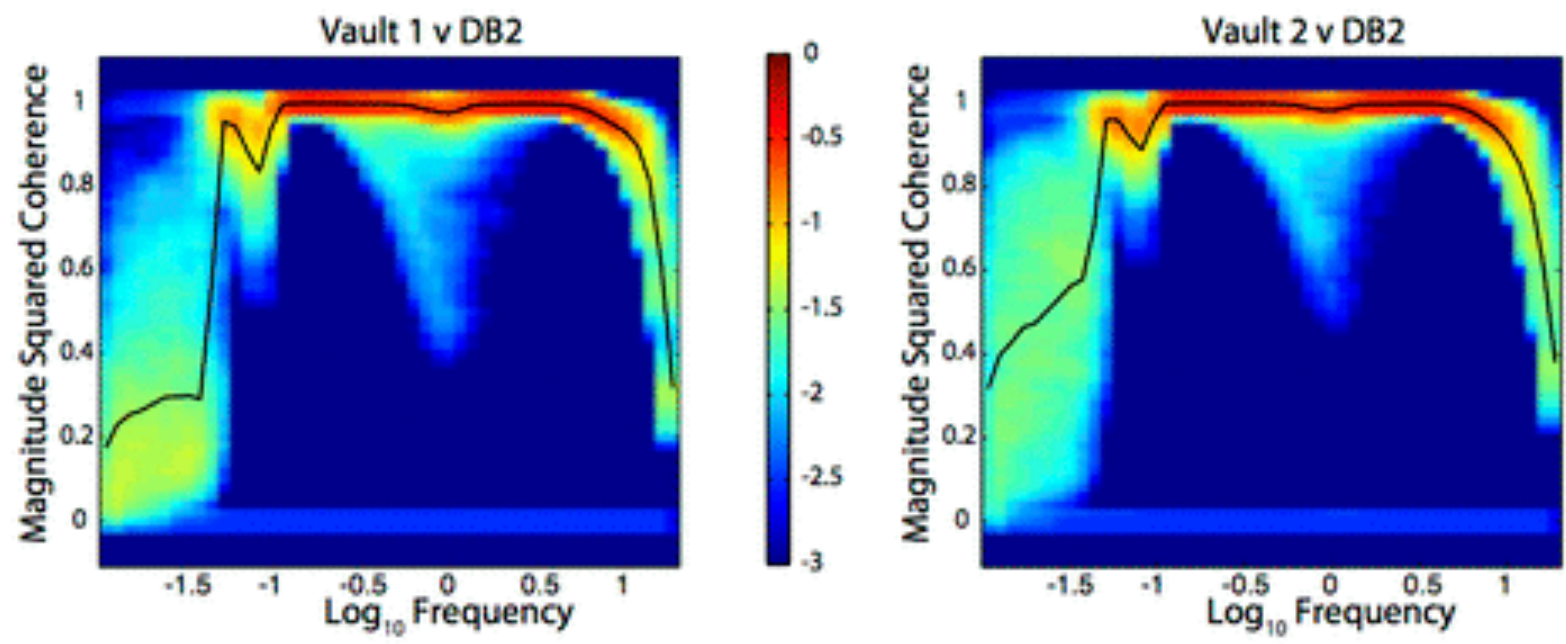

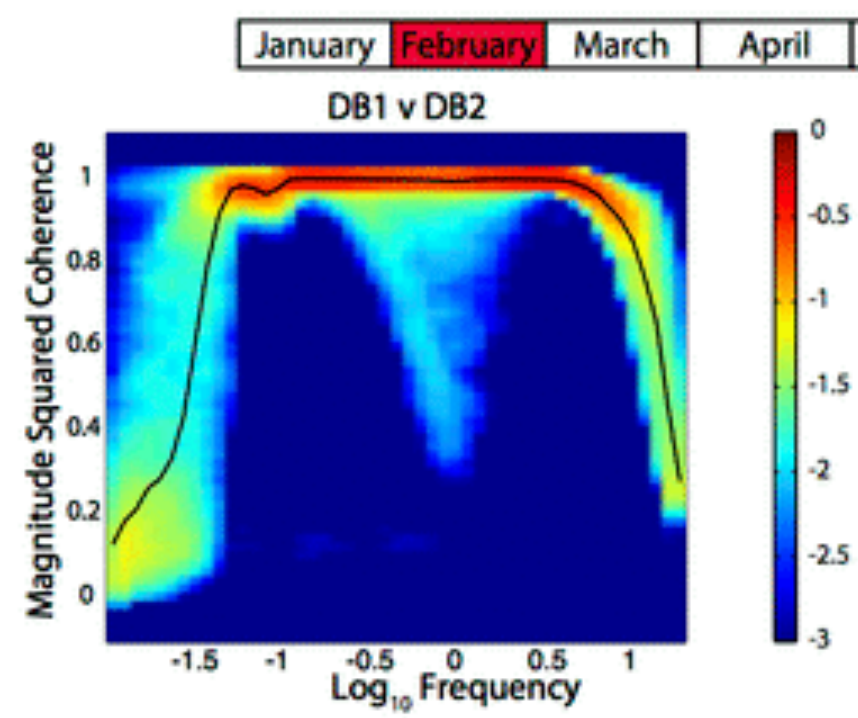

\begin{tabular}{|l|l|l|l|}
\hline May & June & July & August \\
\hline
\end{tabular}

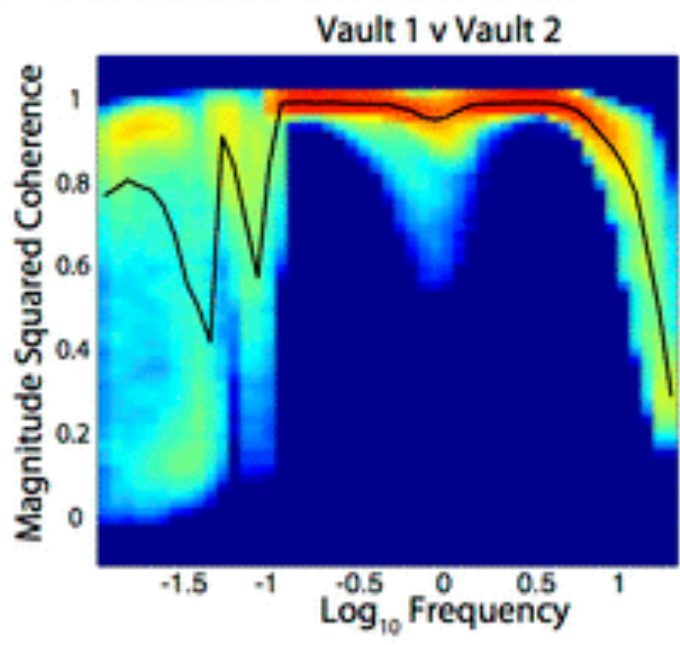

\section{$\mathrm{BHZ}$}
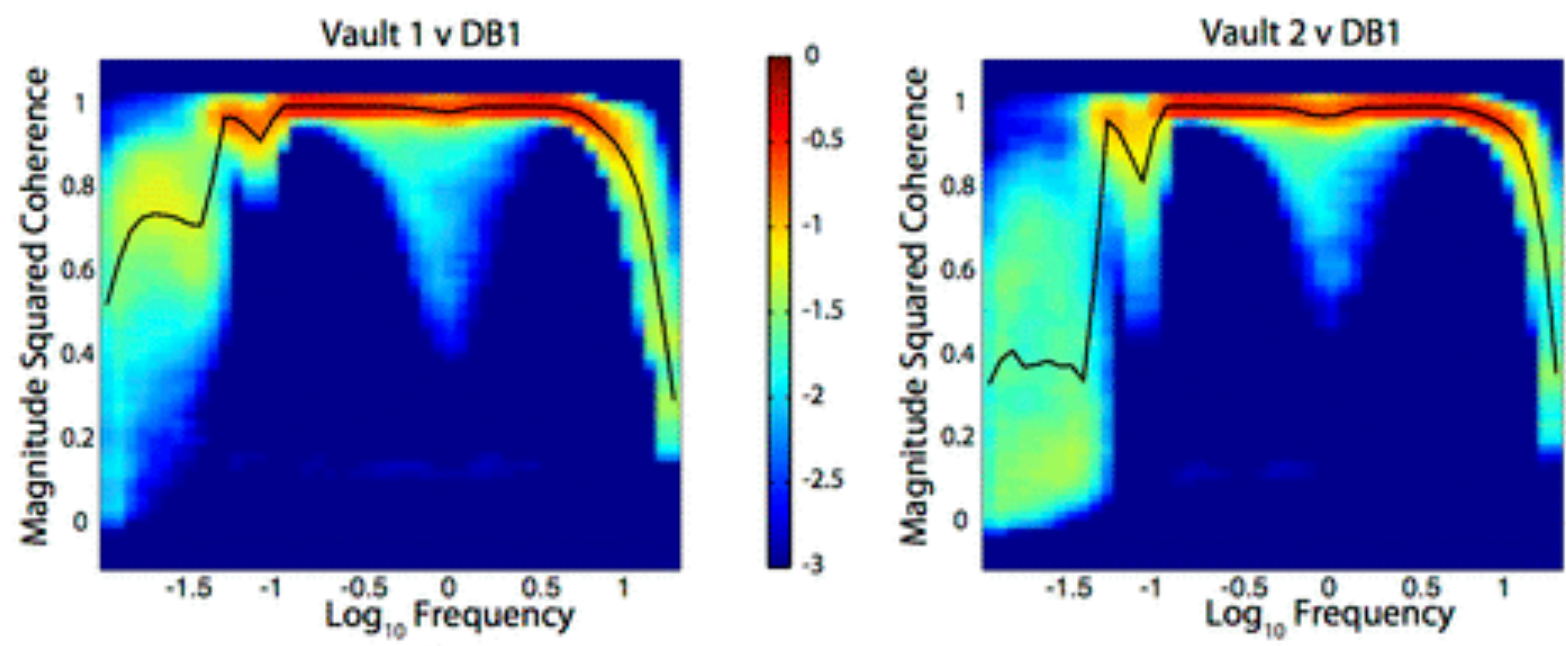

\section{$\mathrm{BHZ}$}
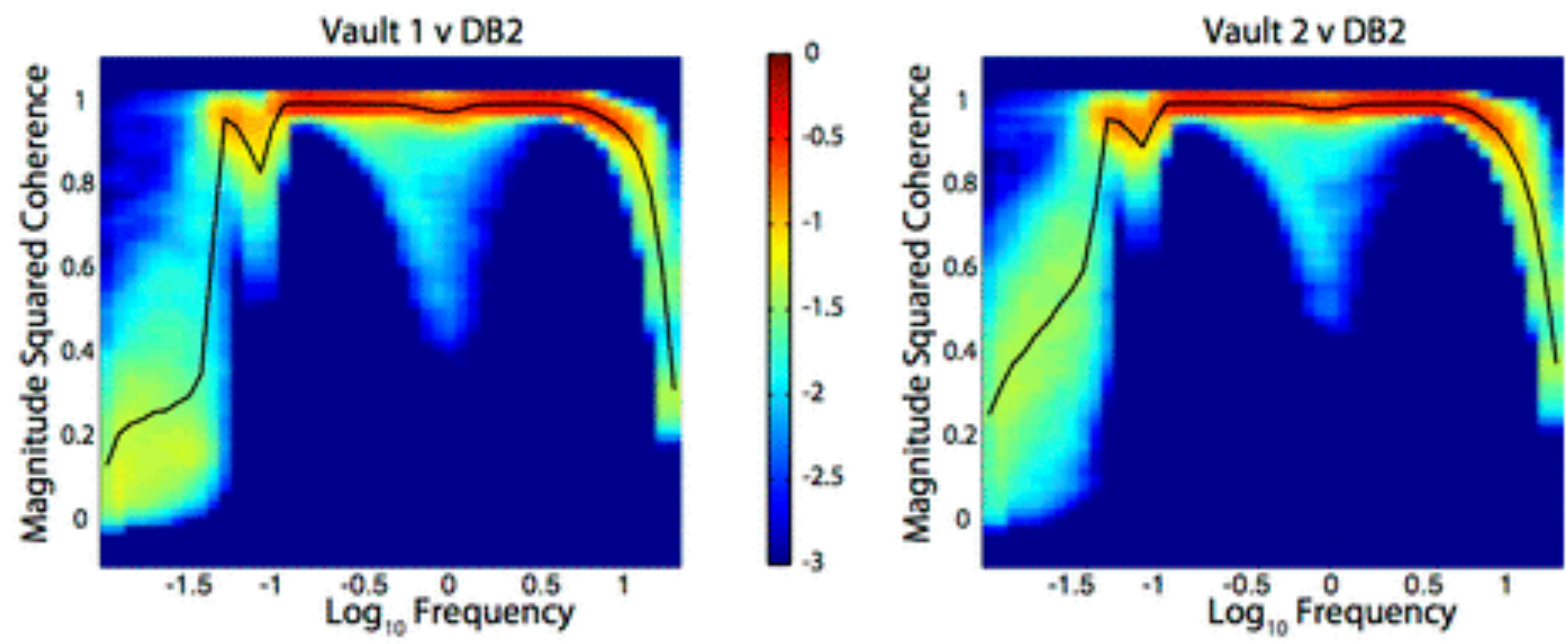

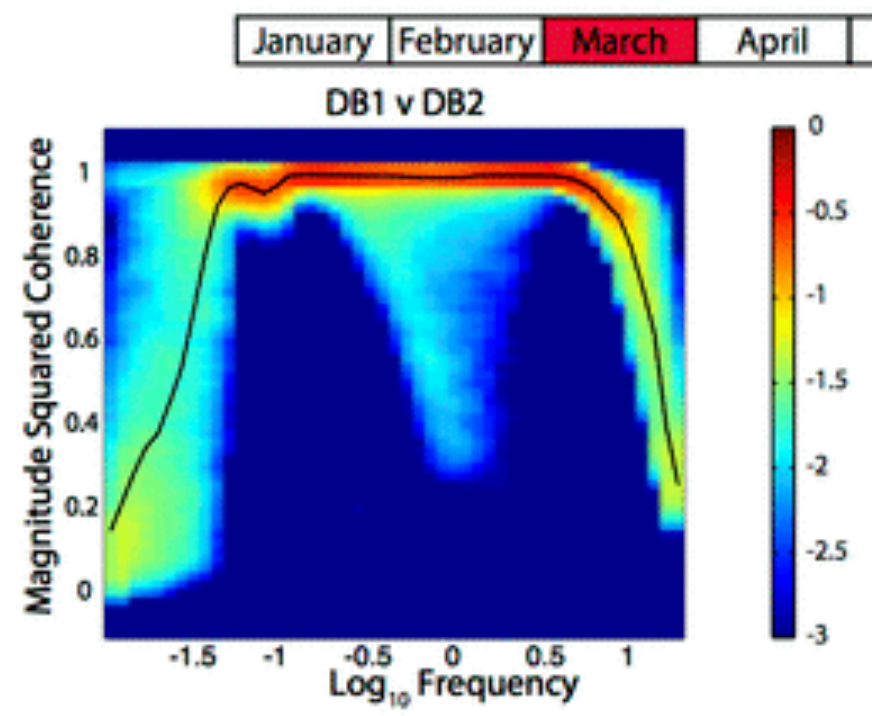

\begin{tabular}{|l|l|l|l|}
\hline May & June & July & August \\
\hline
\end{tabular}

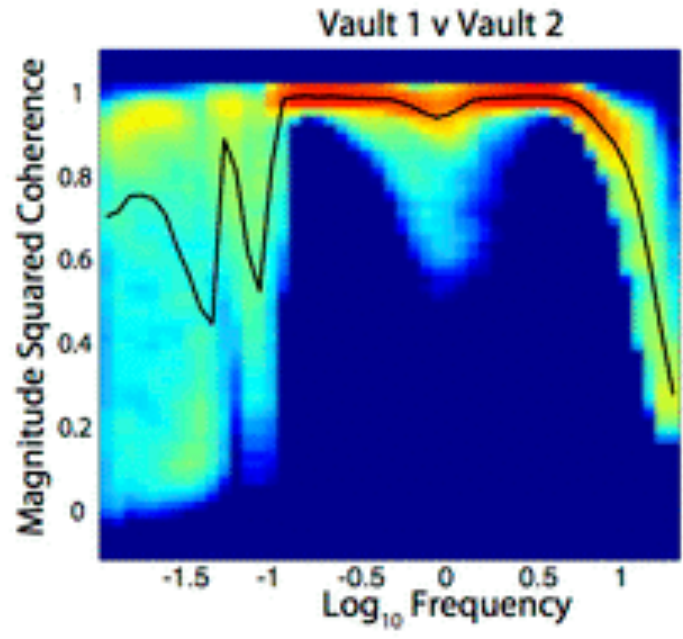

\section{$\mathrm{BHZ}$}
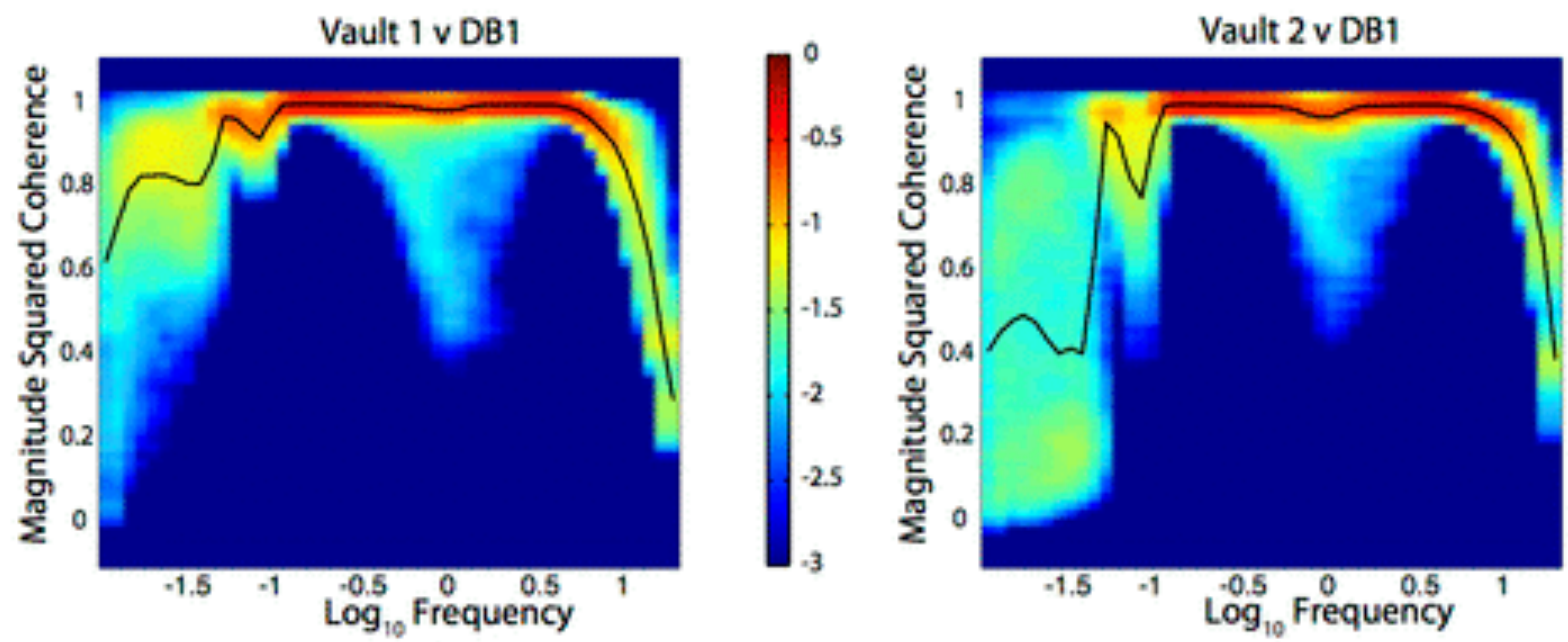

$\mathrm{BHZ}$
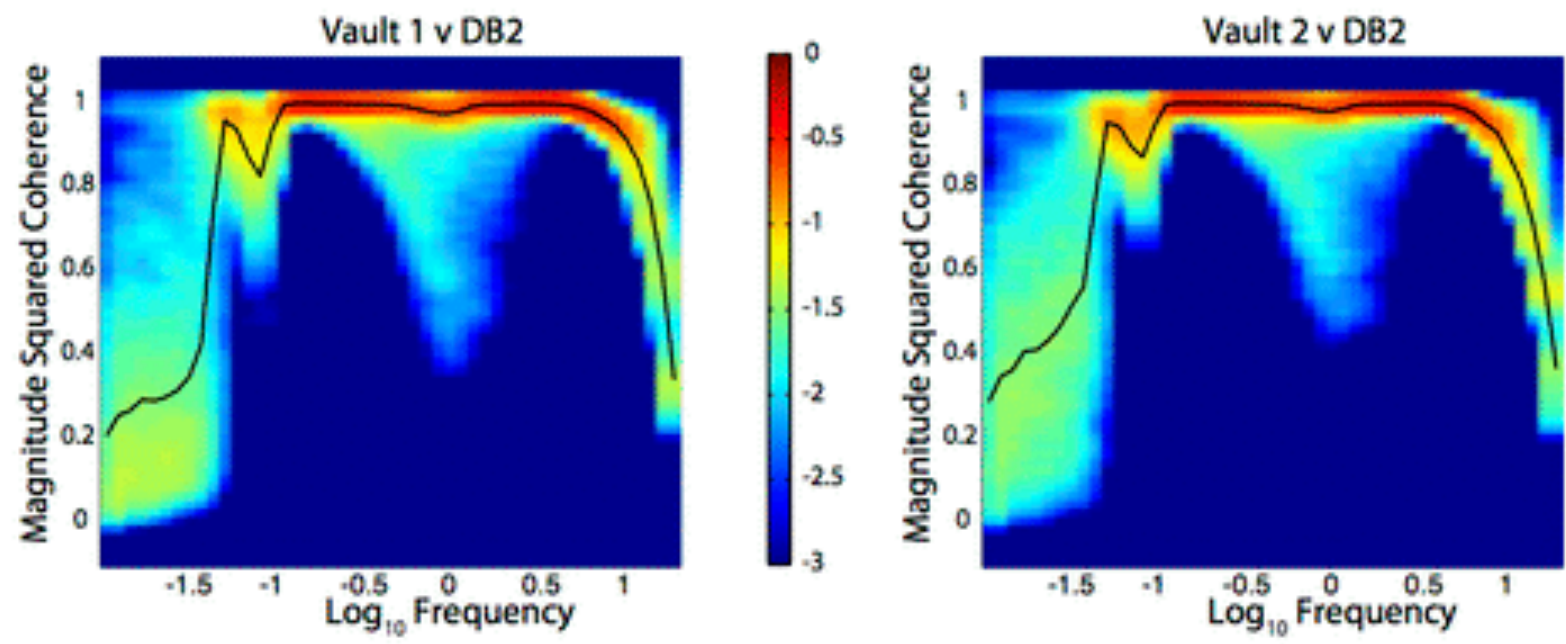

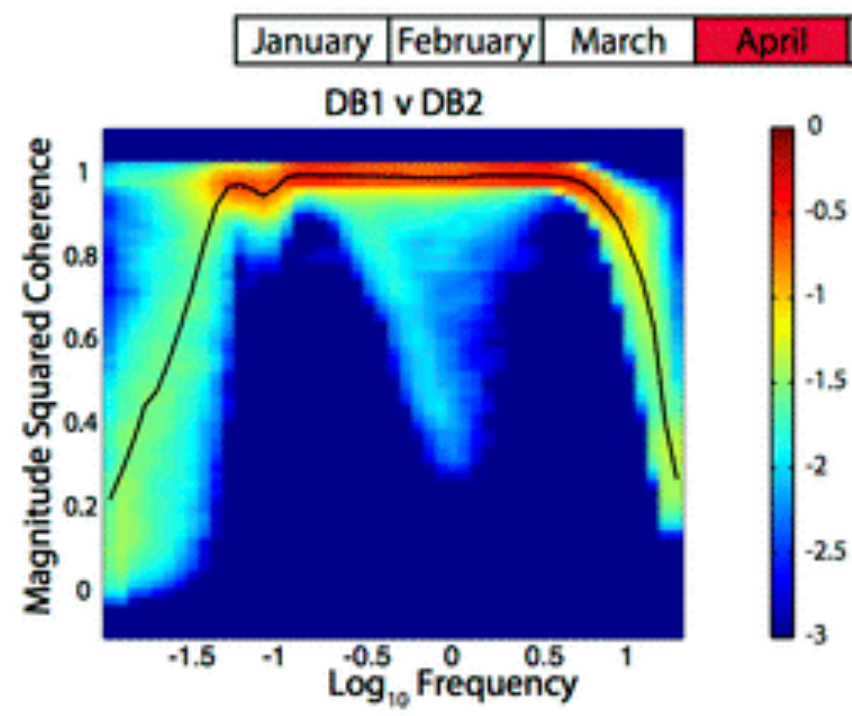

\begin{tabular}{|l|l|l|l|}
\hline May & June & July & August \\
\hline
\end{tabular}

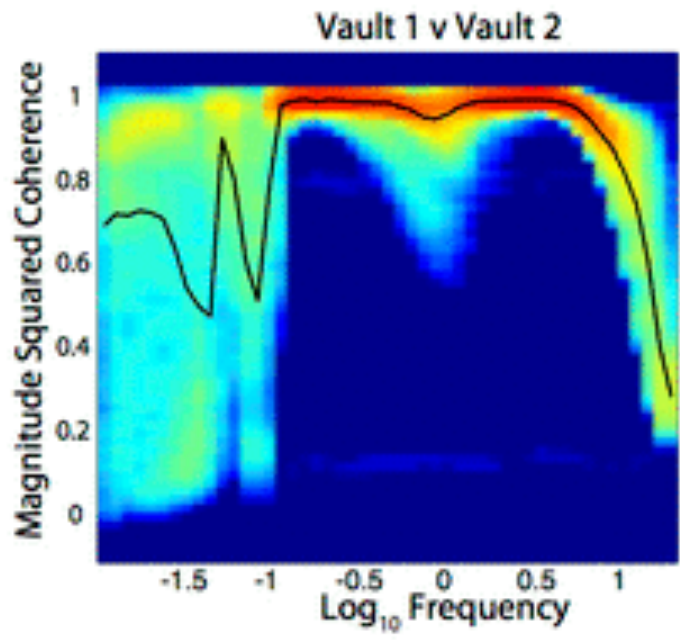

\section{$\mathrm{BHZ}$}
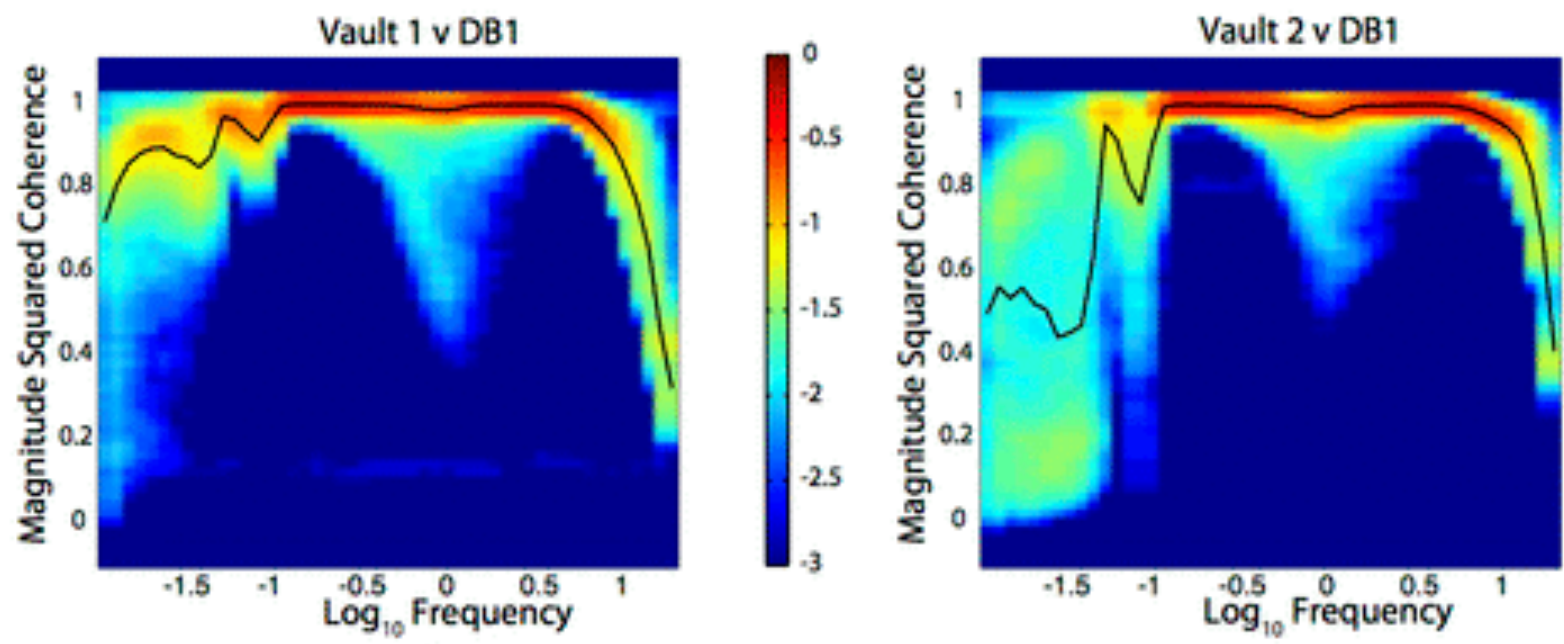

$\mathrm{BHZ}$
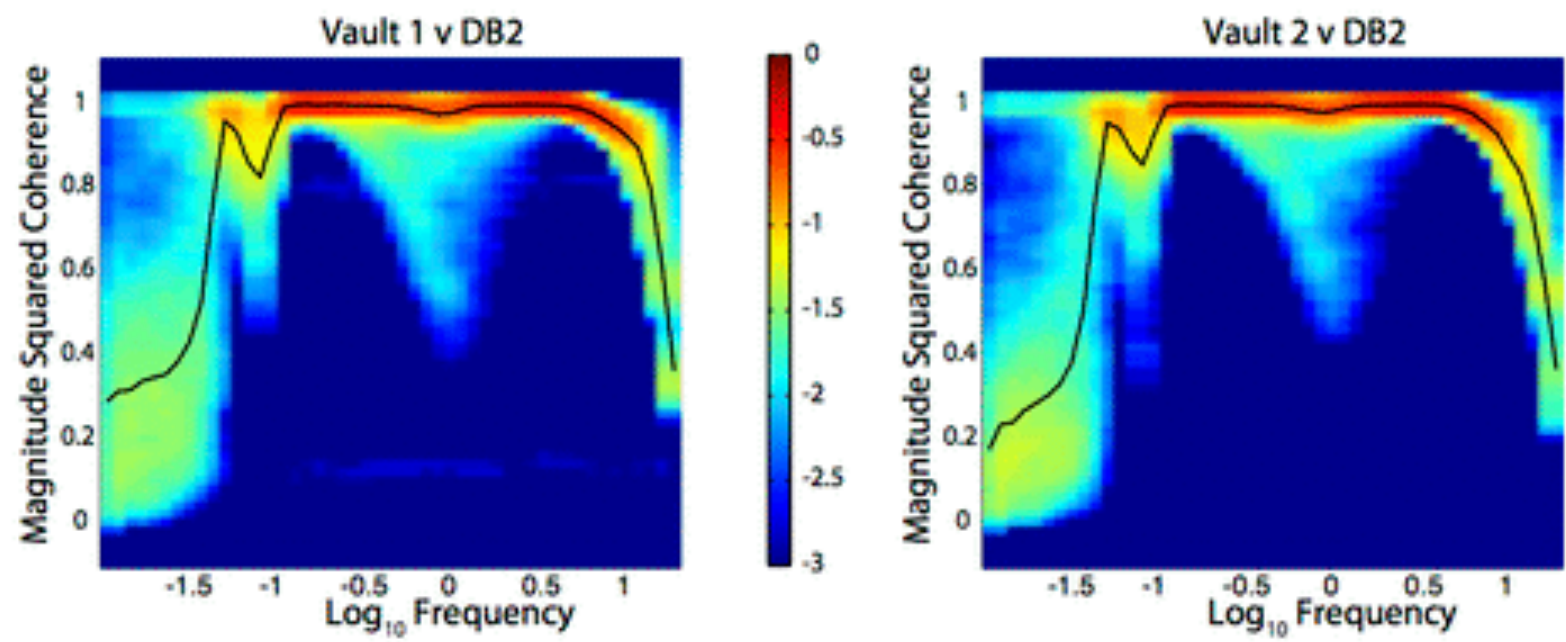

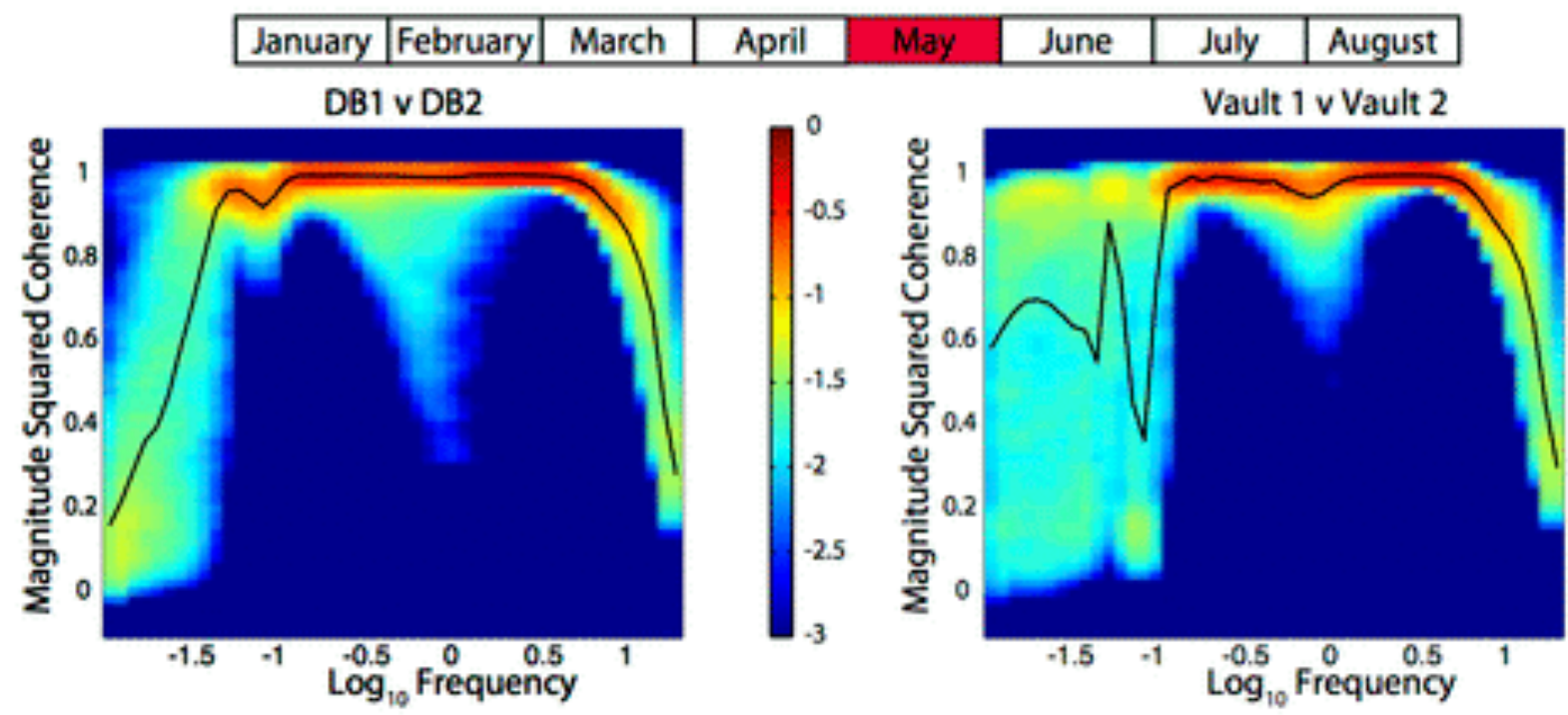

\section{$\mathrm{BHZ}$}
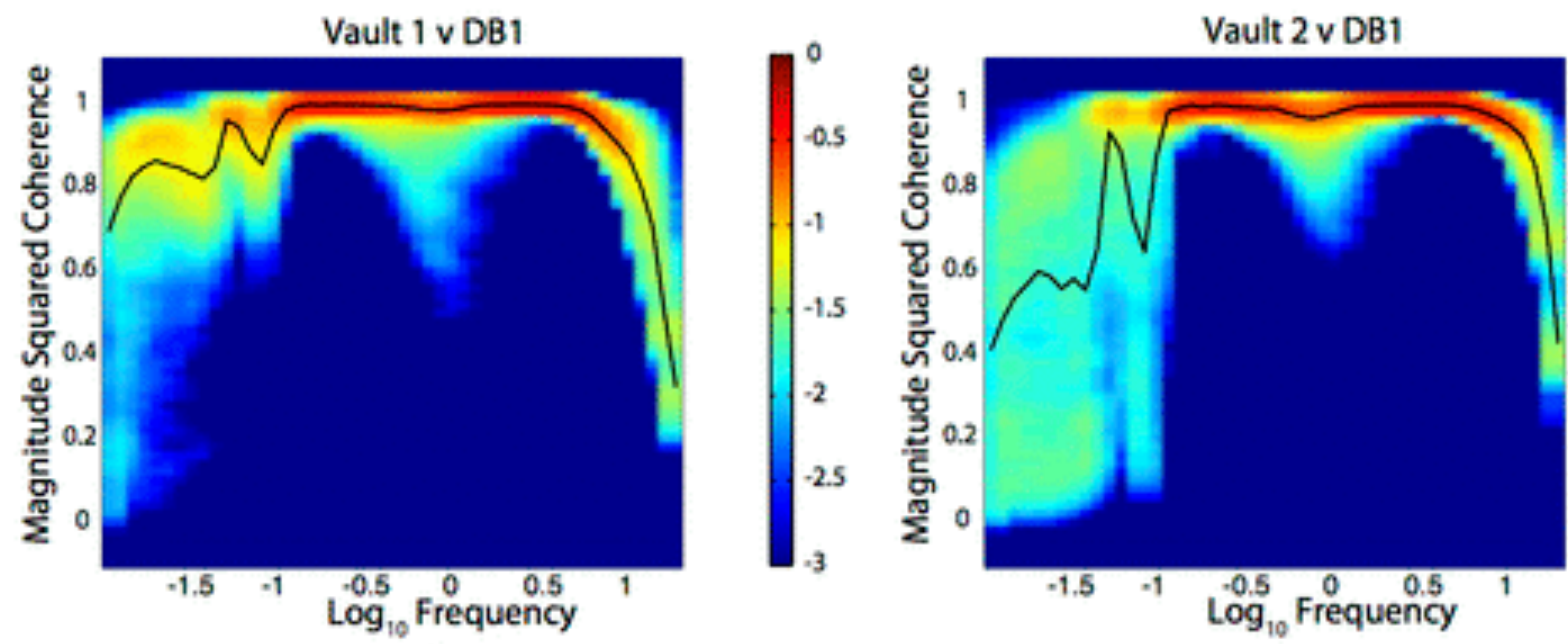

\section{$\mathrm{BHZ}$}
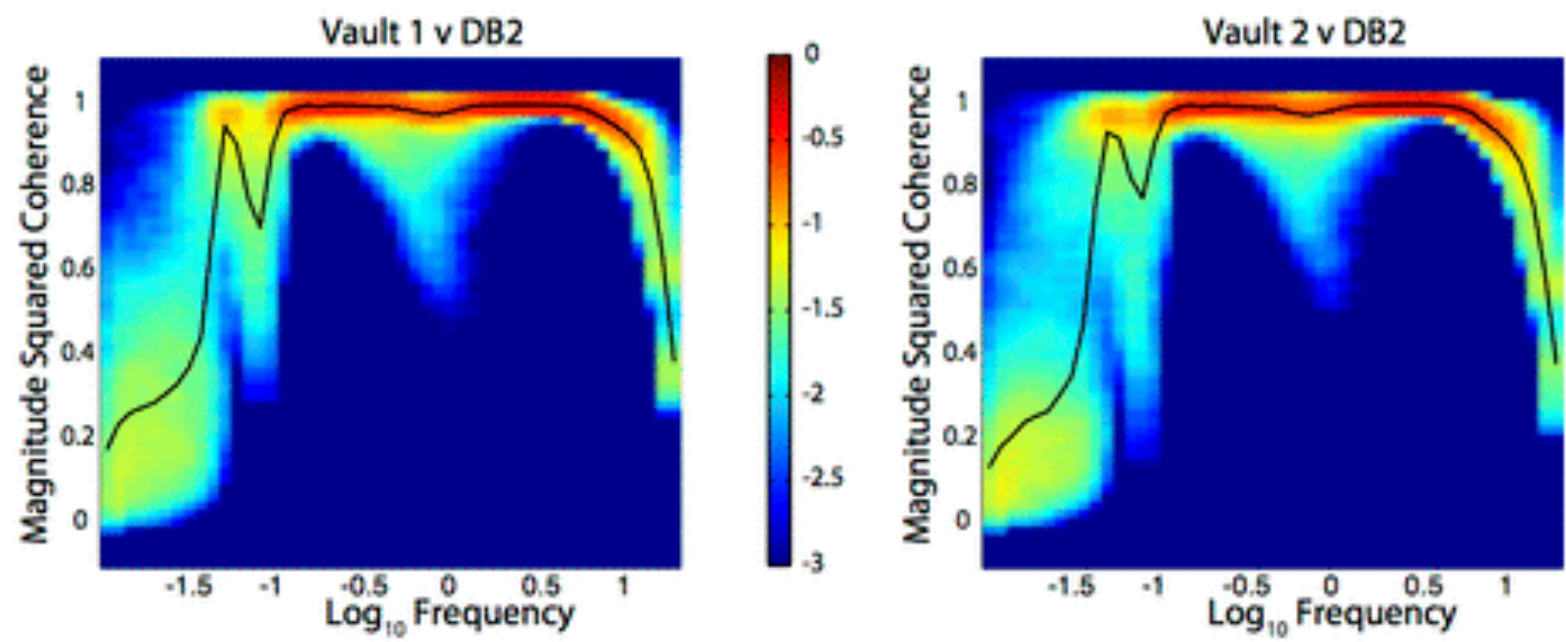

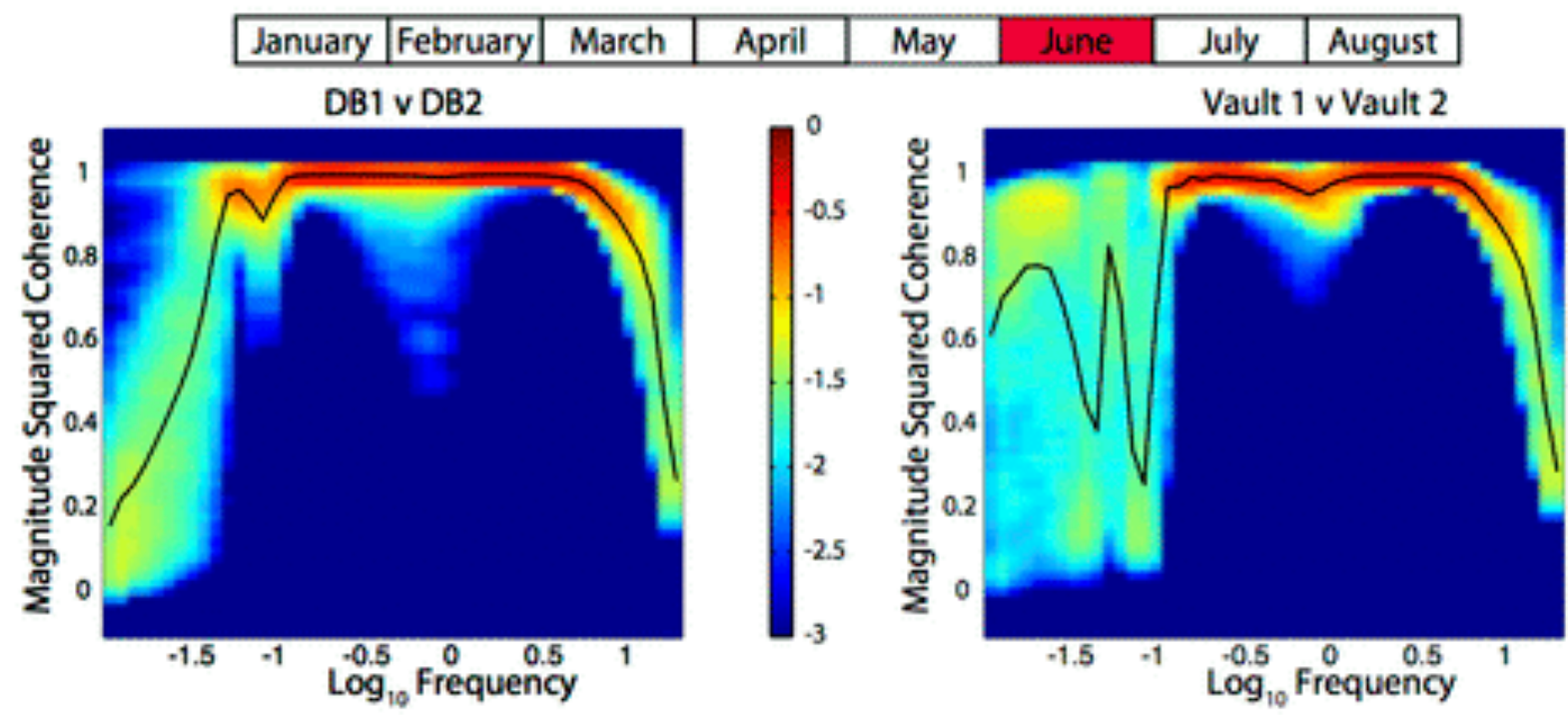

\section{$\mathrm{BHZ}$}
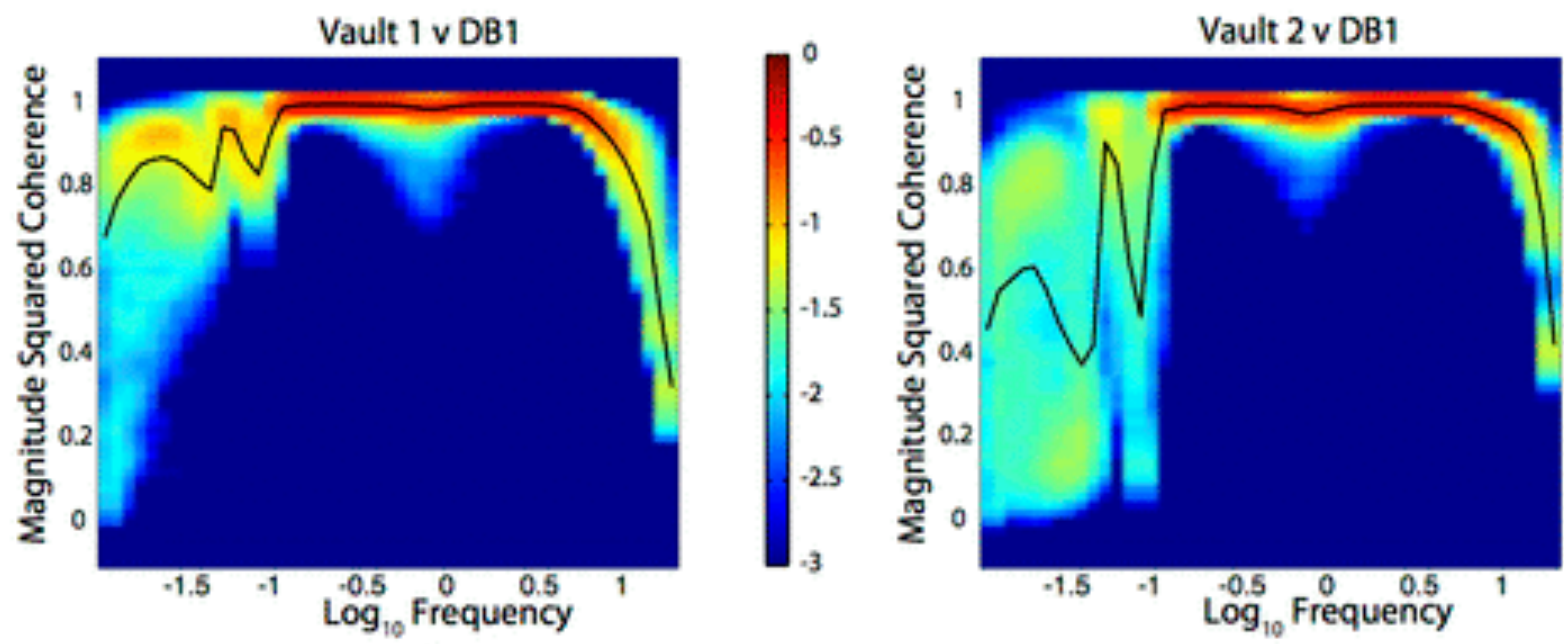

$\mathrm{BHZ}$
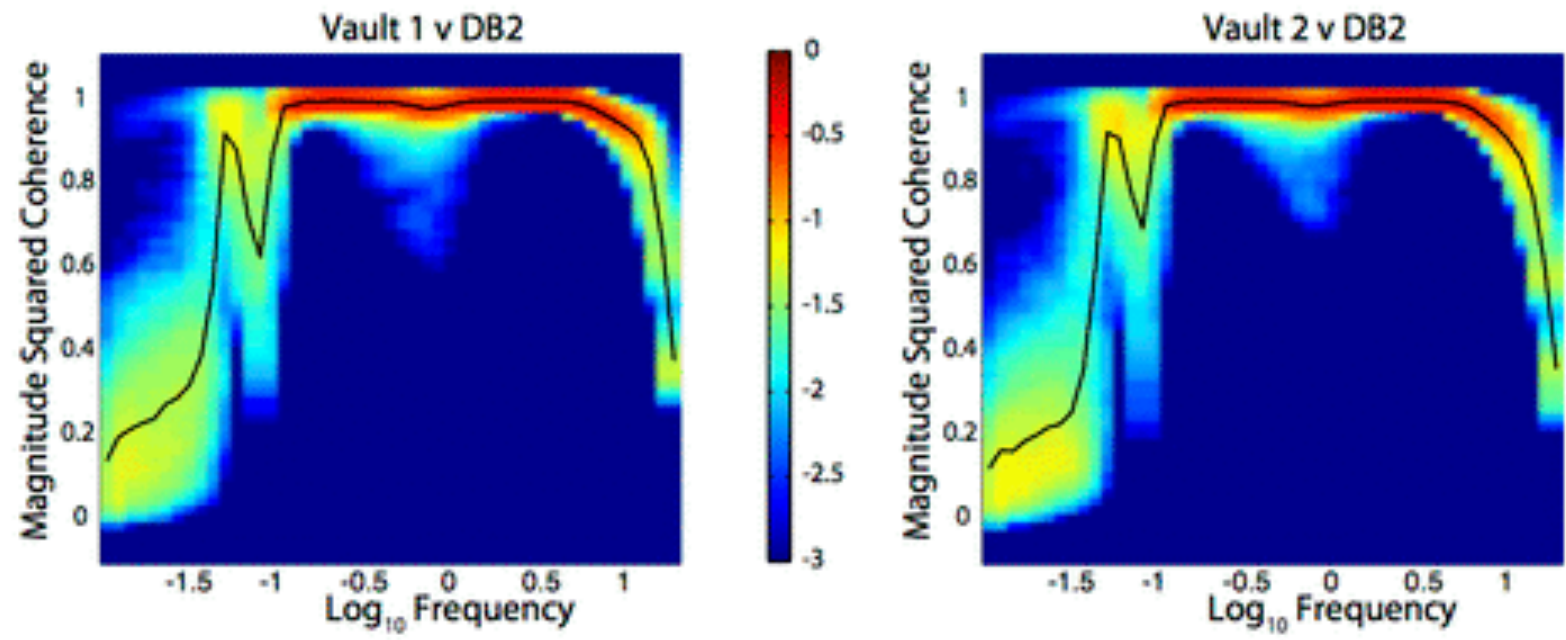

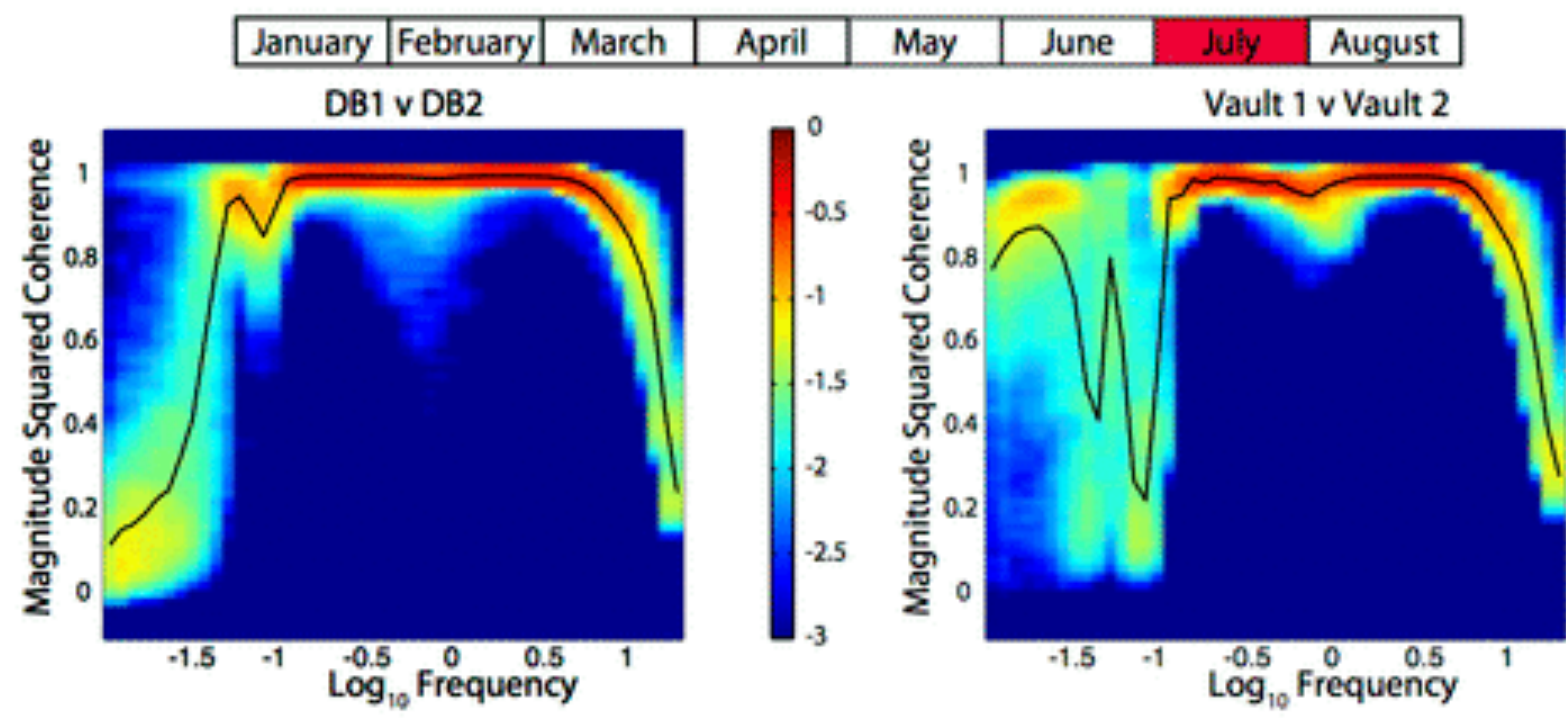

\section{$\mathrm{BHZ}$}
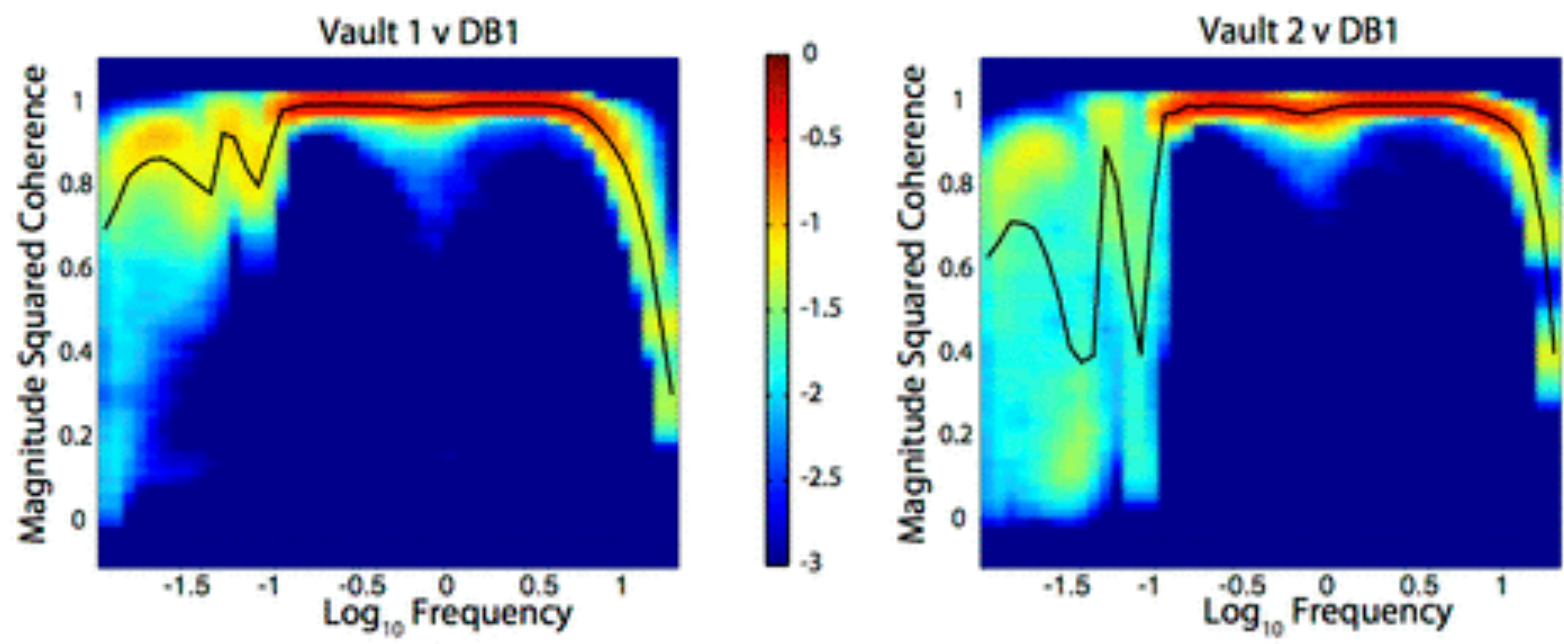

$\mathrm{BHZ}$
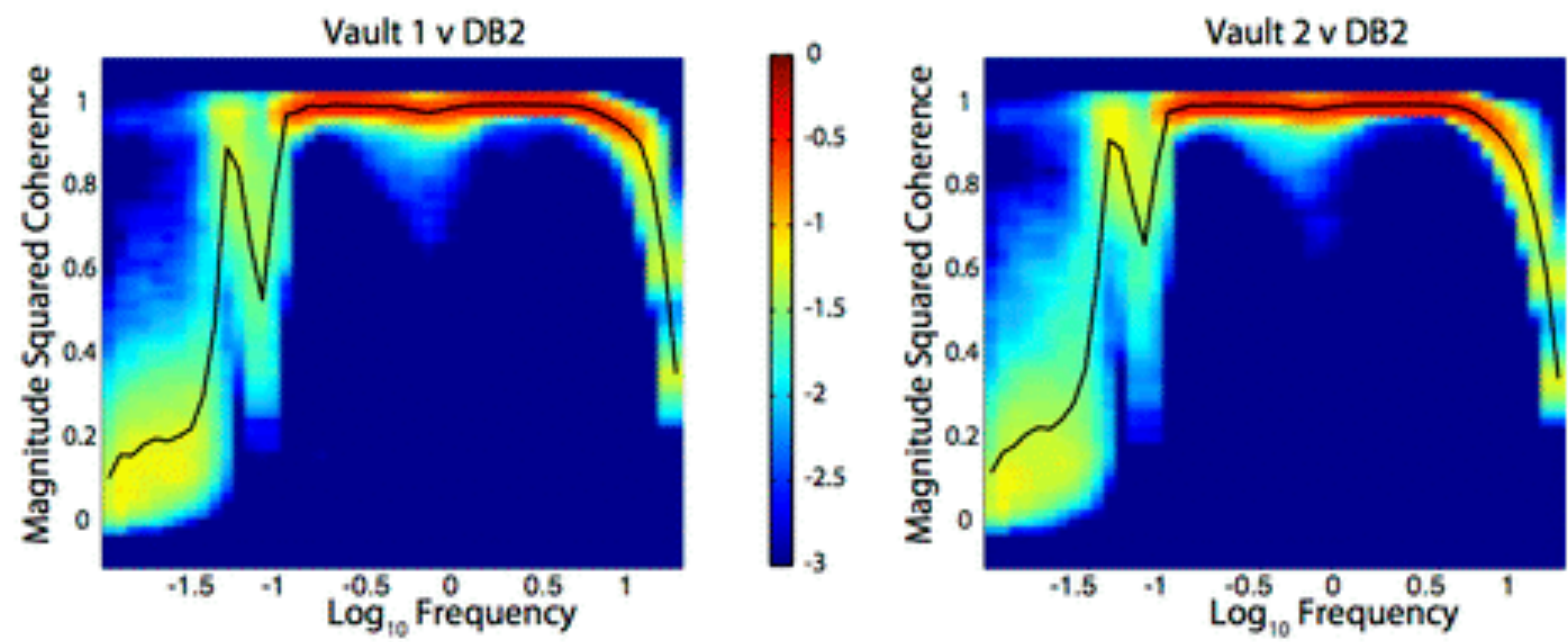

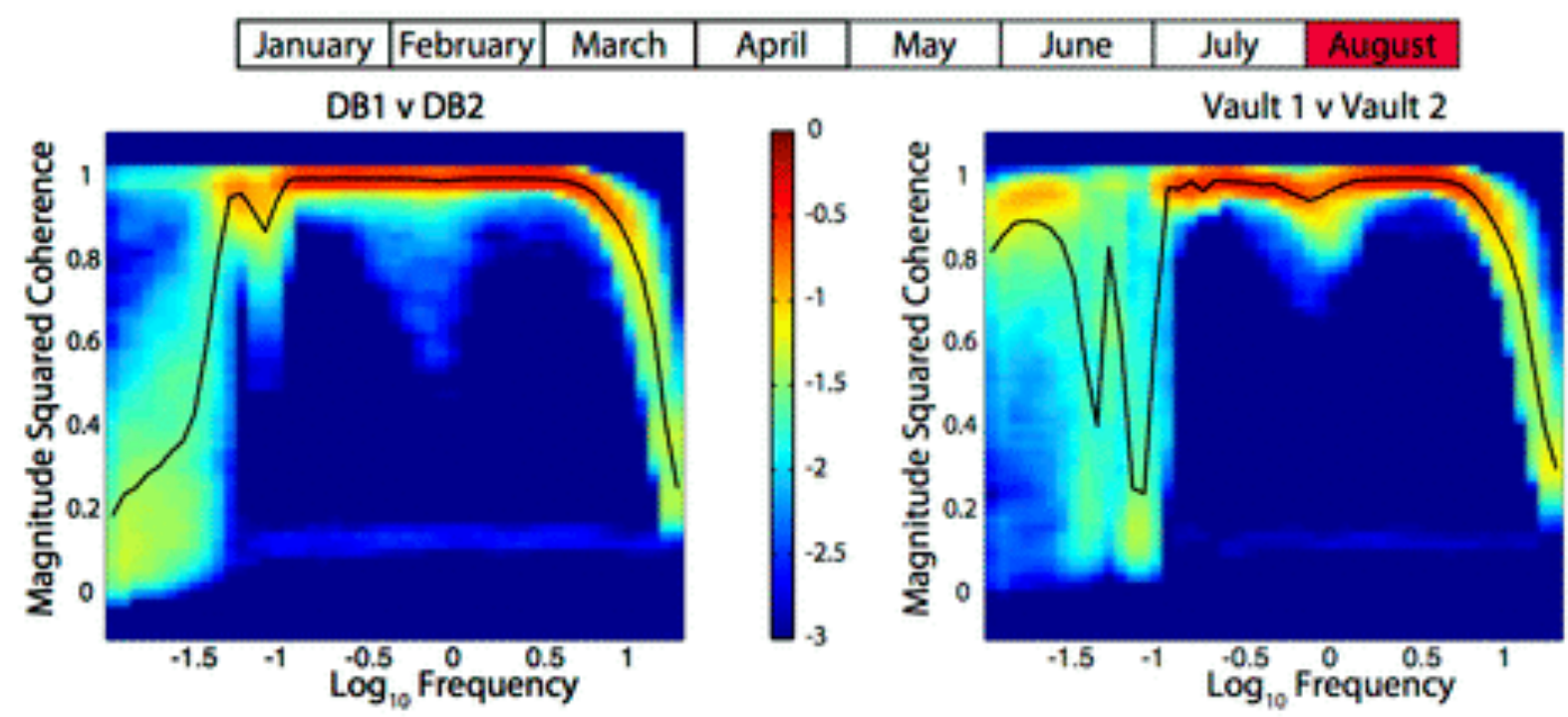

\section{$\mathrm{BHZ}$}
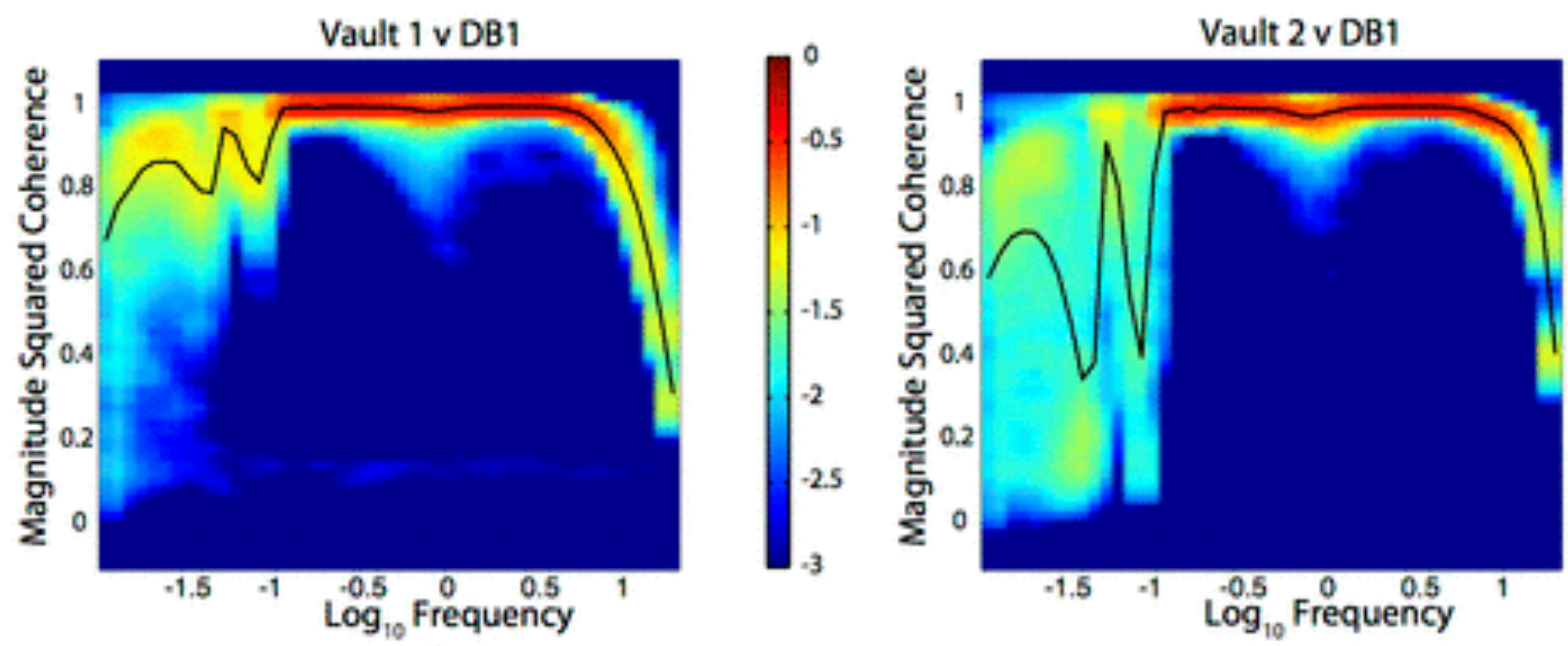

\section{$\mathrm{BHZ}$}
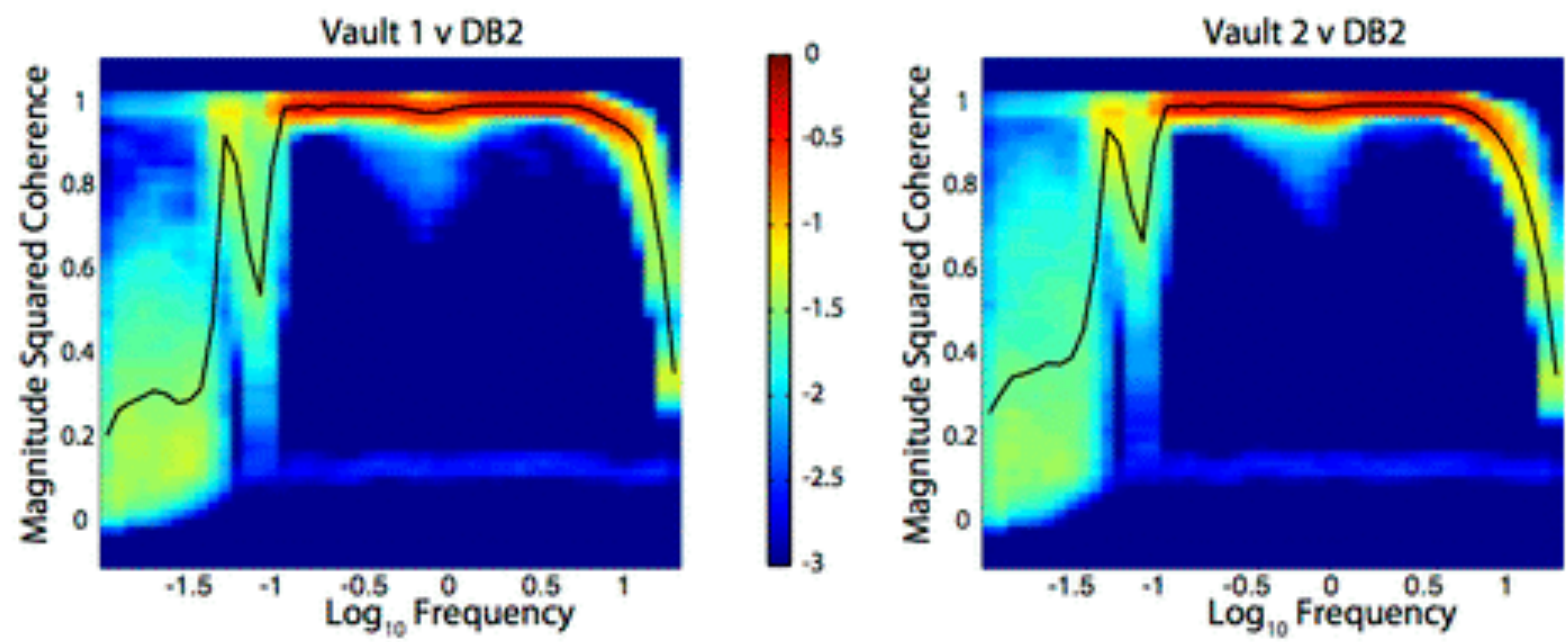

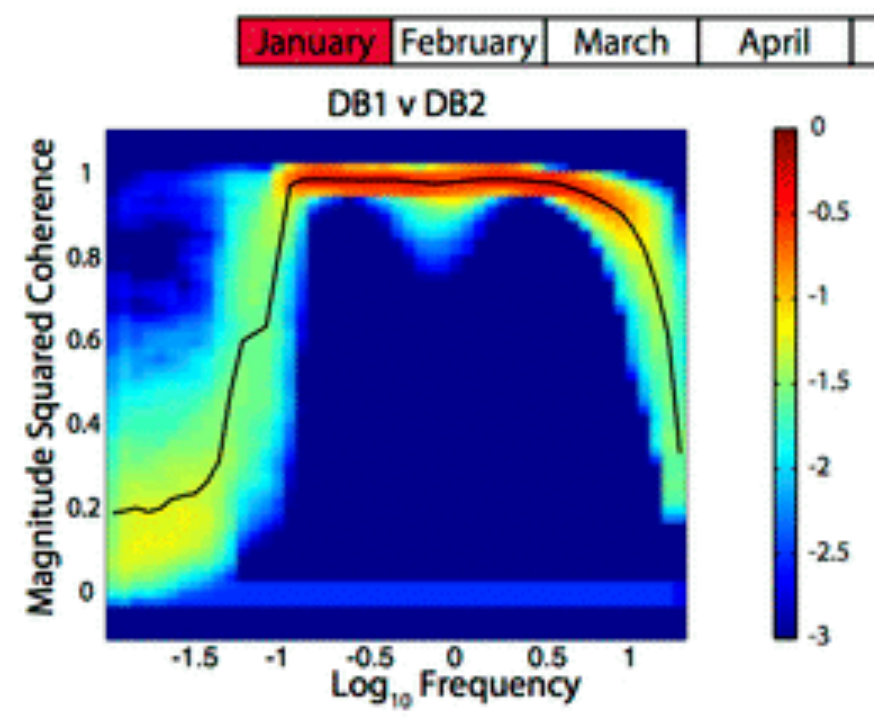

\begin{tabular}{|l|l|l|l|} 
May & June & July & August \\
\hline
\end{tabular}

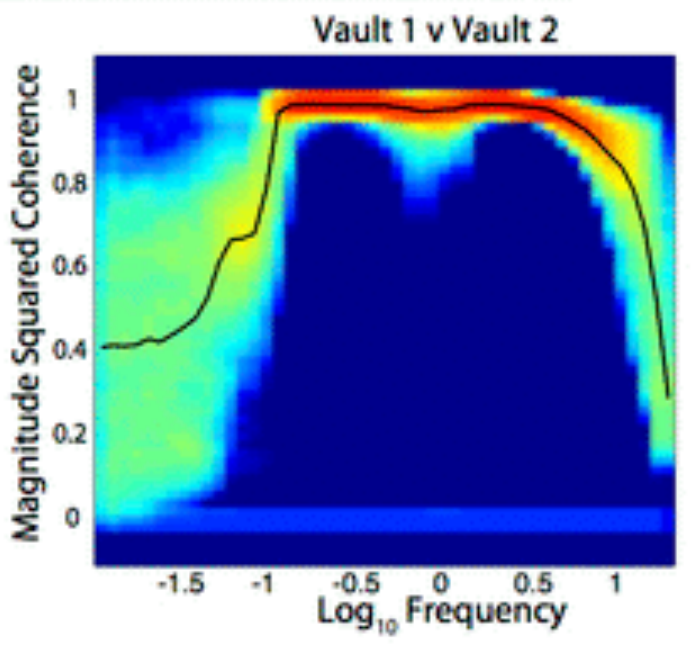

\section{BHE}
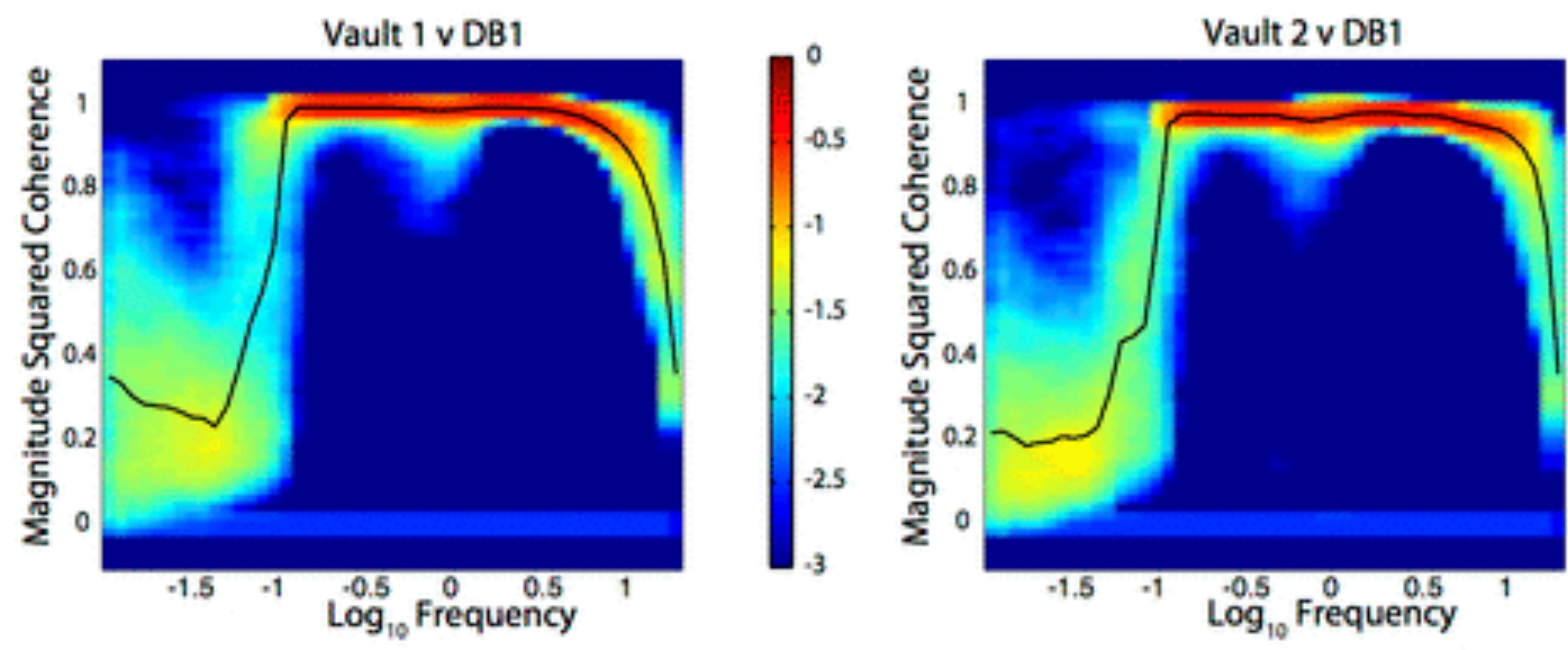

\section{BHE}
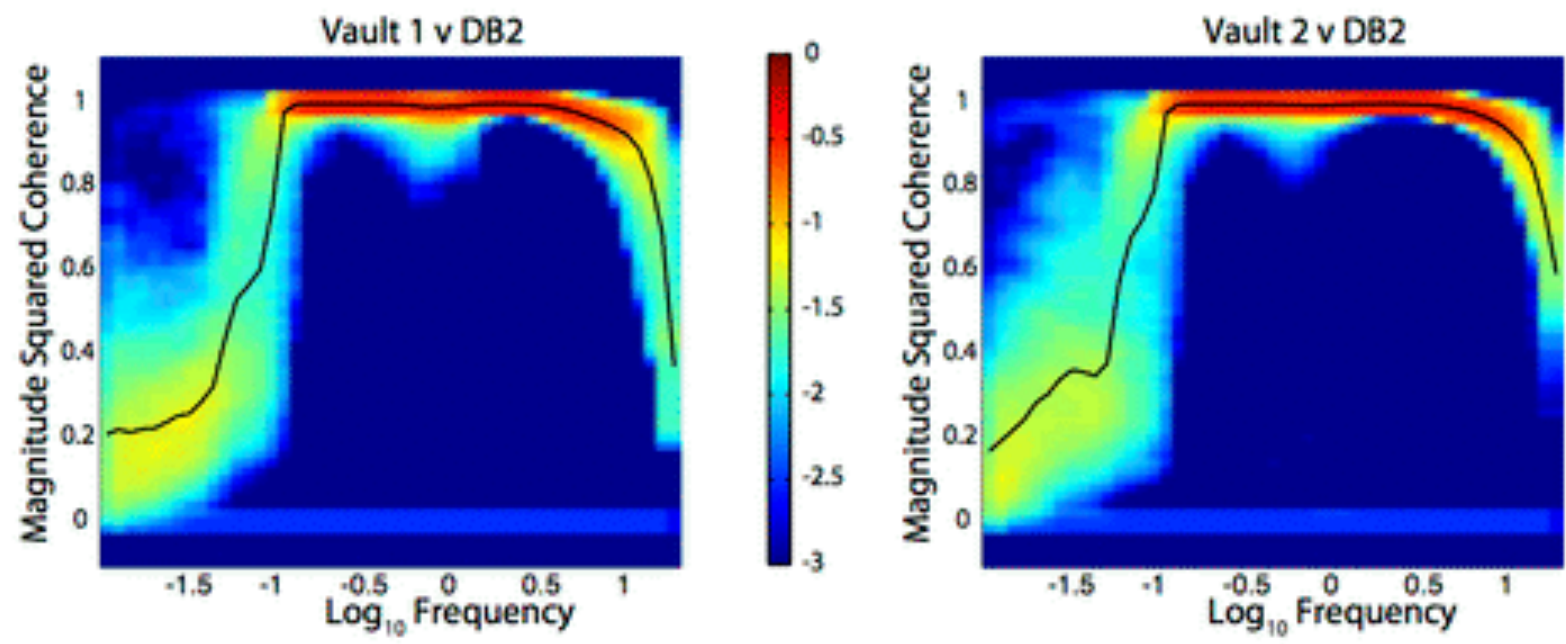

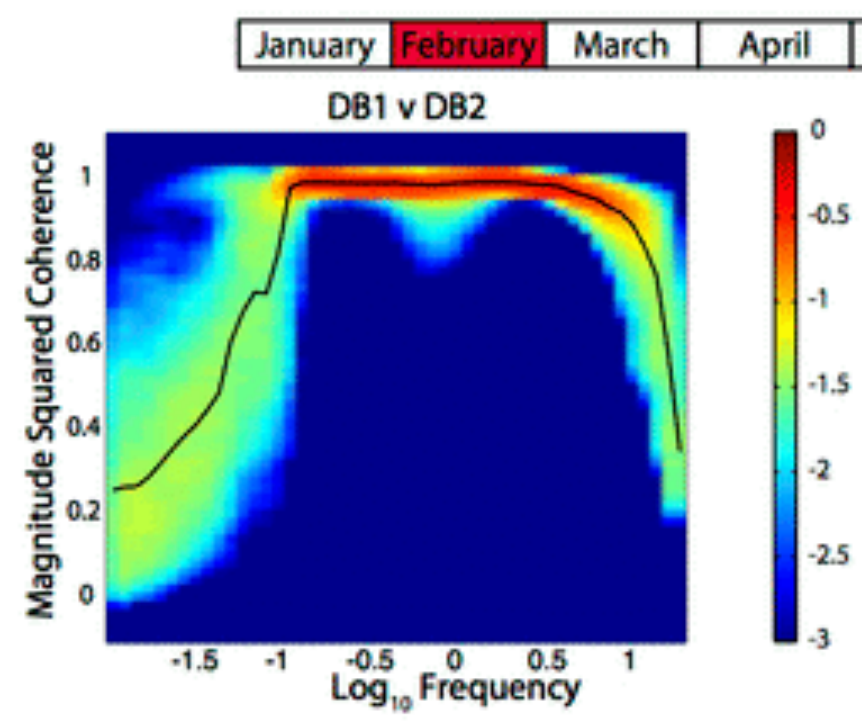

\begin{tabular}{|l|l|l|l|}
\hline May & June & July & August \\
\hline
\end{tabular}

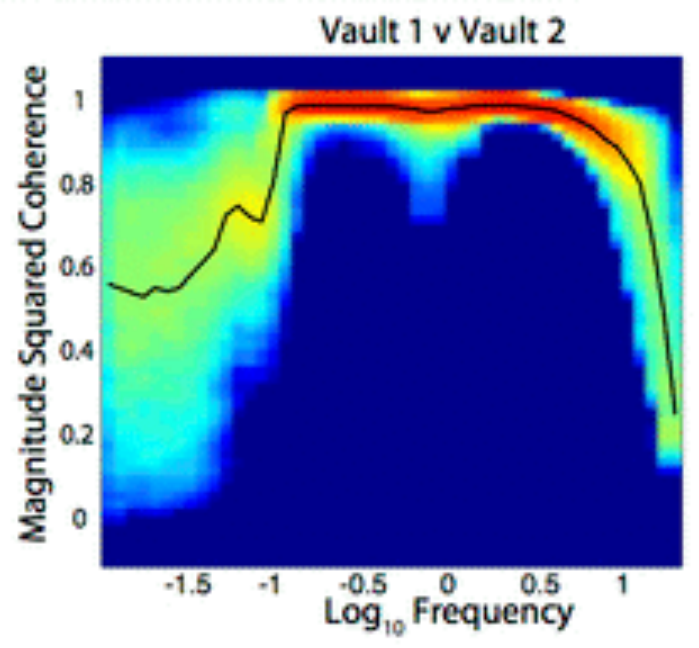

\section{BHE}
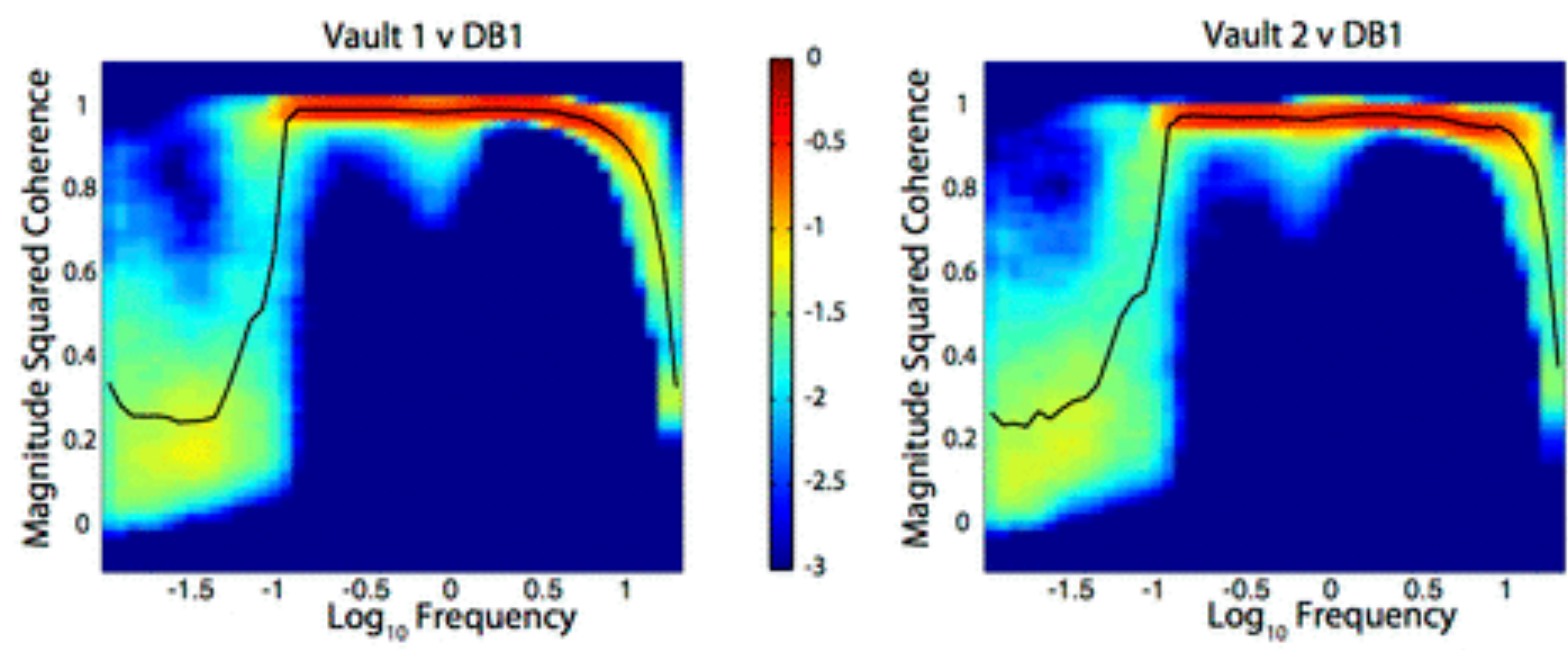

\section{BHE}
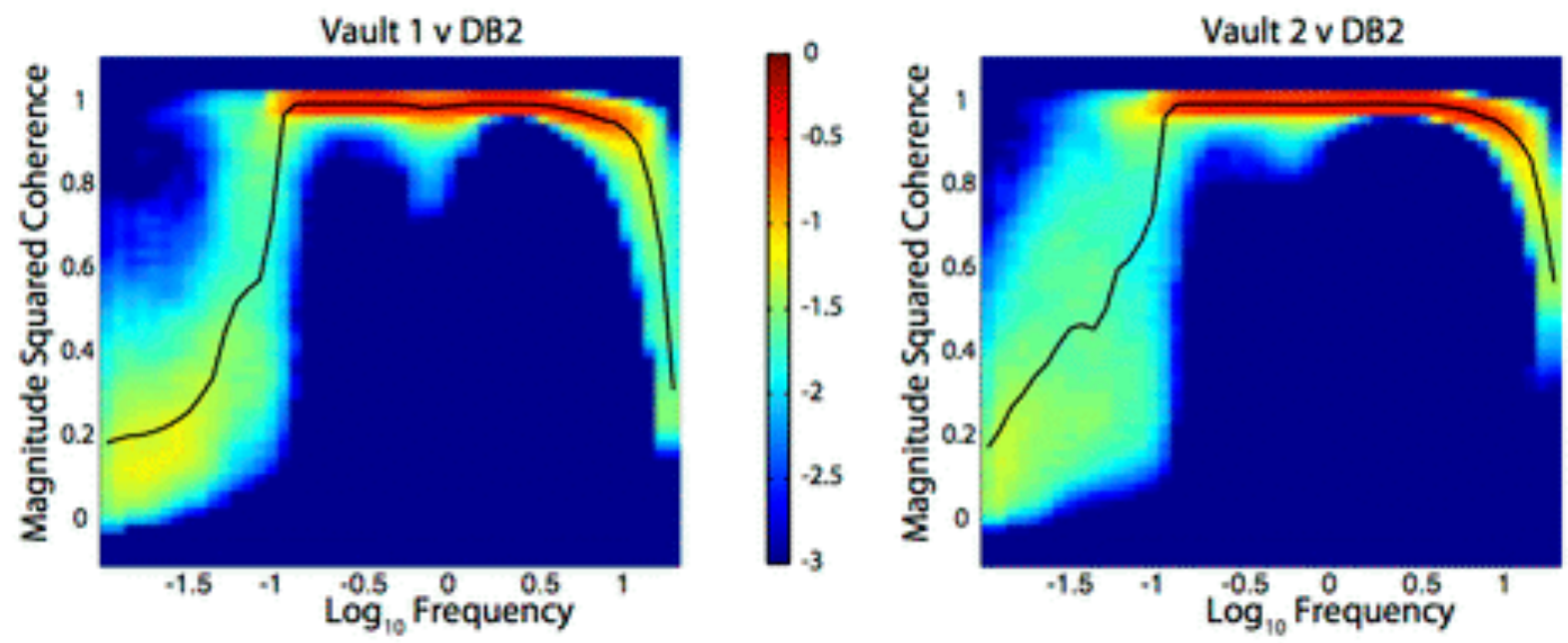

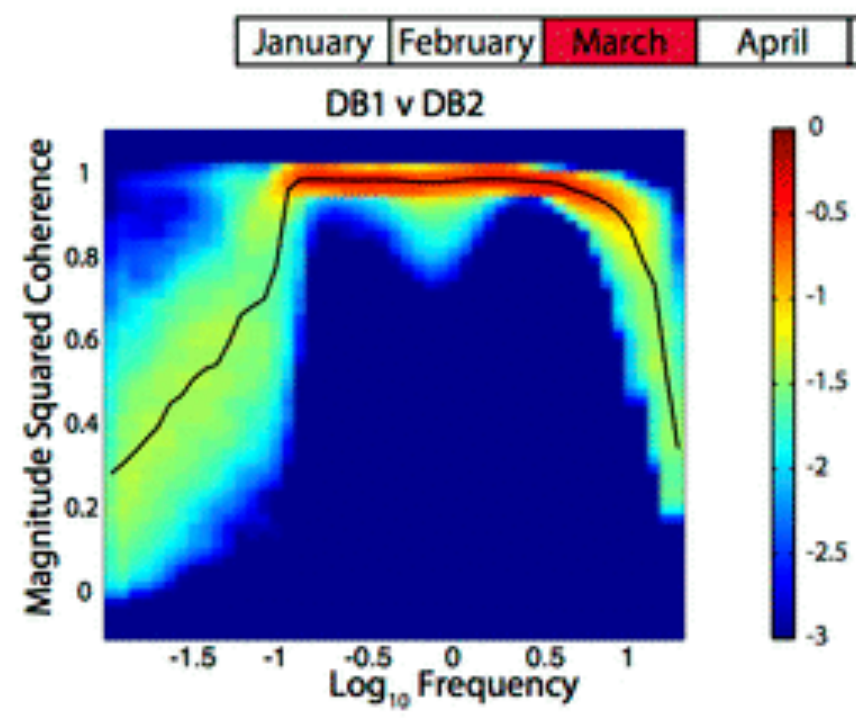

\begin{tabular}{|l|l|l|l|}
\hline May & June & July & August \\
\hline
\end{tabular}

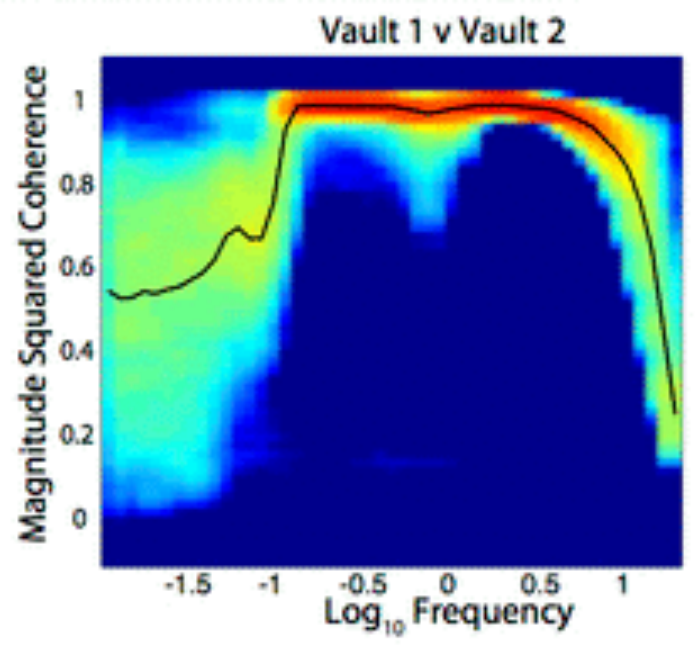

\section{BHE}
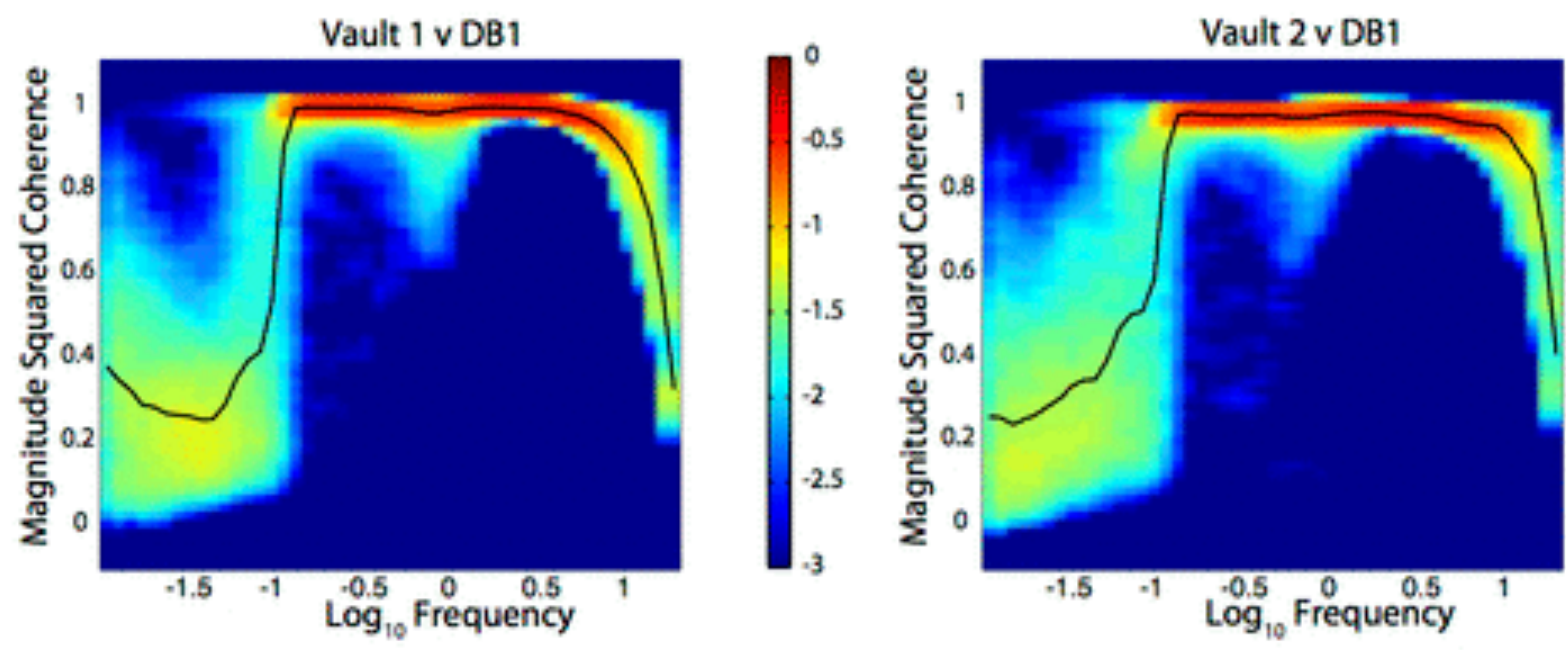

\section{BHE}
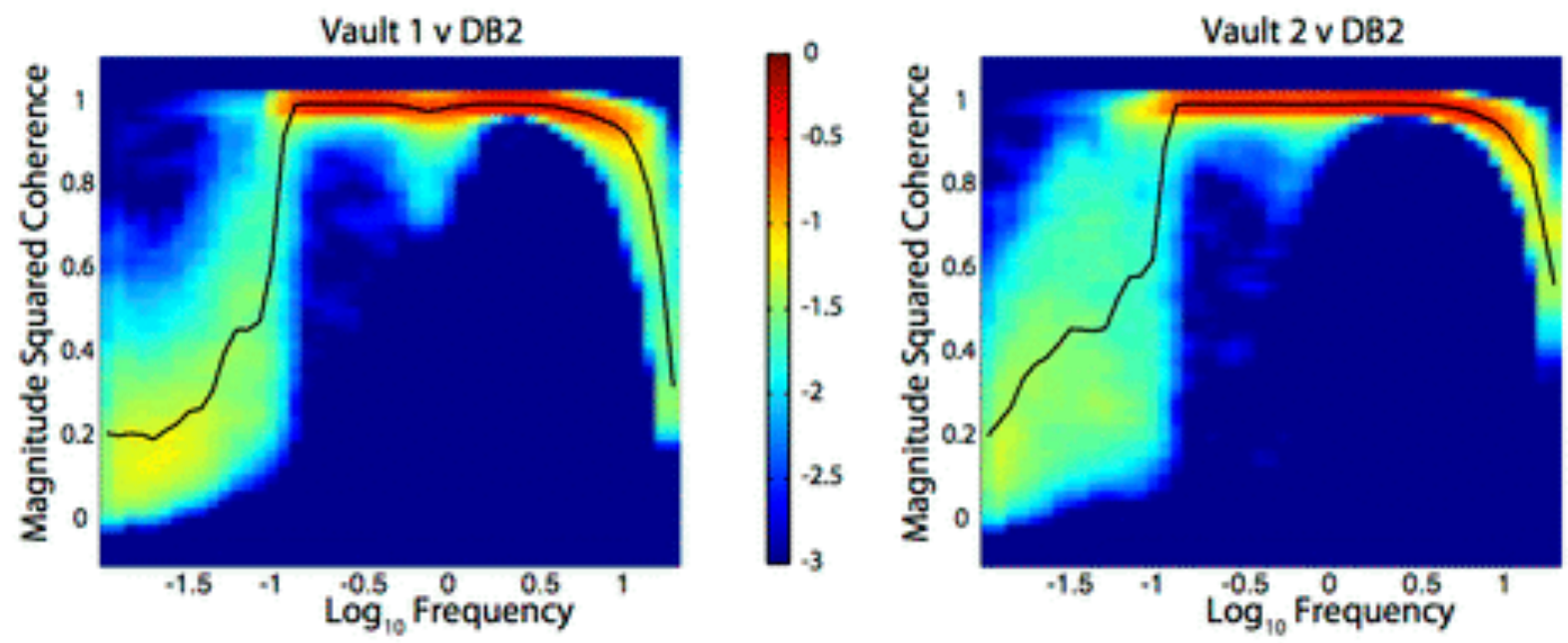

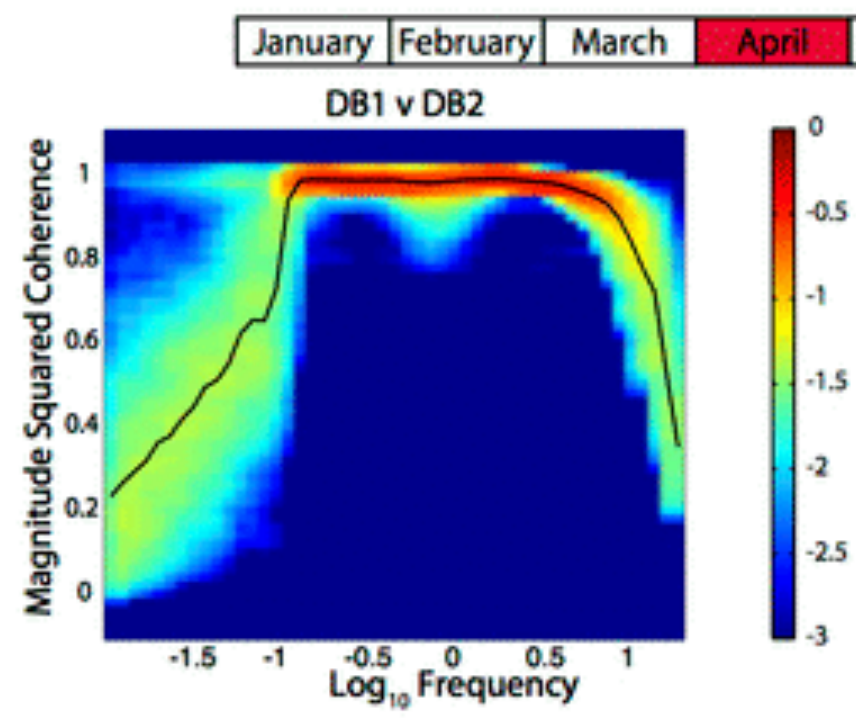

\begin{tabular}{|l|l|l|l|}
\hline May & June & July & August \\
\hline
\end{tabular}

\section{BHE}
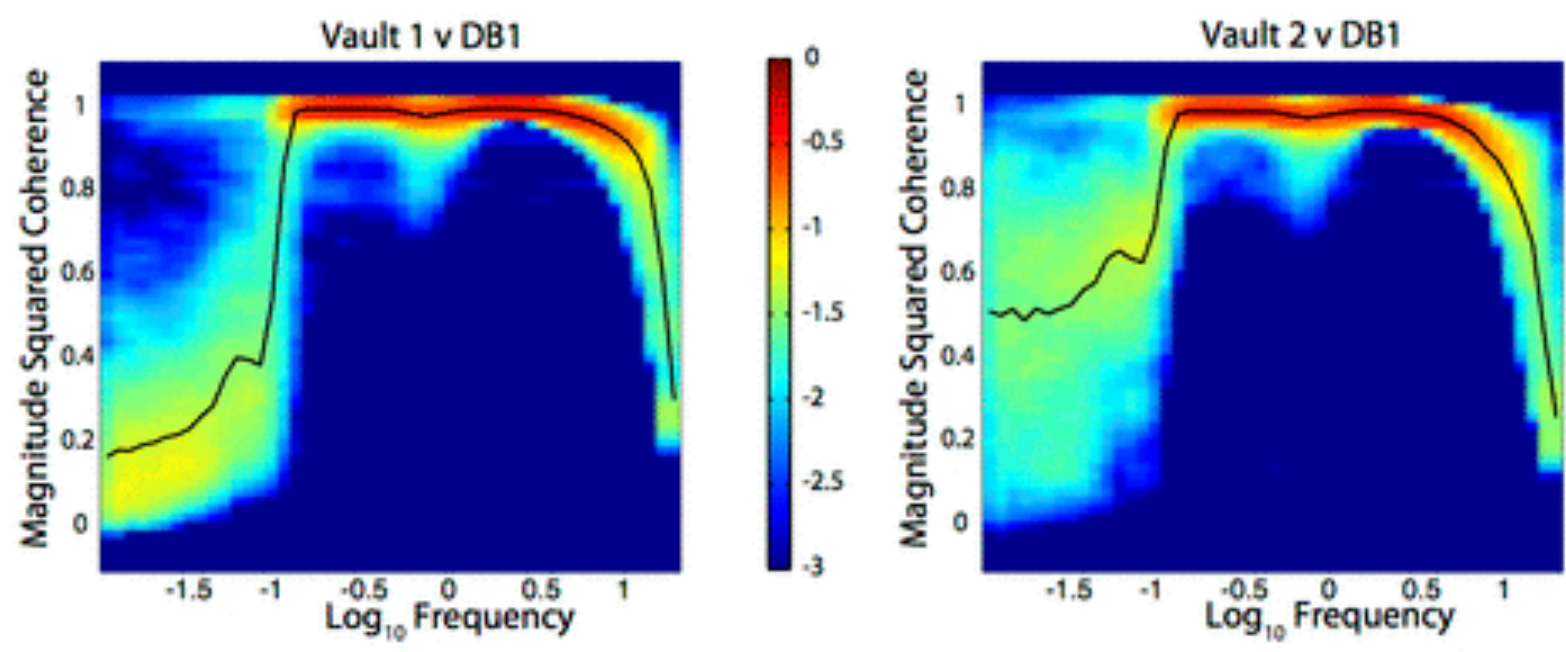

\section{BHE}
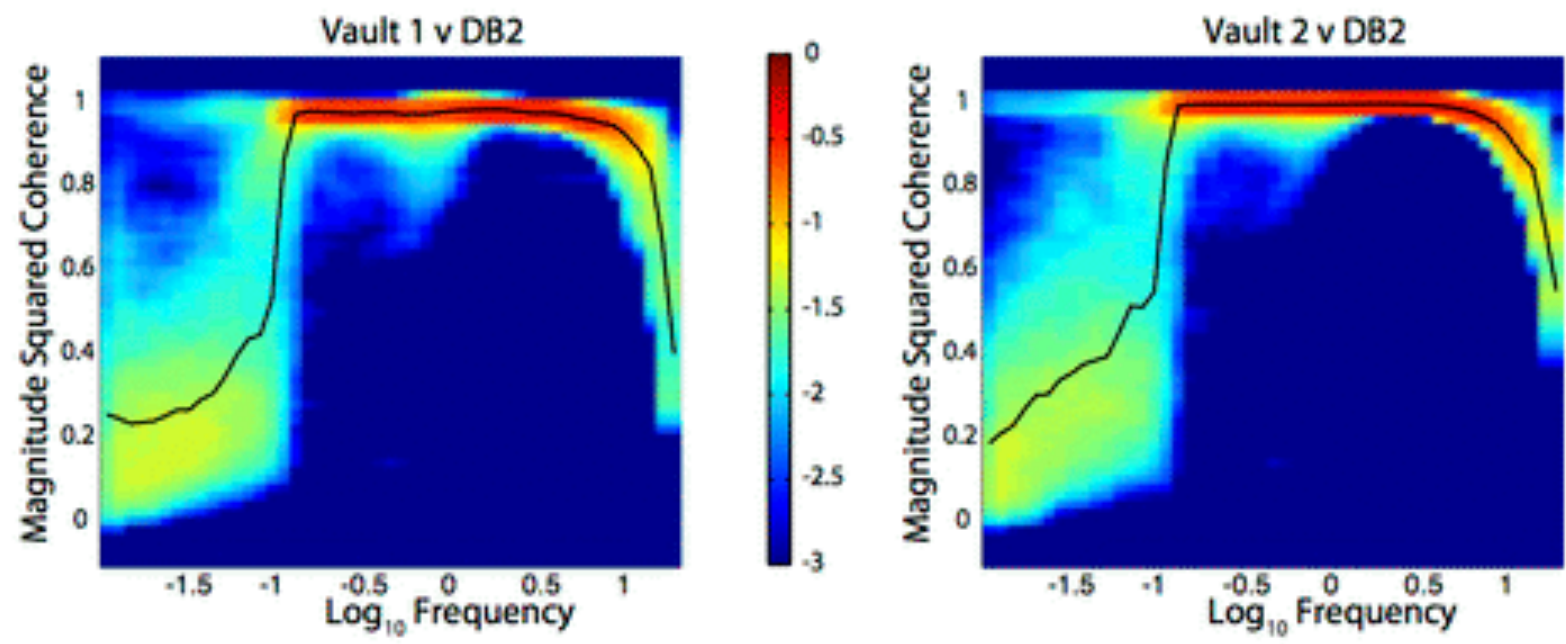

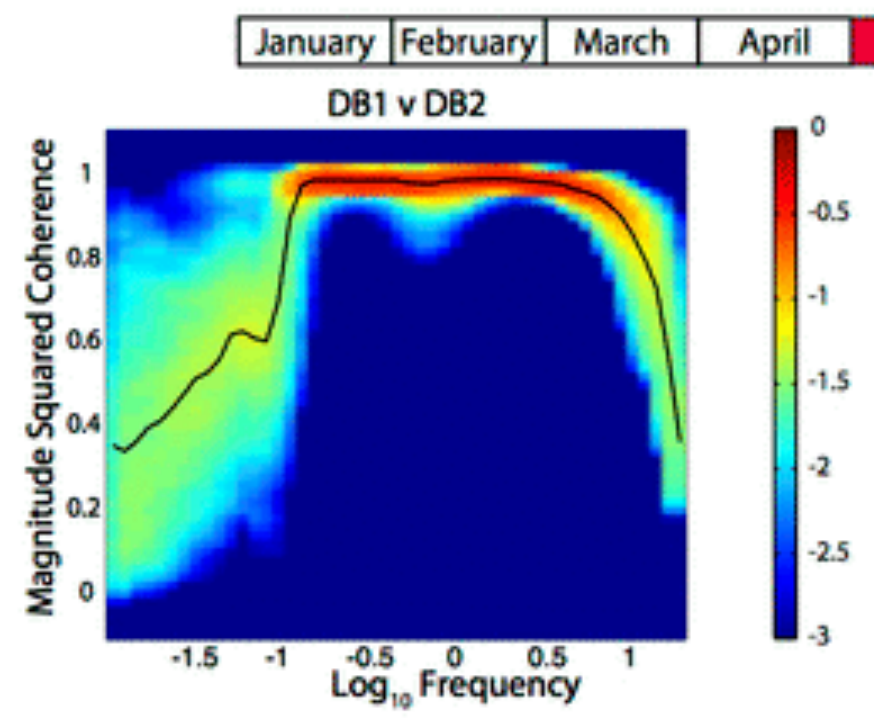

\begin{tabular}{|l|l|l|l|} 
May & June & July & August \\
\hline
\end{tabular}

\section{BHE}
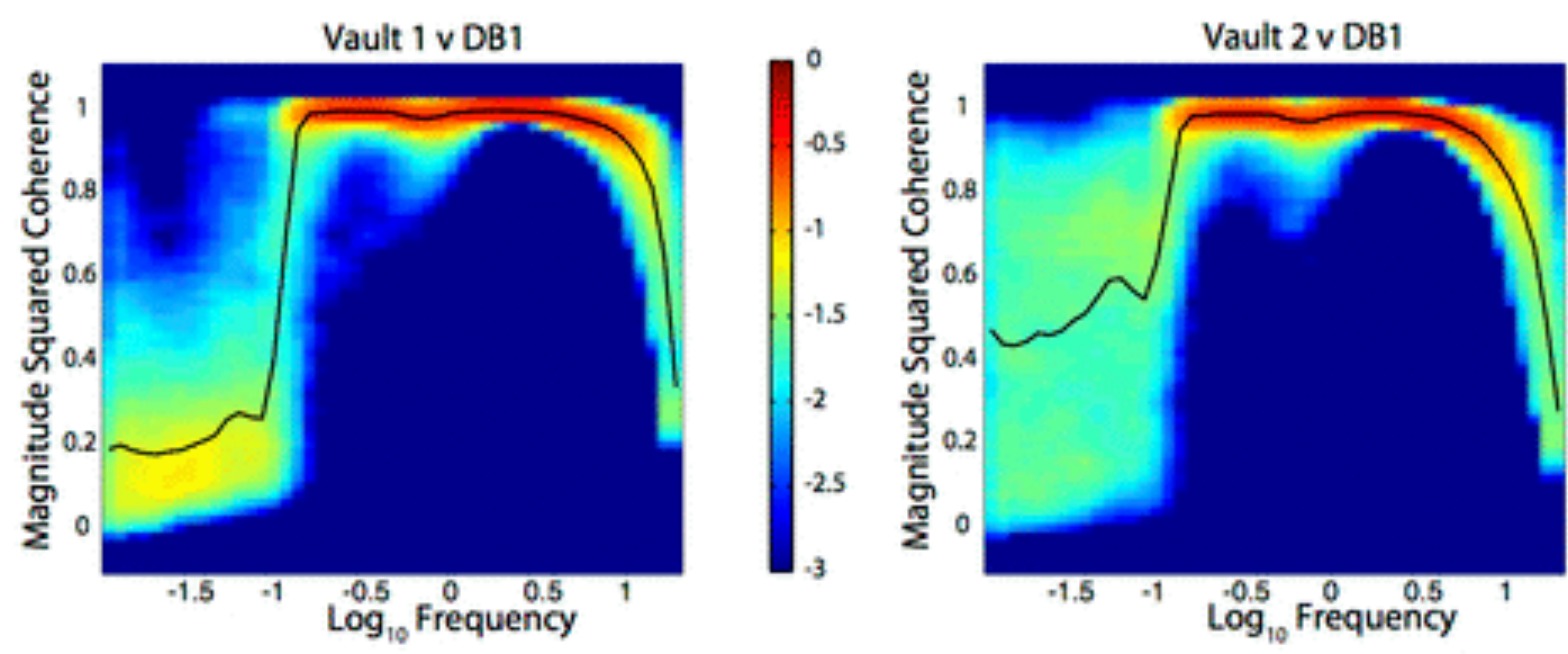

\section{BHE}
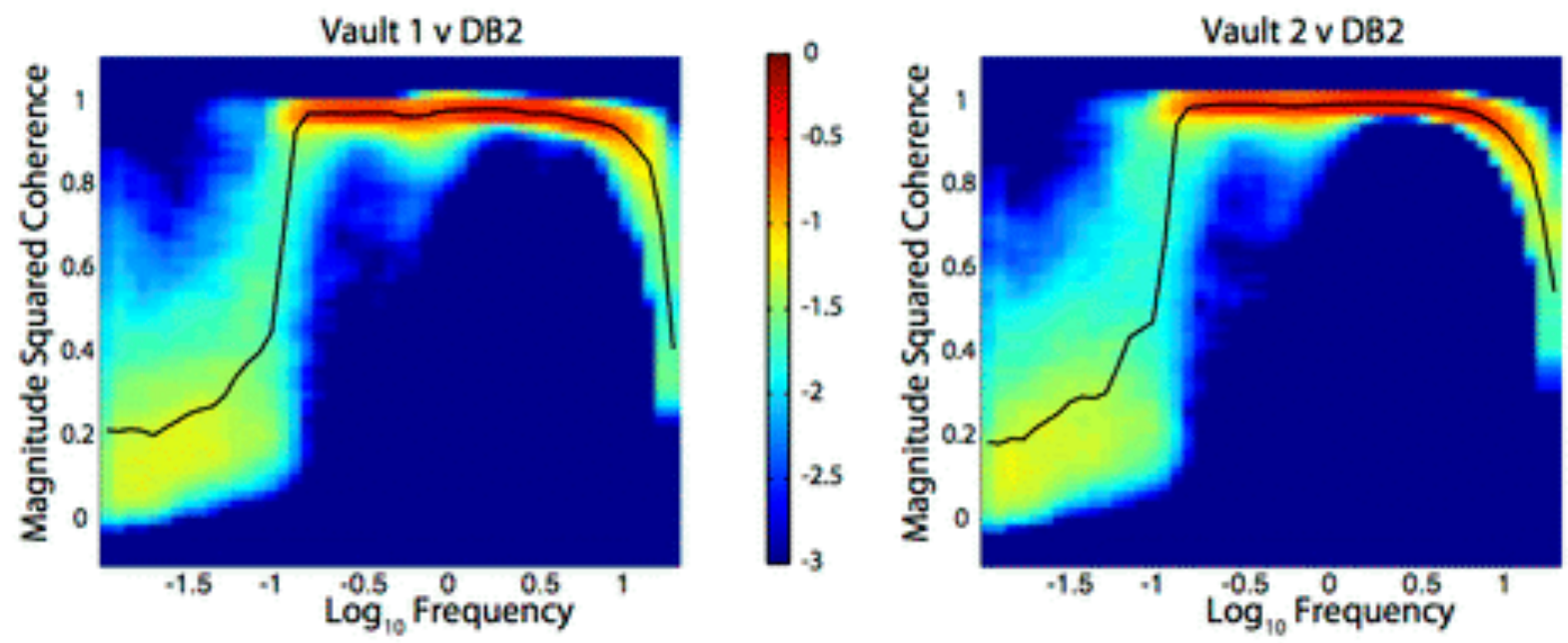

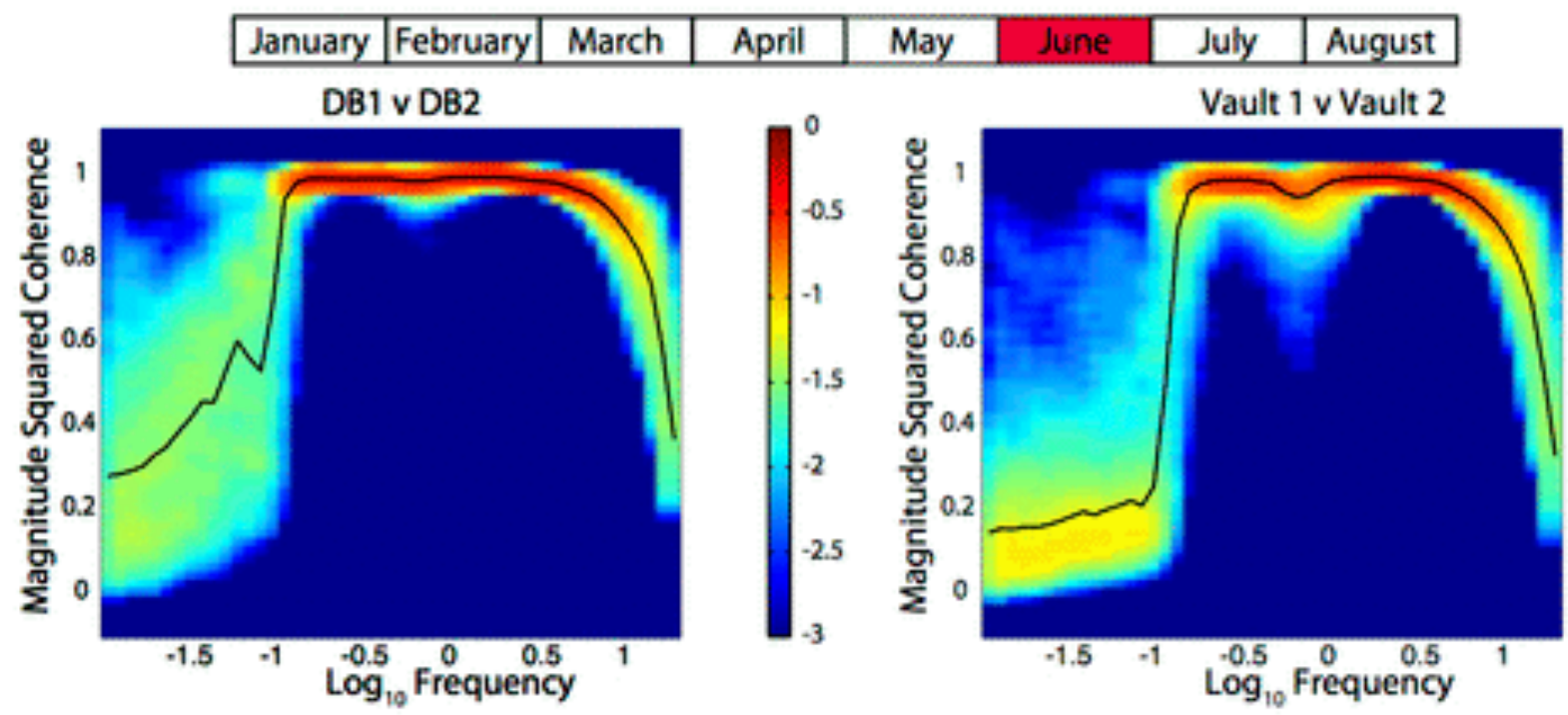

\section{BHE}
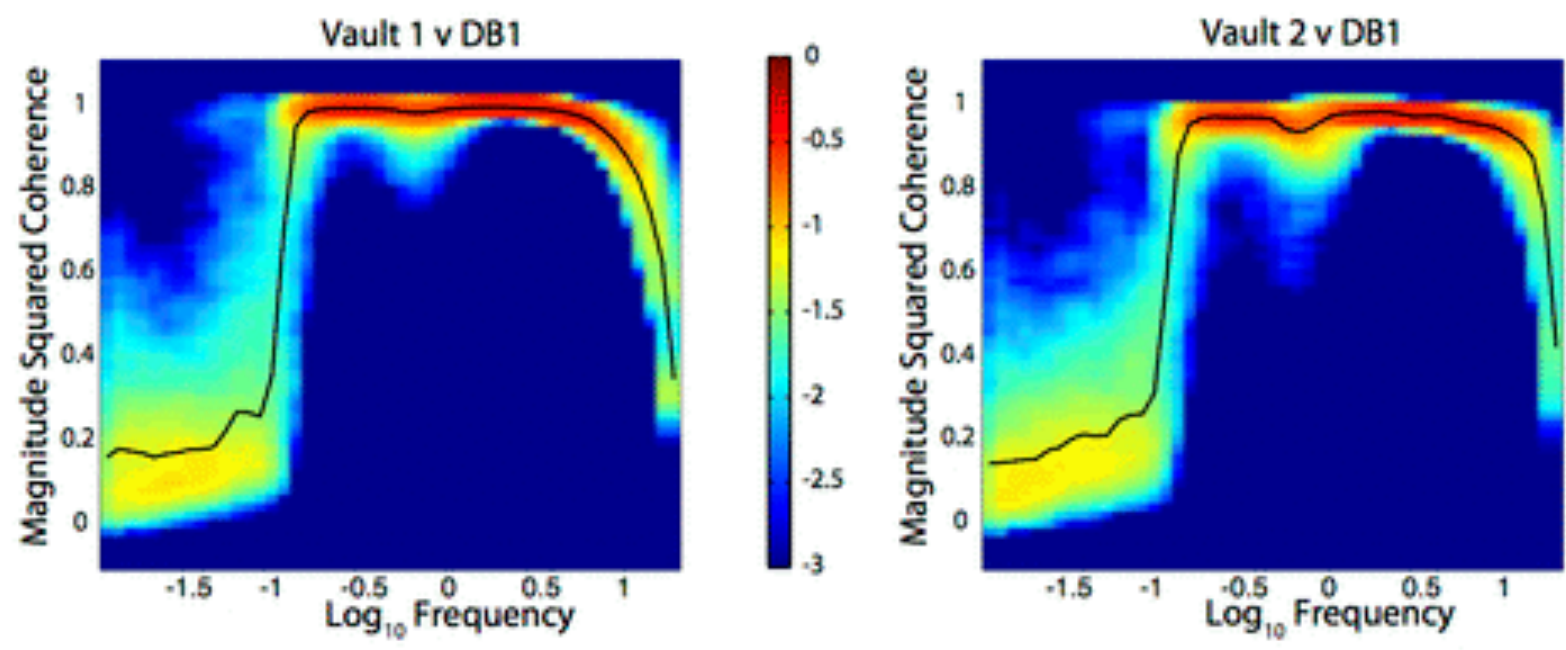

\section{BHE}
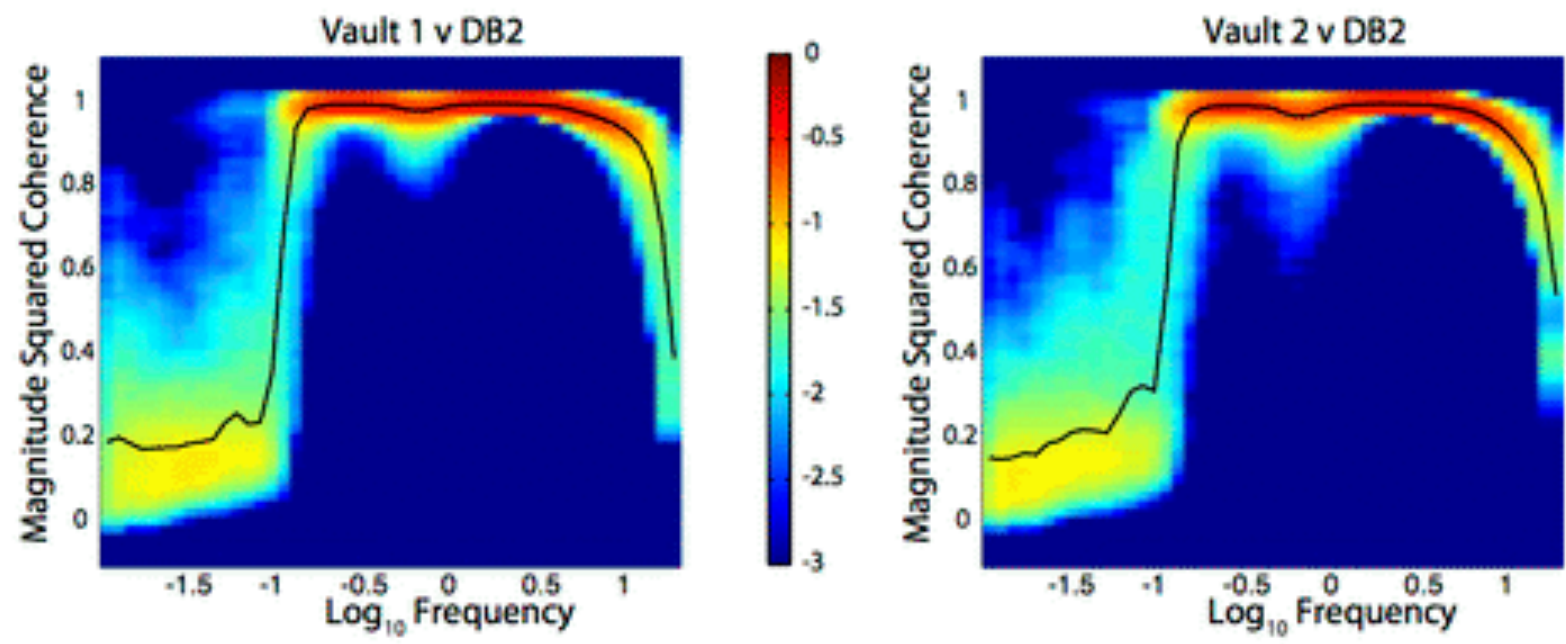

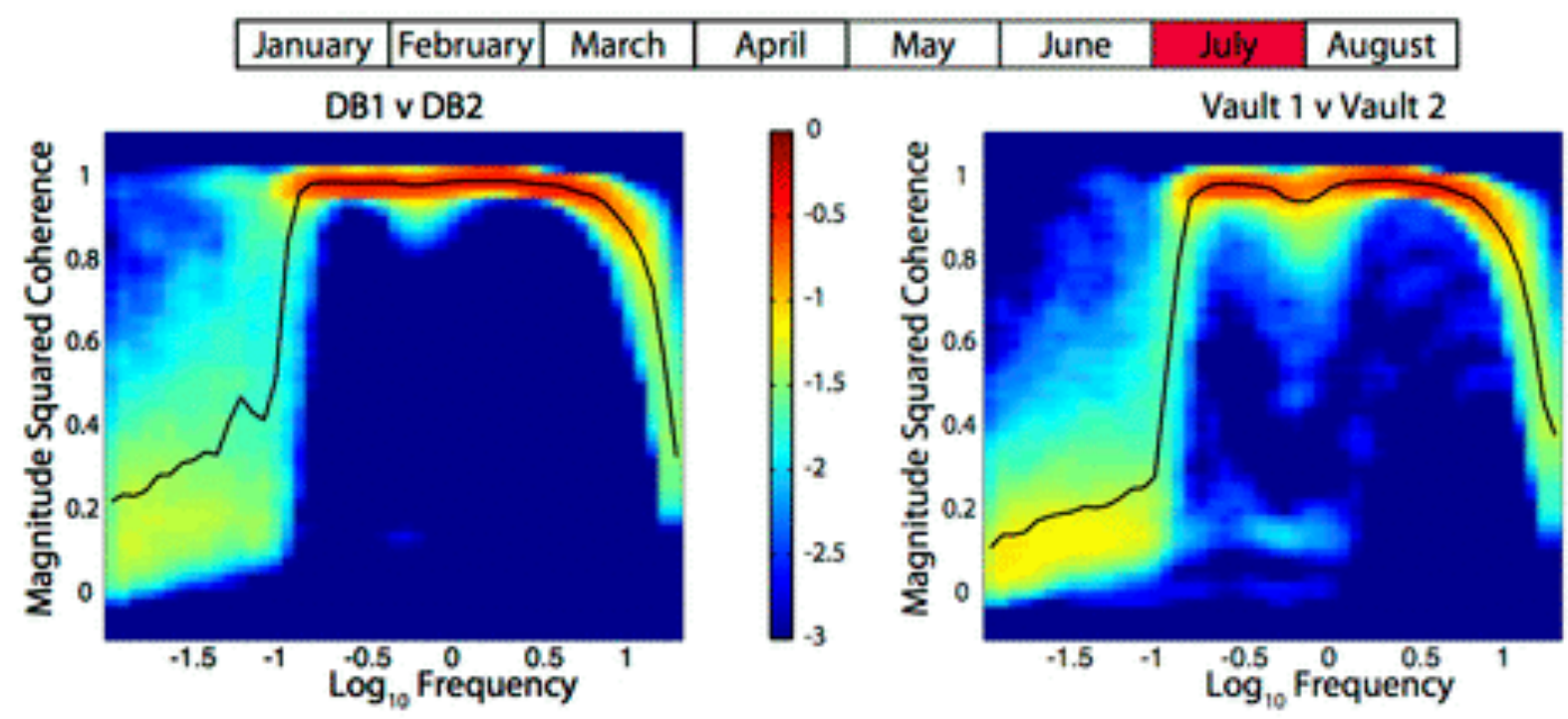

\section{BHE}
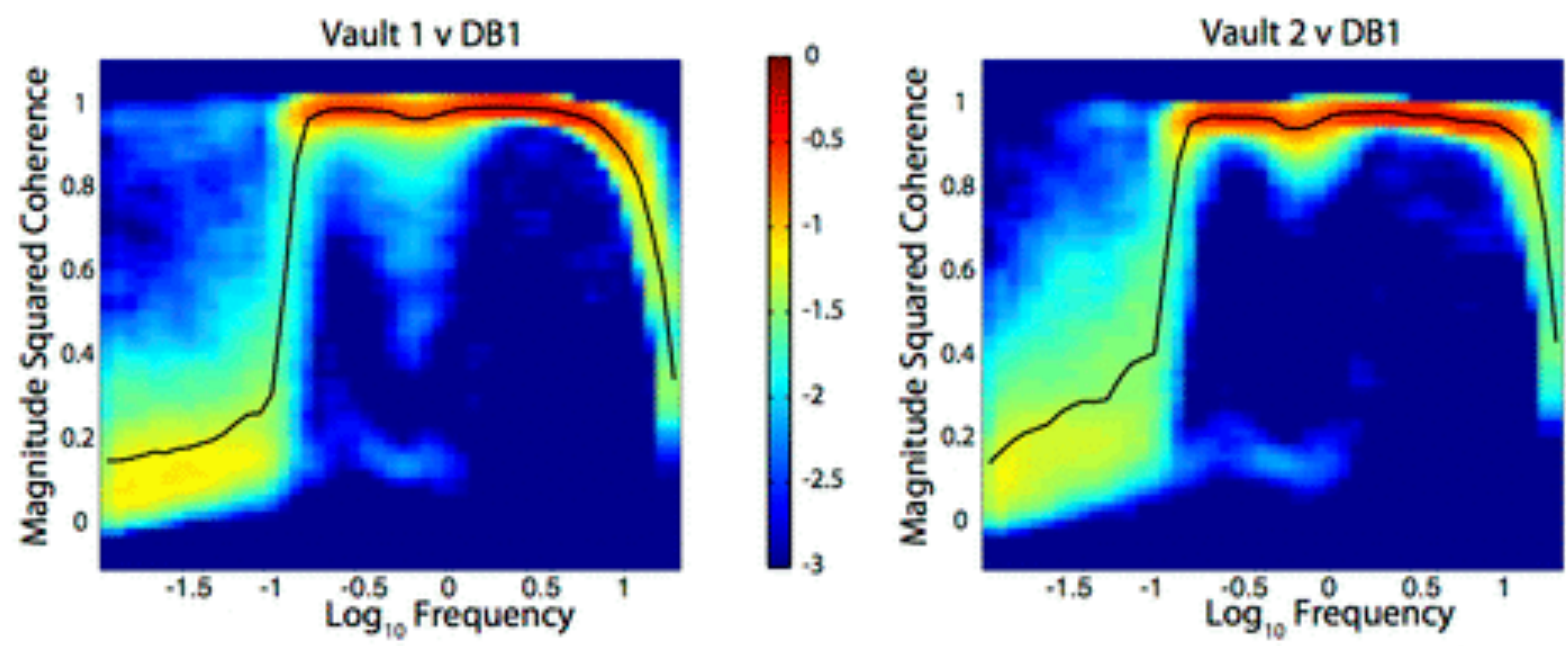

\section{BHE}
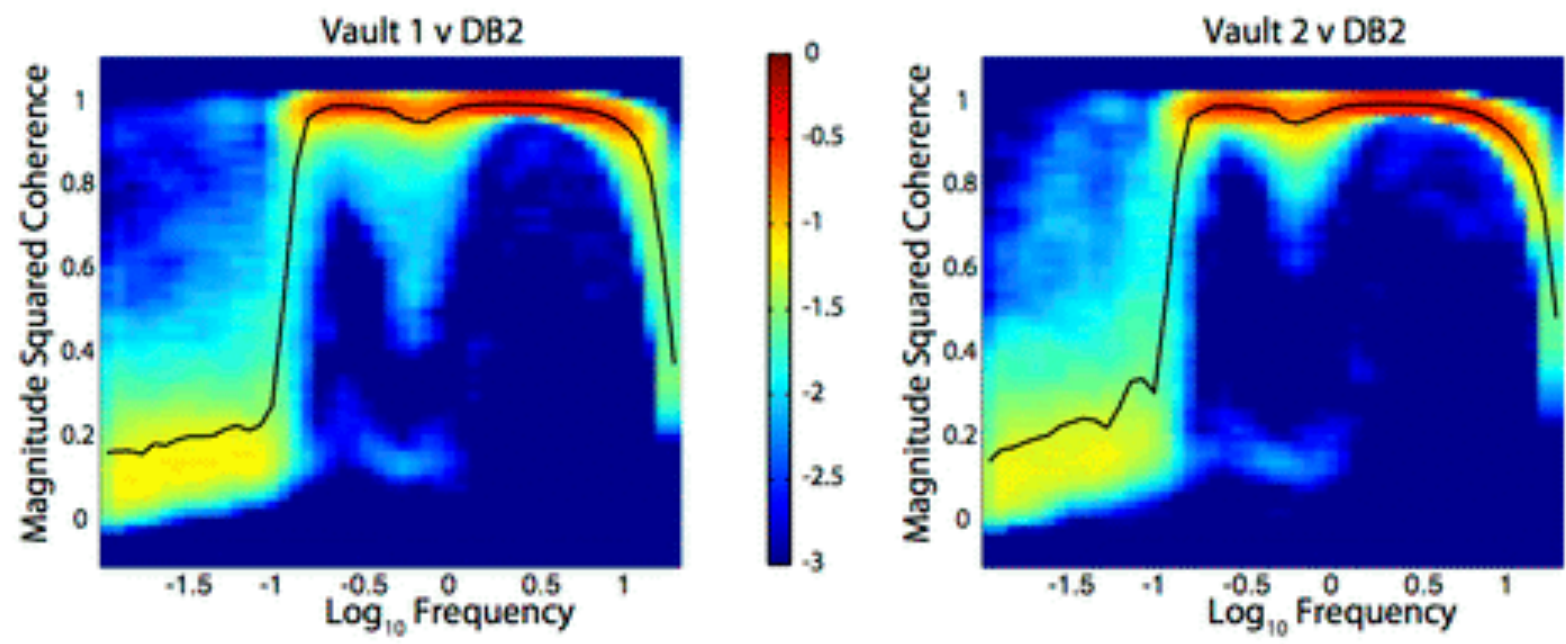

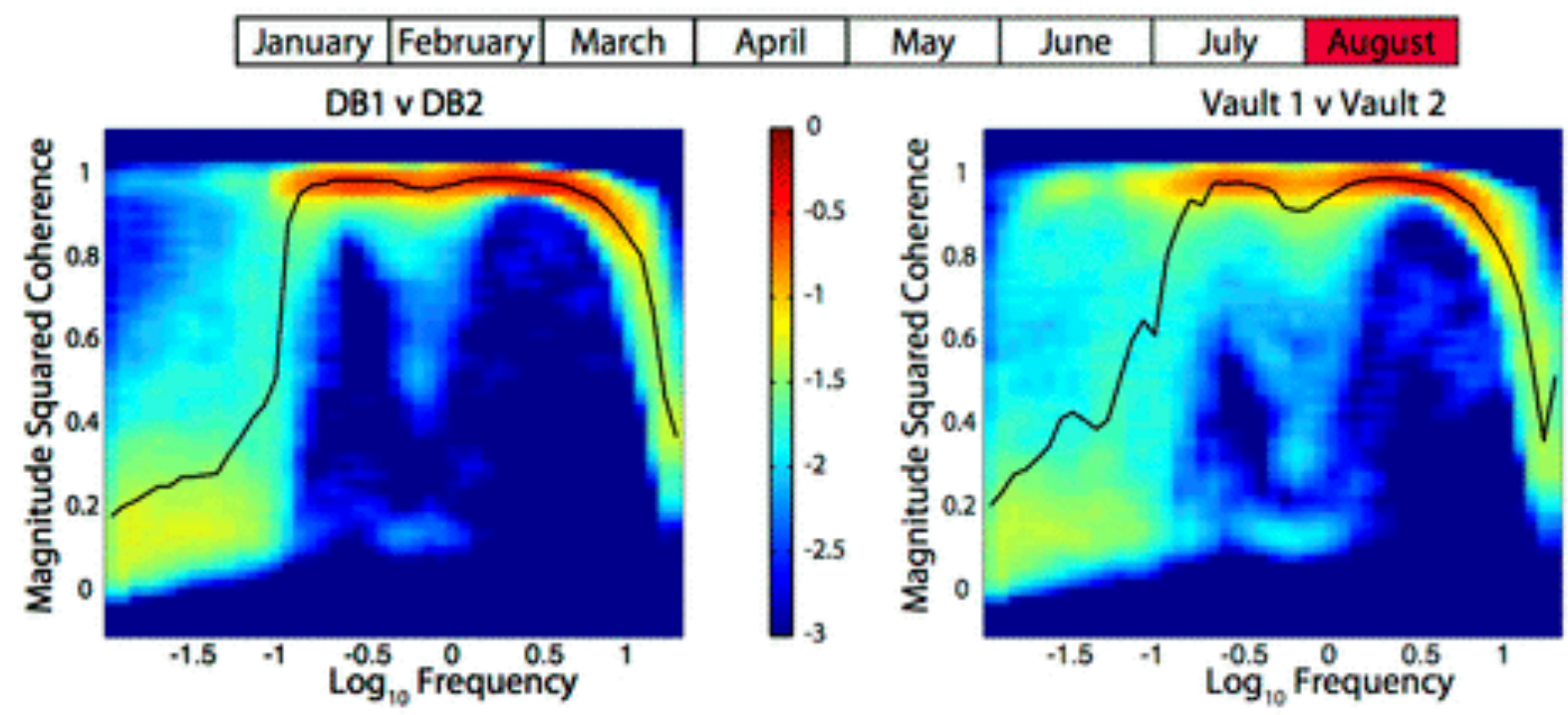

\section{BHE}
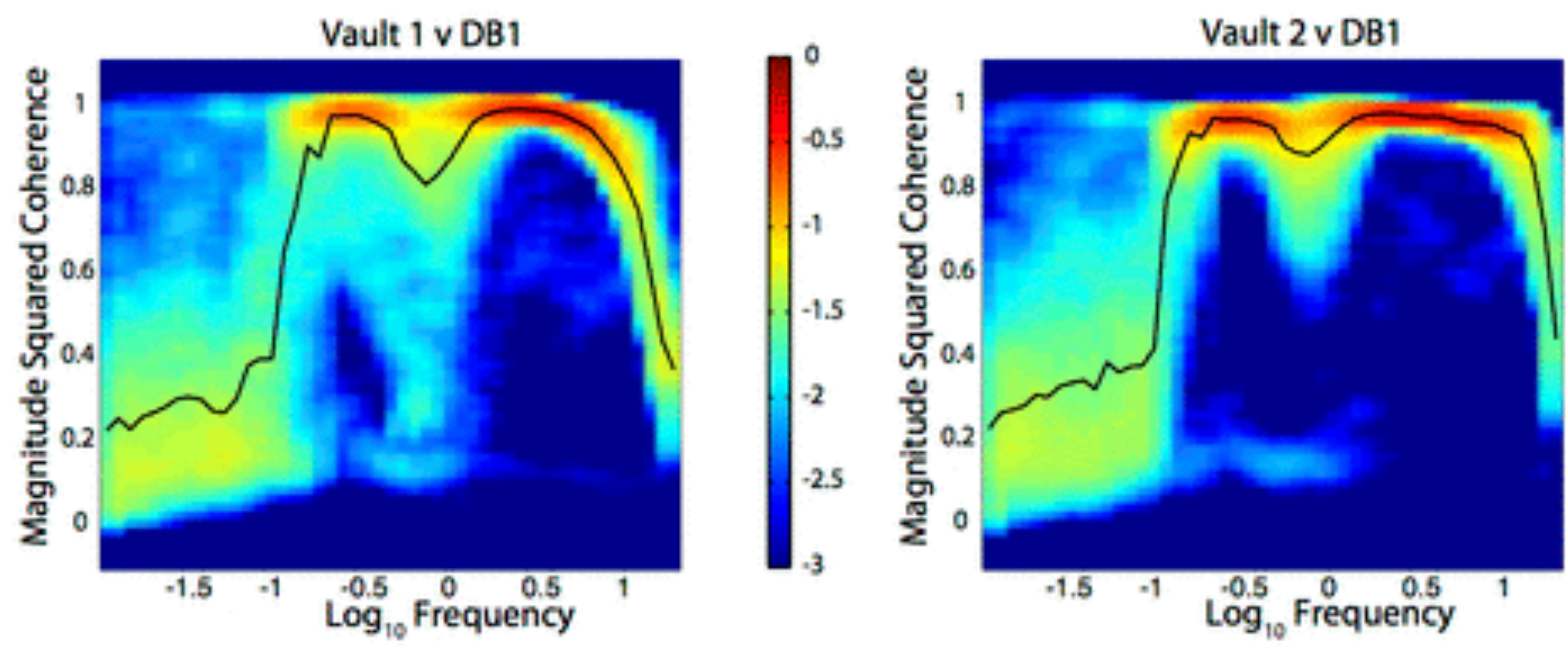

\section{BHE}
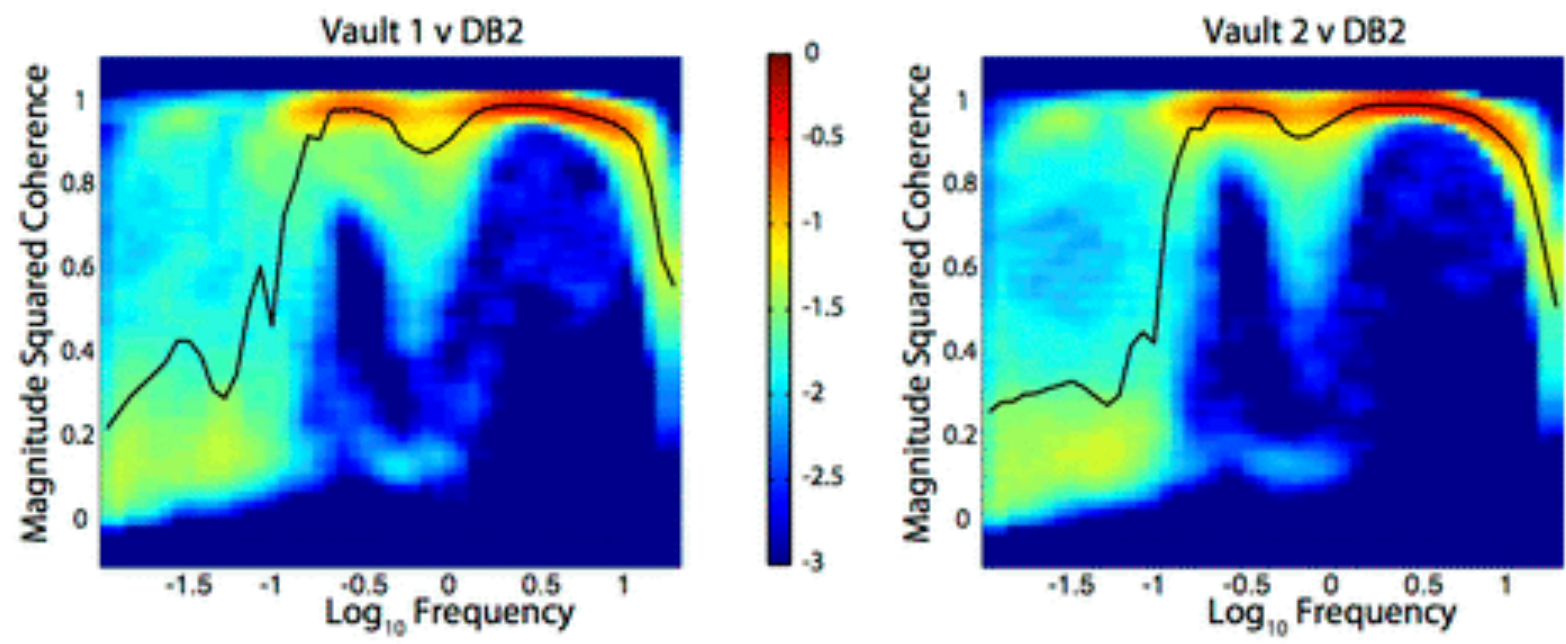

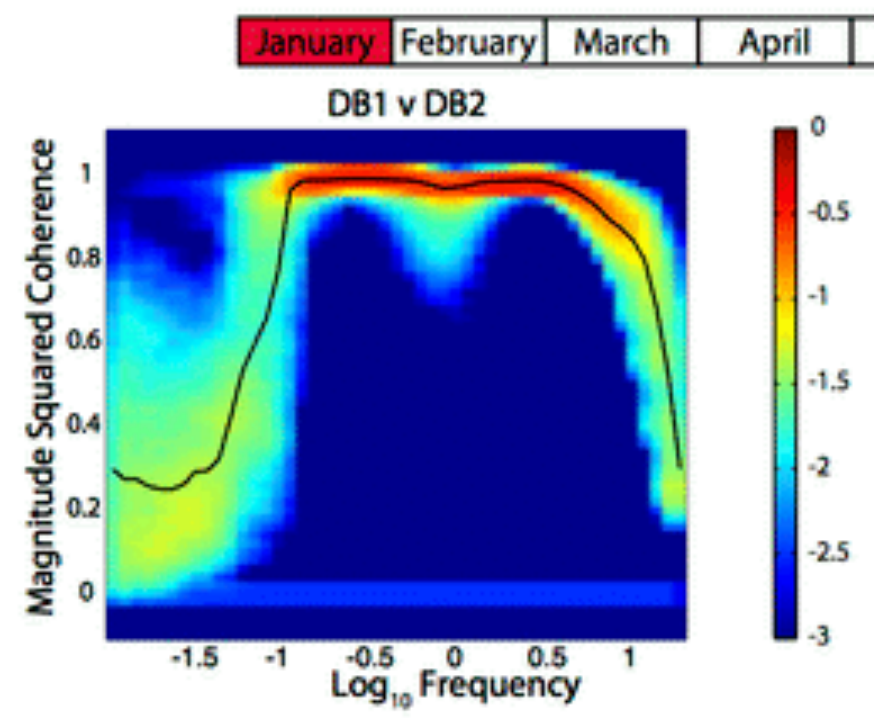

\begin{tabular}{|l|l|l|l|} 
May & June & July & August \\
\hline
\end{tabular}

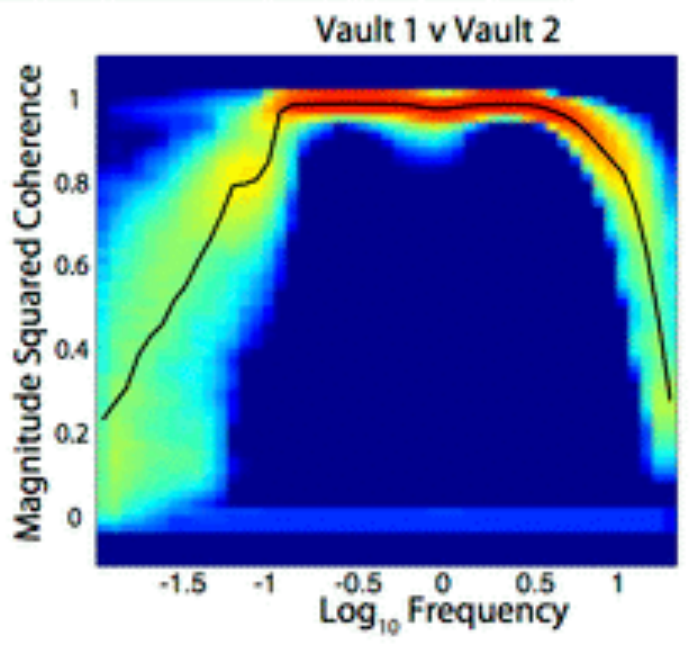

\section{$\mathrm{BHN}$}
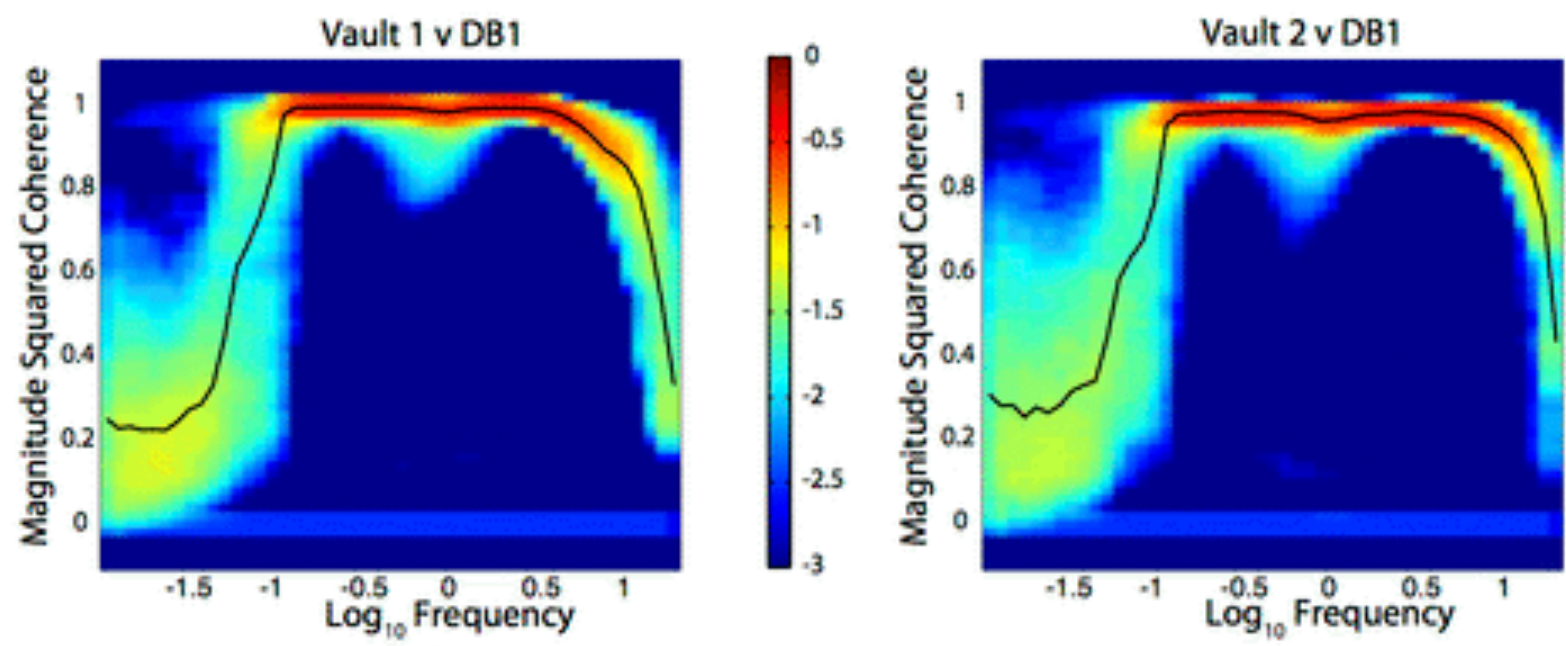

\section{$\mathrm{BHN}$}
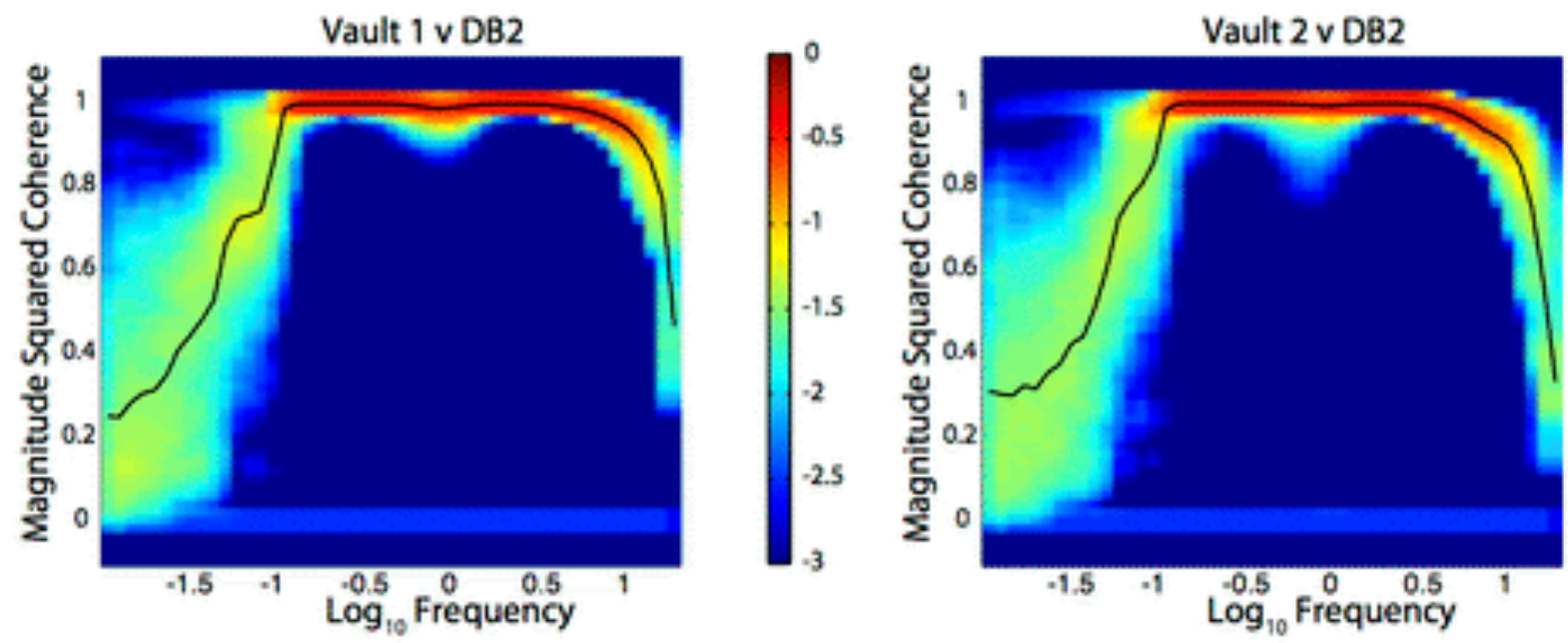

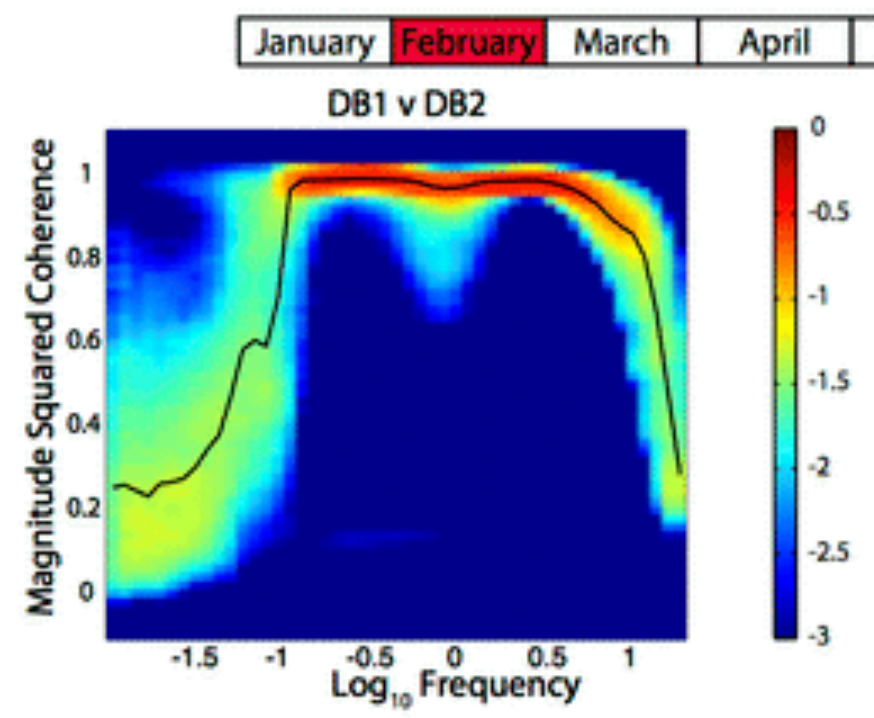

\begin{tabular}{|l|l|l|l|} 
May & June & July & August \\
\hline
\end{tabular}

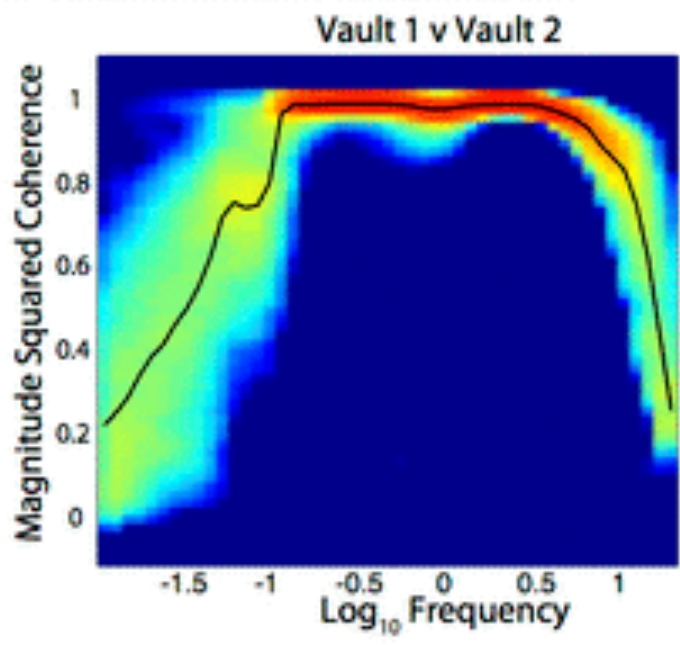

\section{$\mathrm{BHN}$}
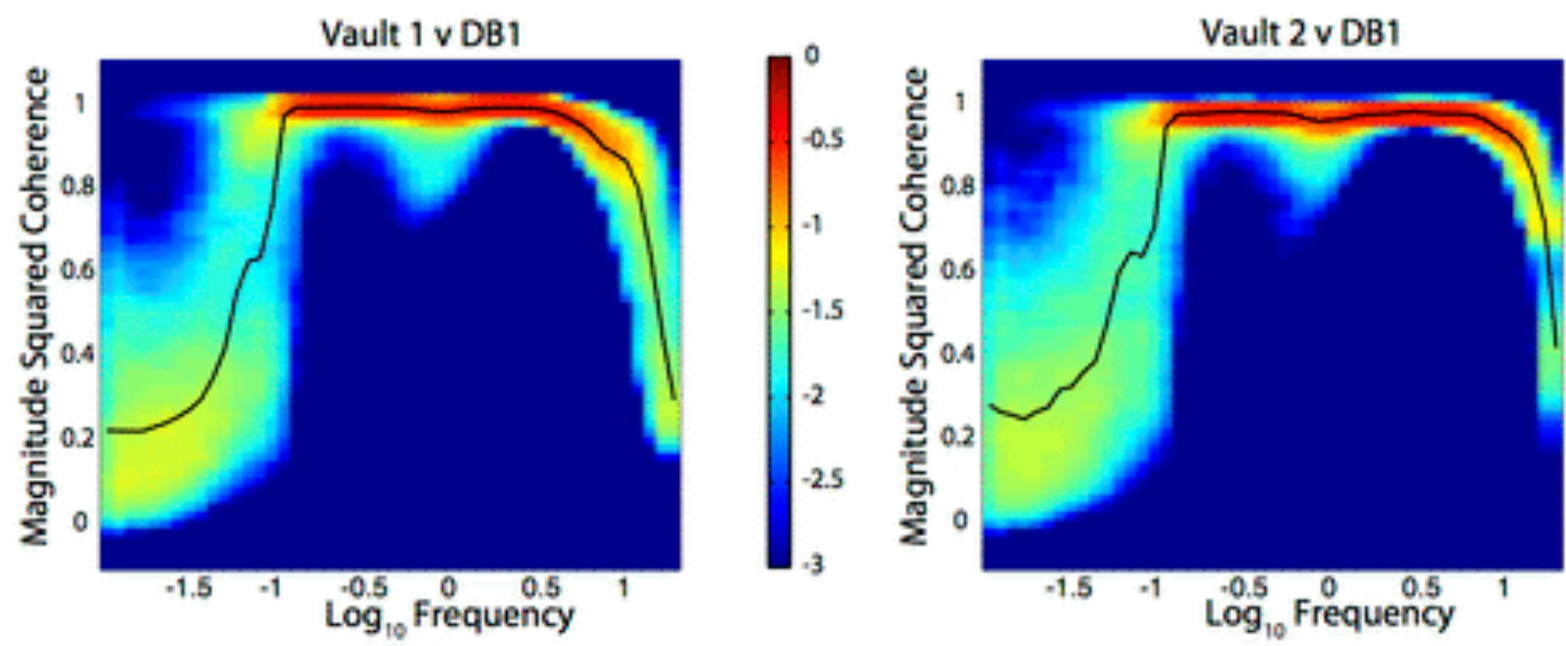

\section{$\mathrm{BHN}$}
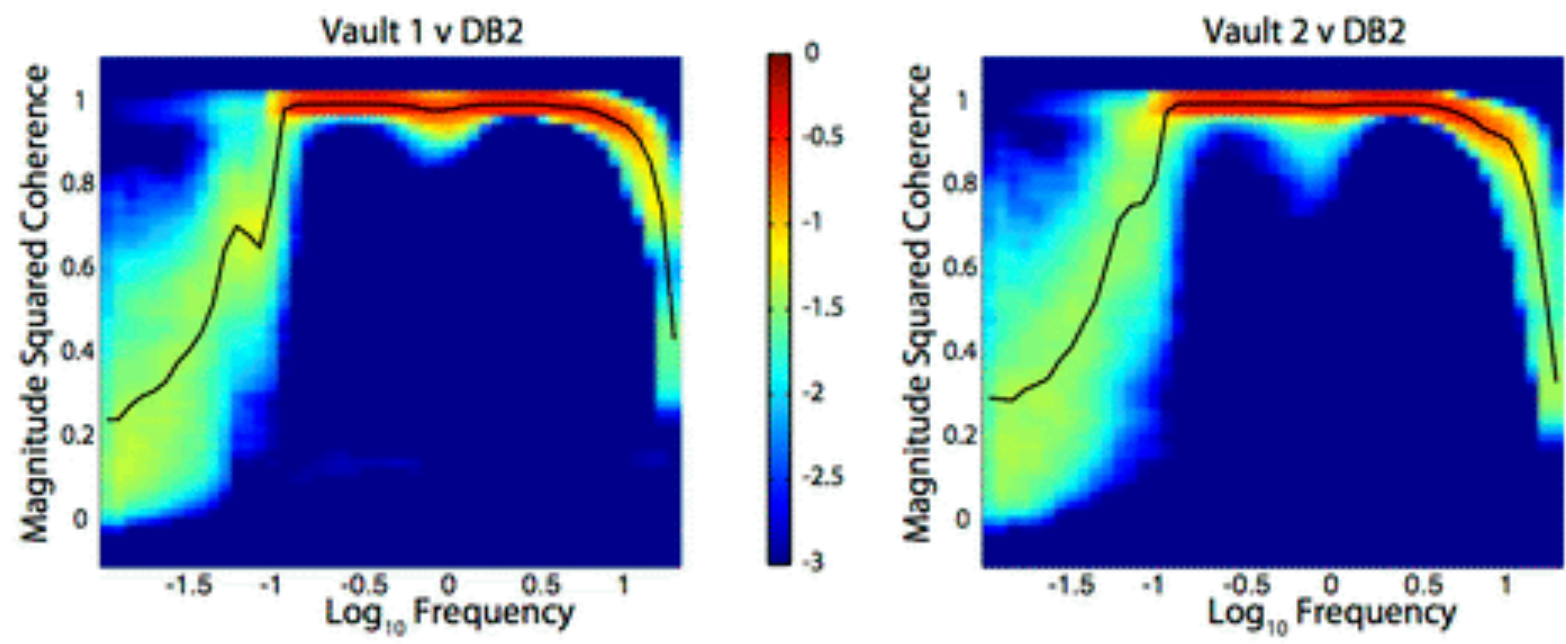

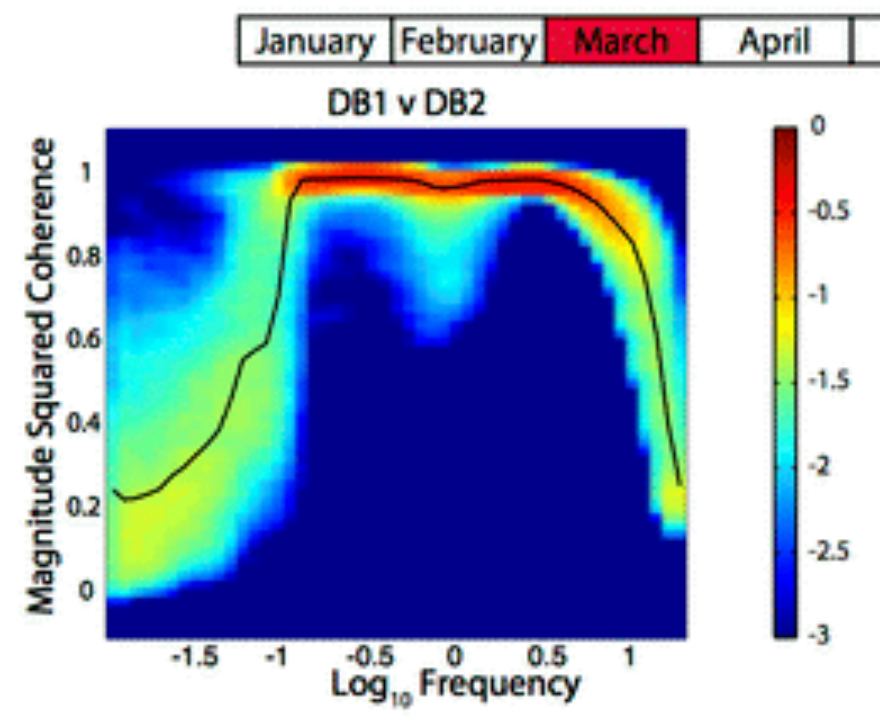

\begin{tabular}{|l|l|l|l|} 
May & June & July & August \\
\hline
\end{tabular}

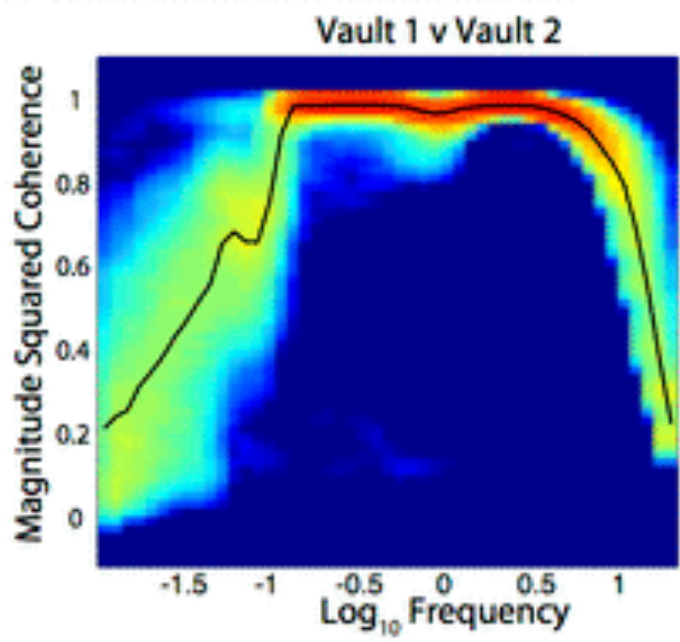

\section{$\mathrm{BHN}$}
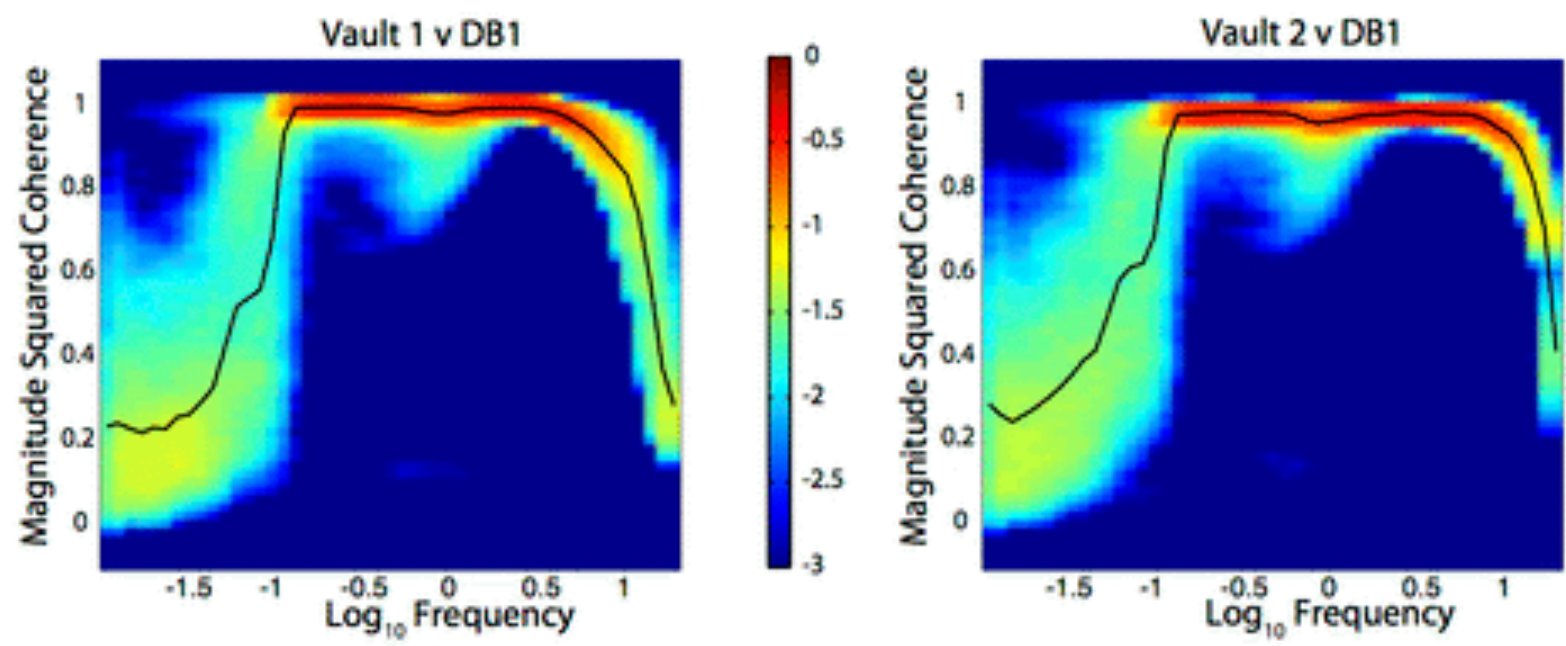

\section{$\mathrm{BHN}$}
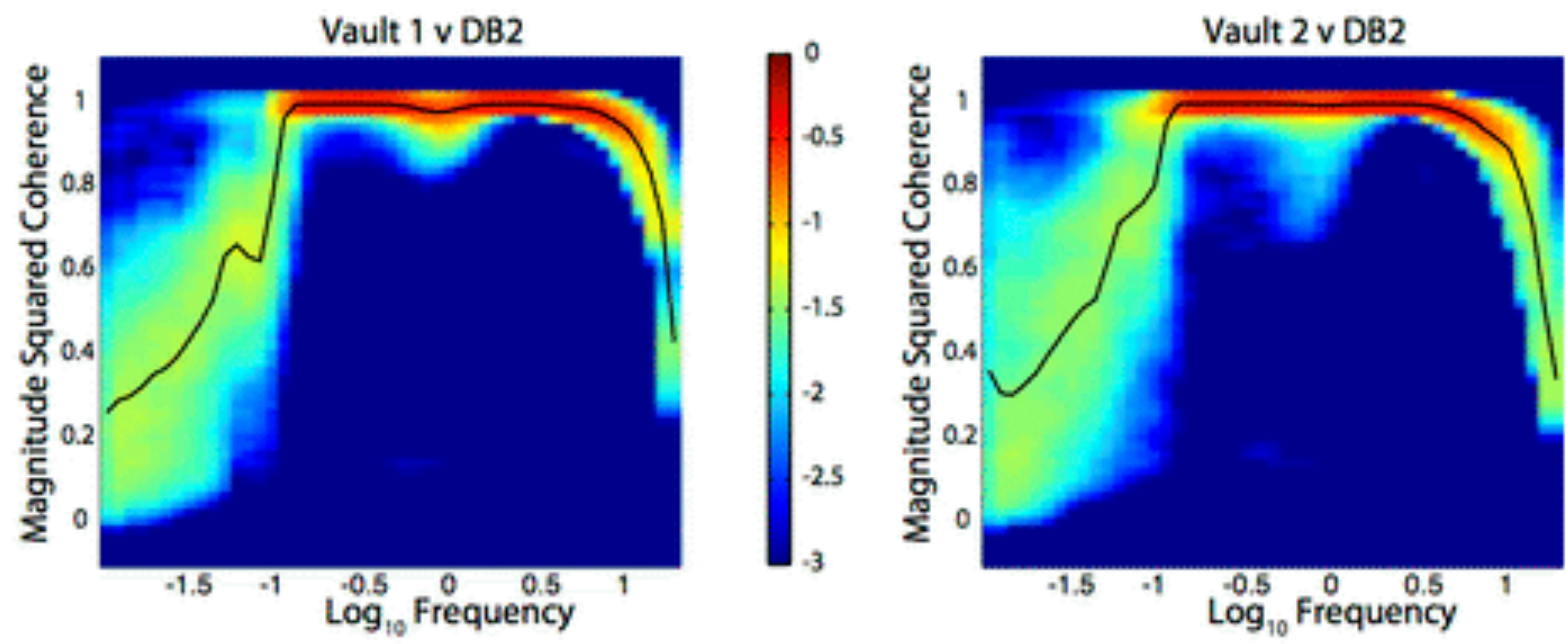

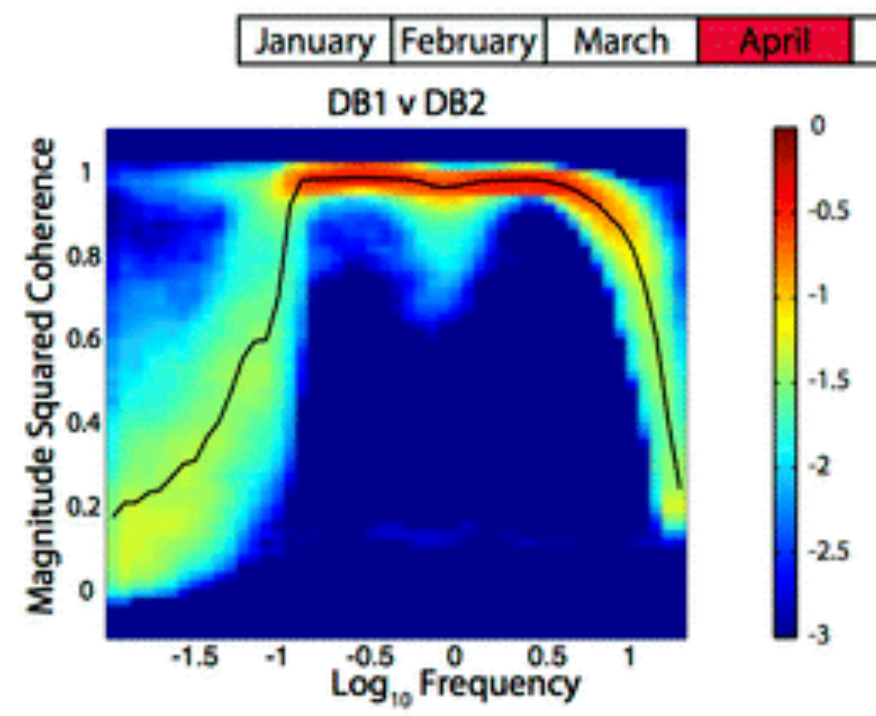

\begin{tabular}{|l|l|l|l|}
\hline May & June & July & August \\
\hline
\end{tabular}

\section{BHN}
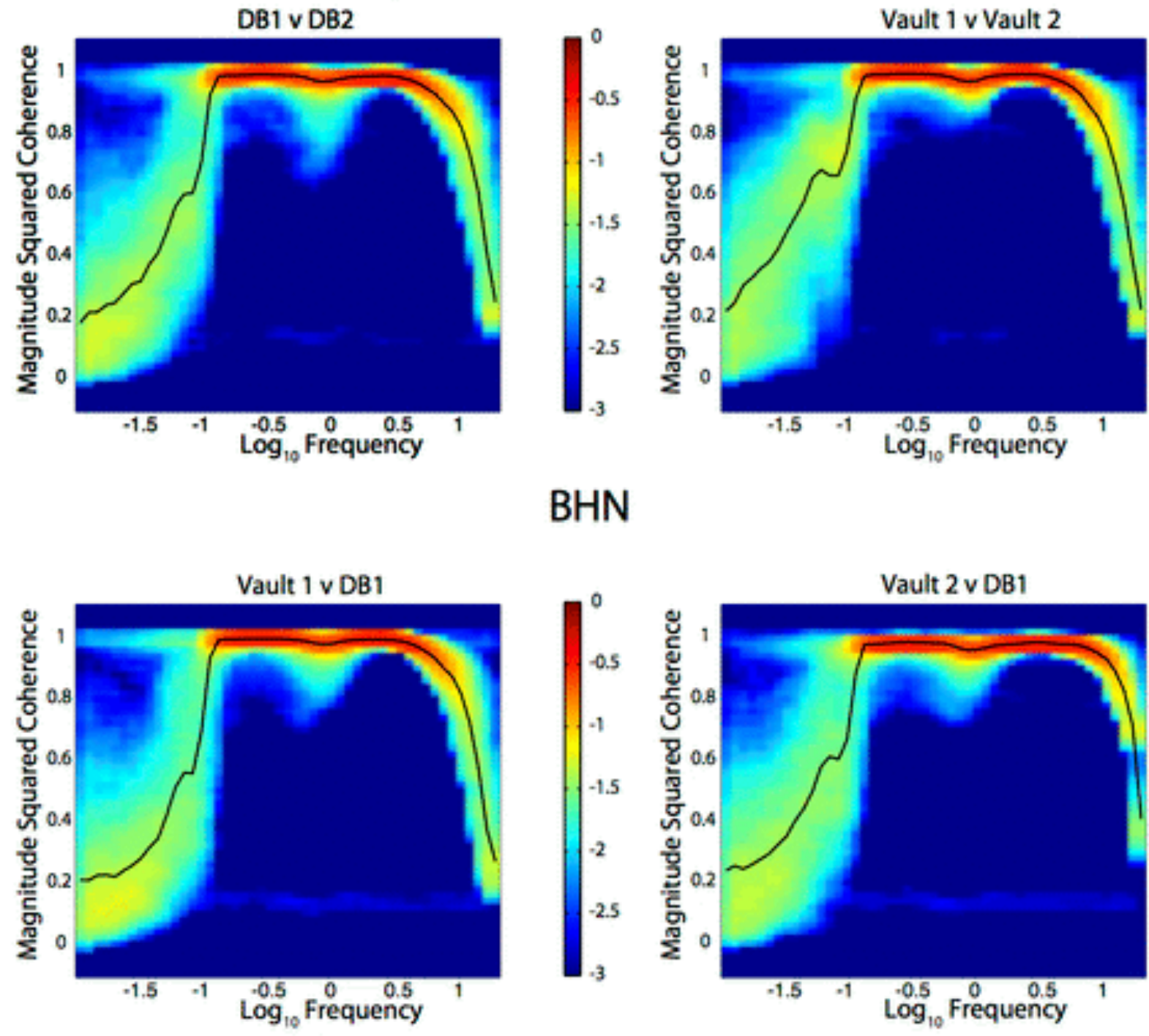


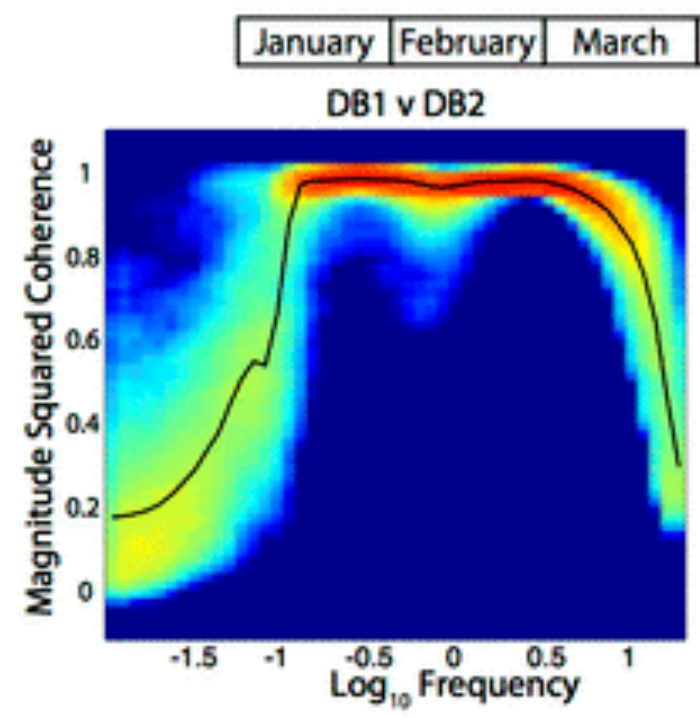

\begin{tabular}{|l|l|l|l|} 
May & June & July & August \\
\hline
\end{tabular}
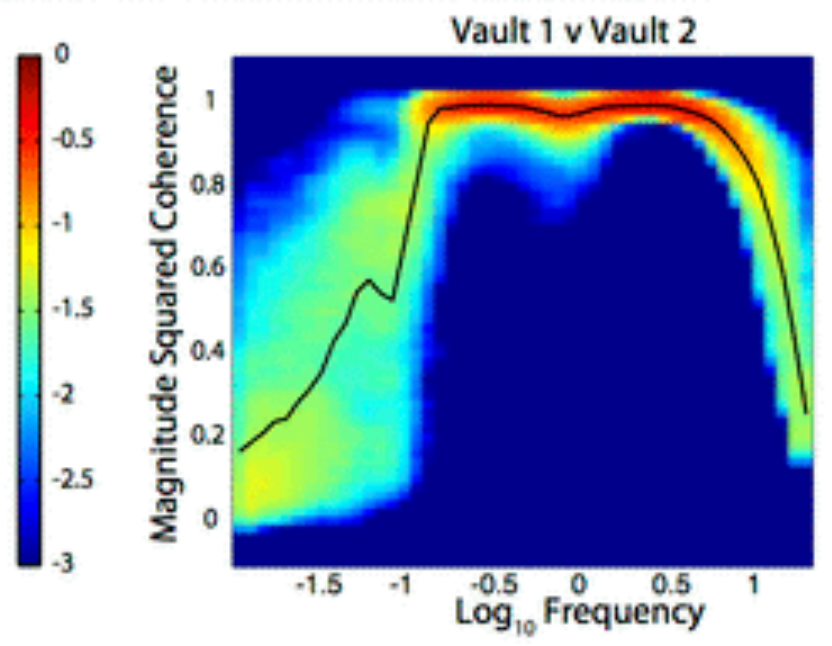

\section{$\mathrm{BHN}$}
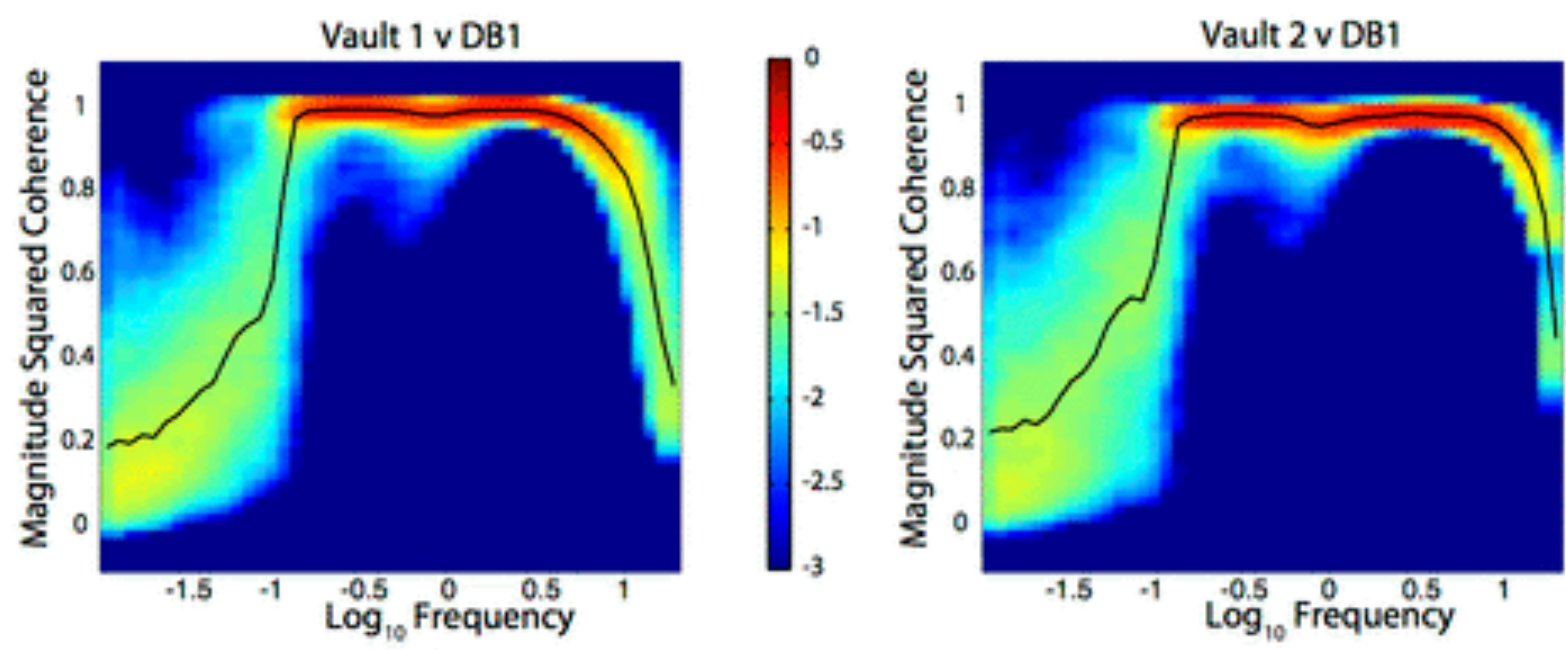

\section{$\mathrm{BHN}$}
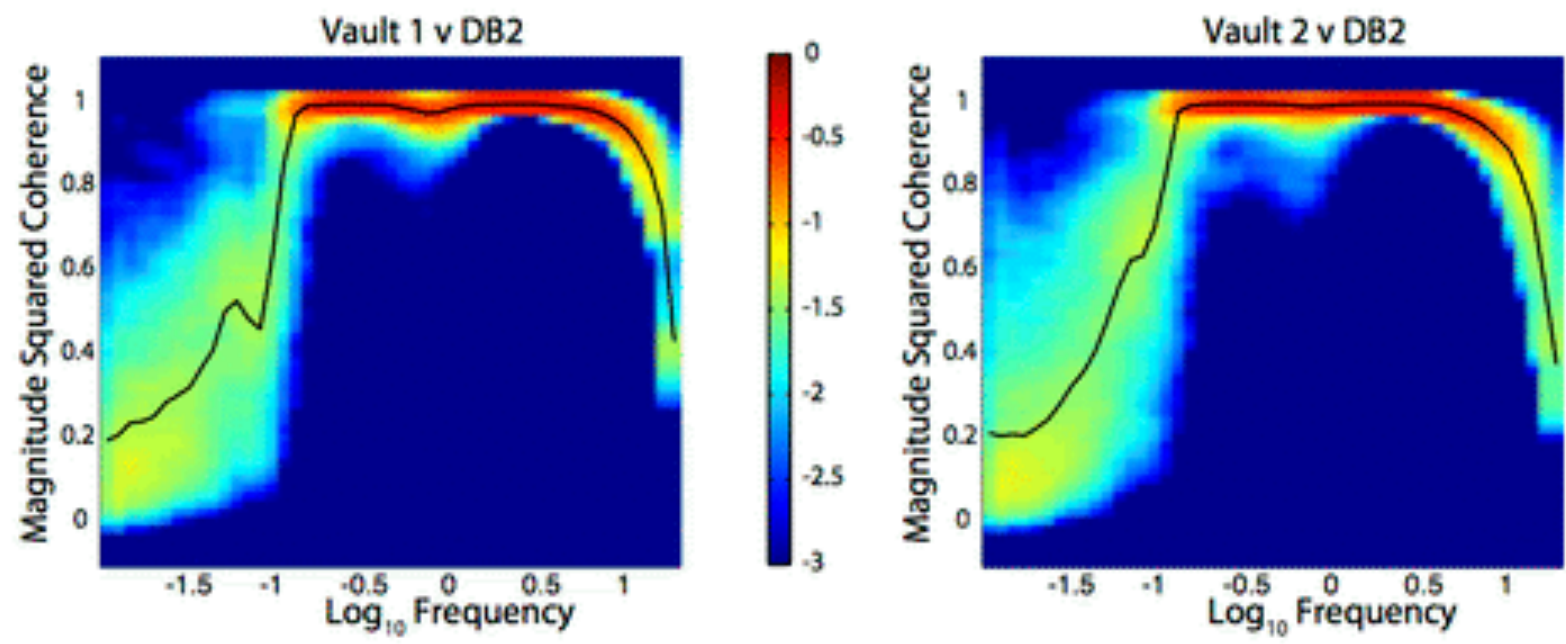

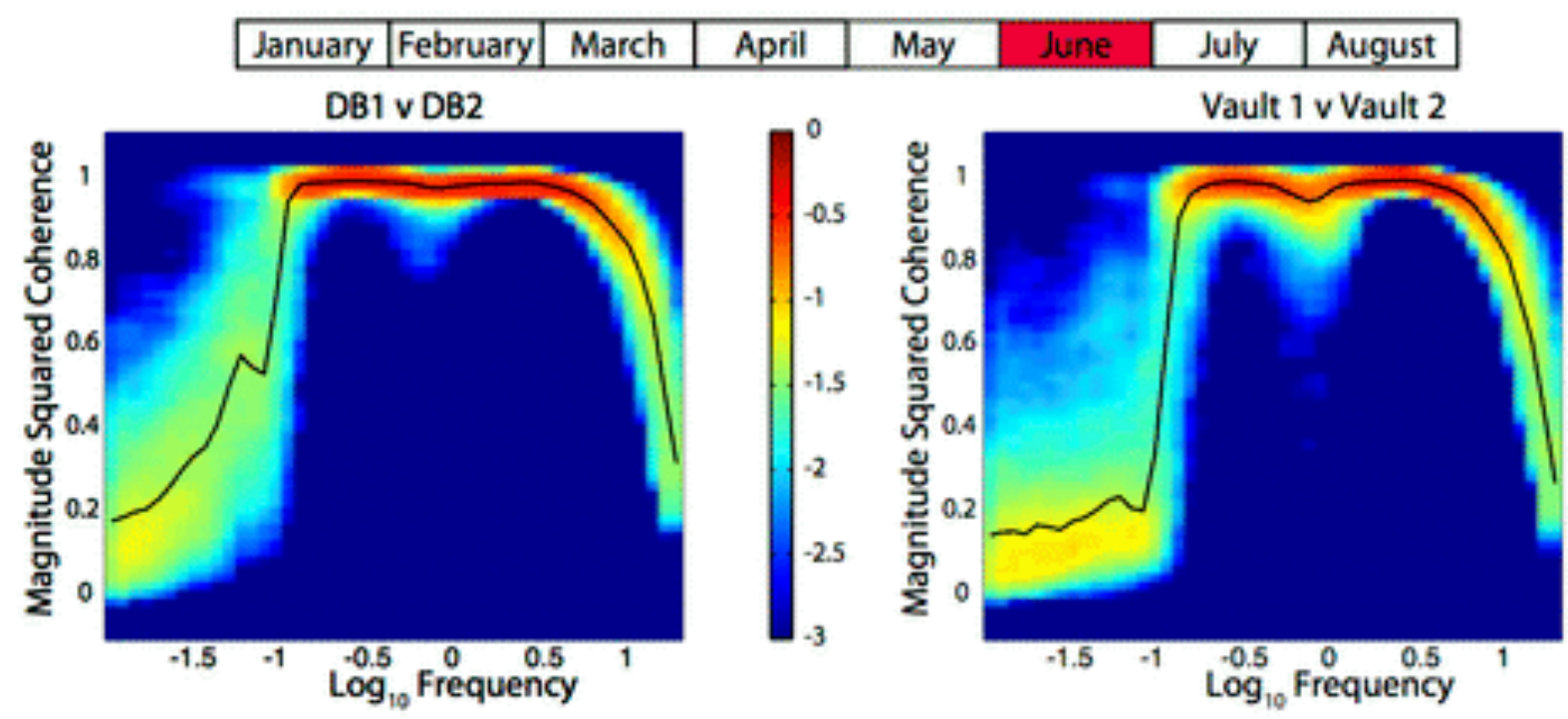

\section{$\mathrm{BHN}$}
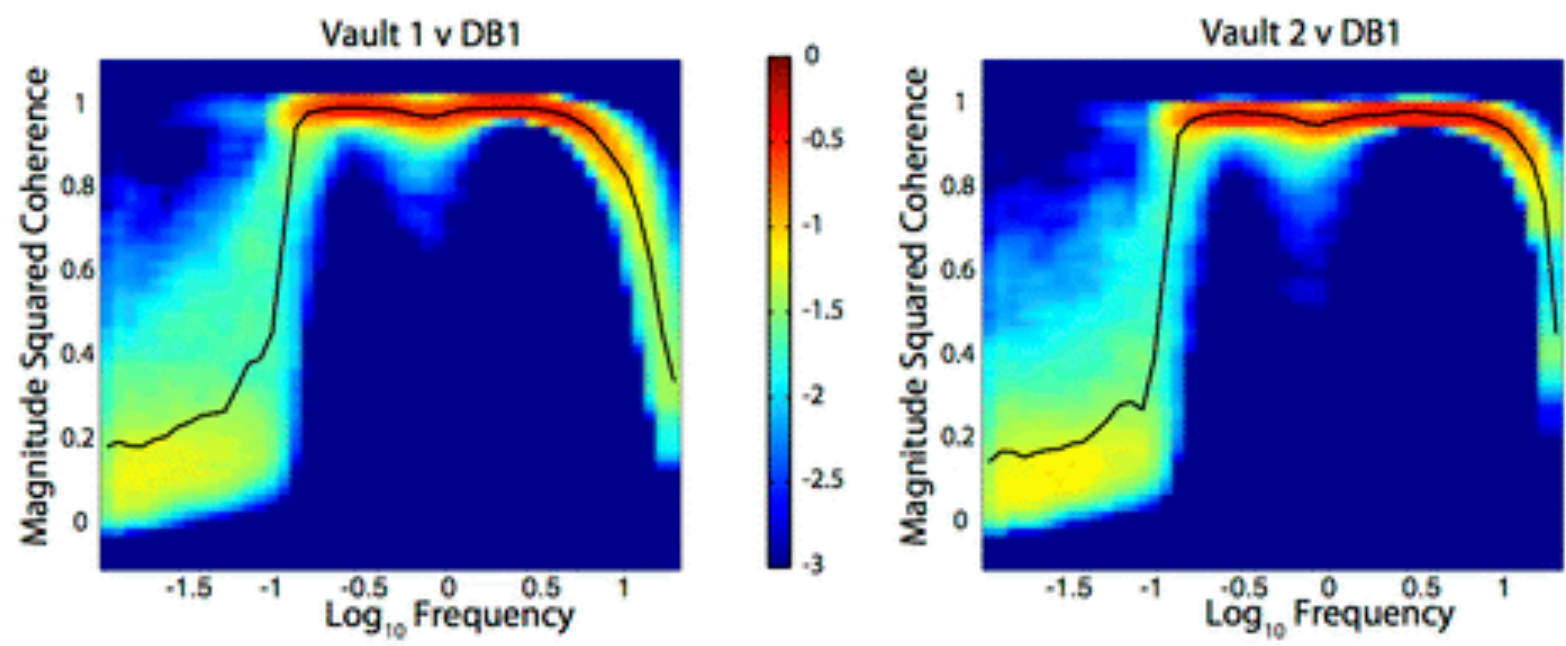

\section{$\mathrm{BHN}$}
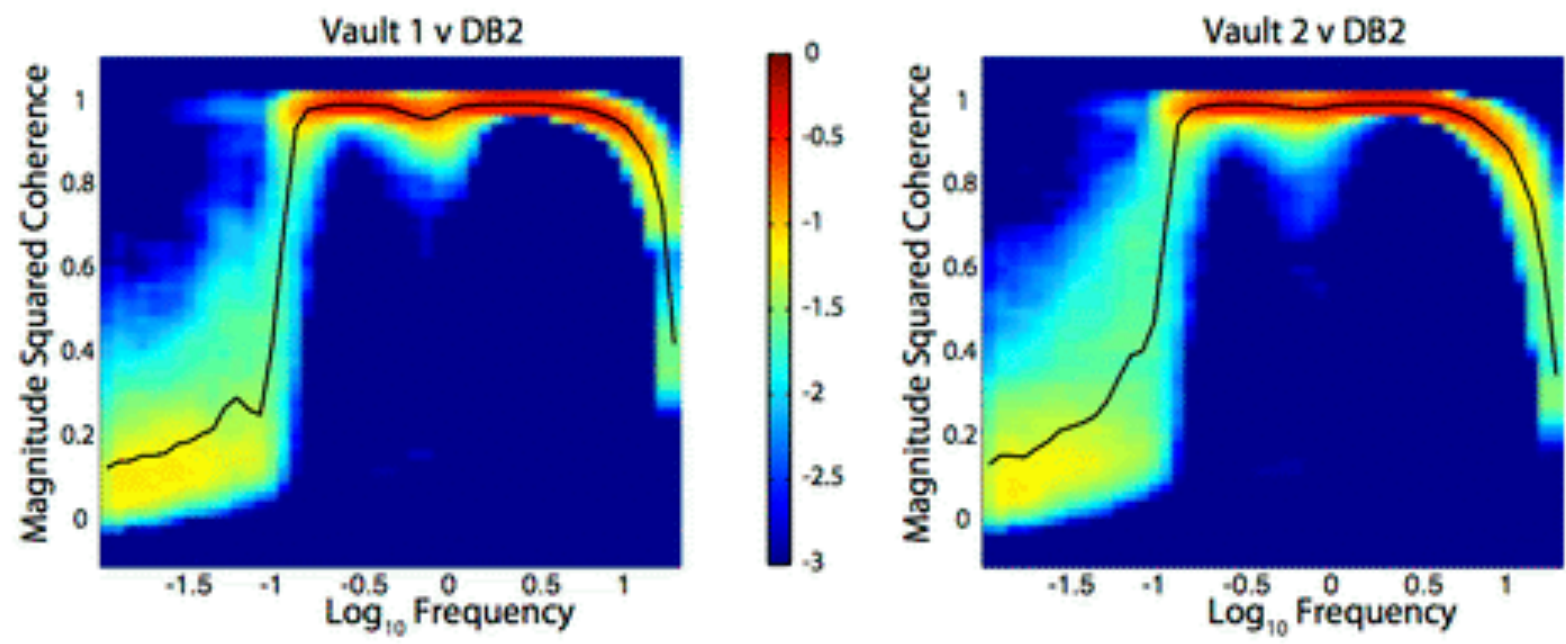

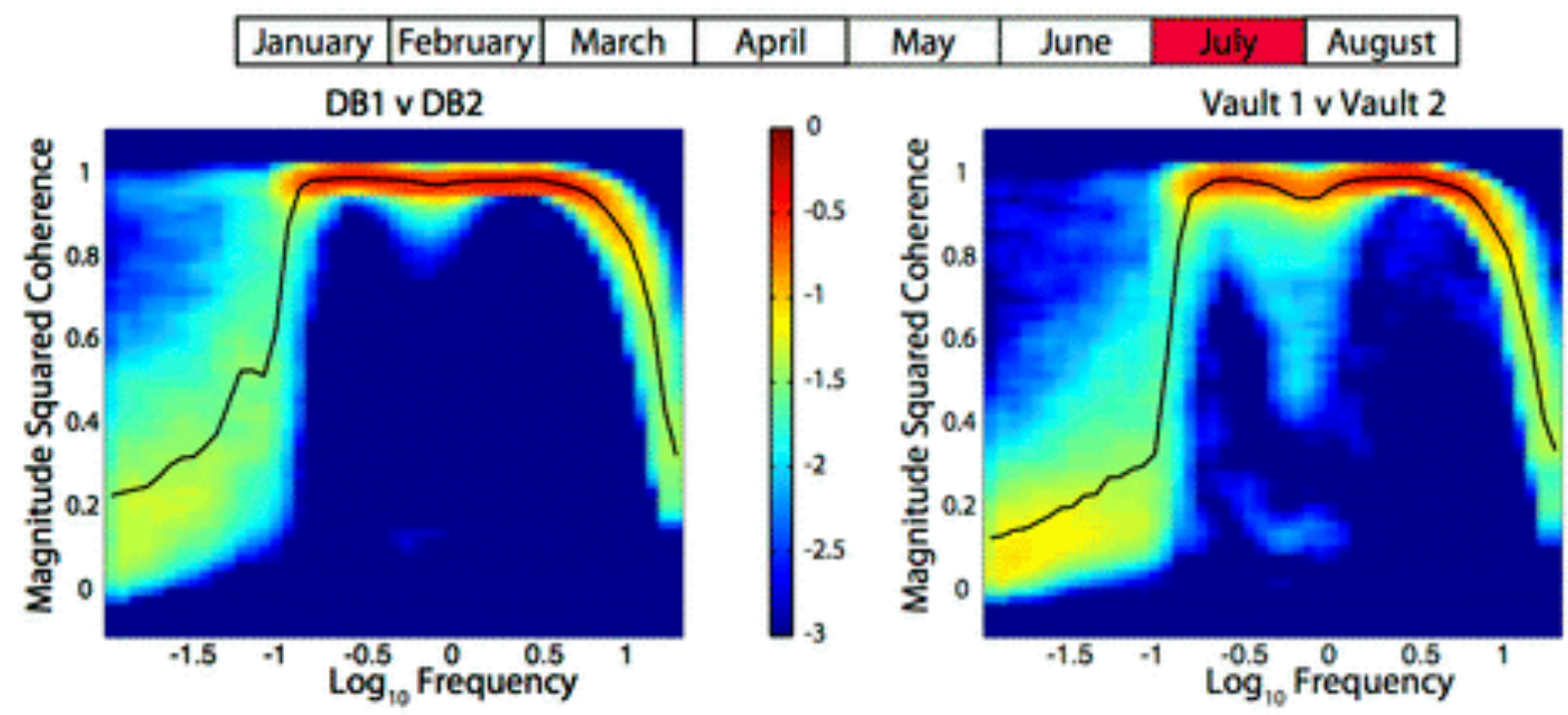

\section{$\mathrm{BHN}$}
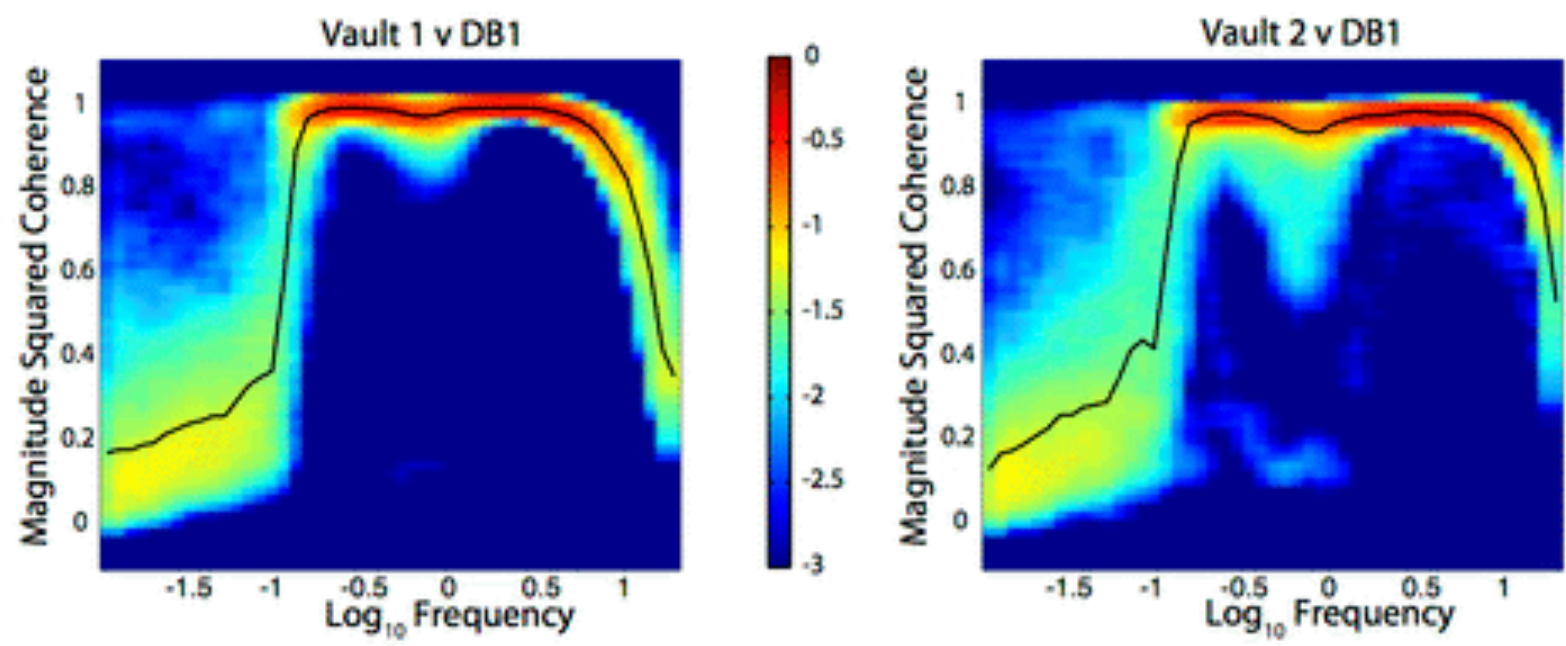

\section{$\mathrm{BHN}$}
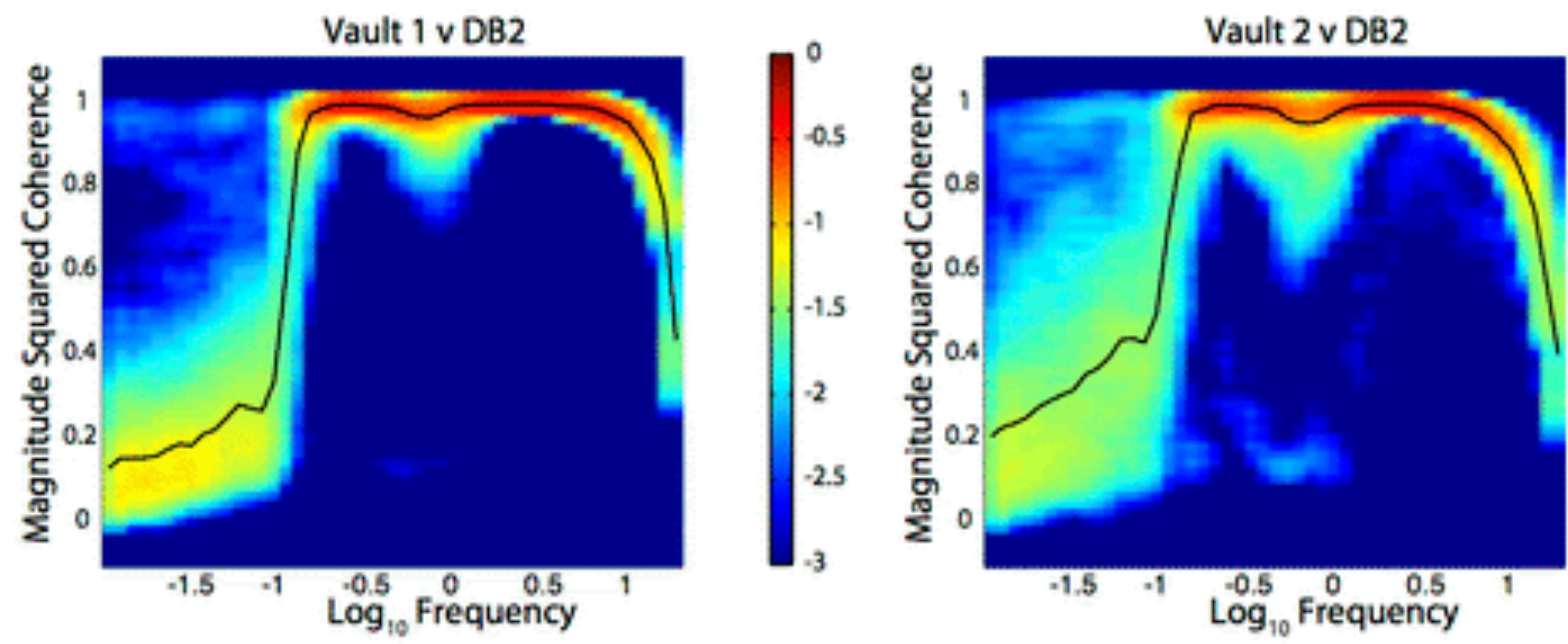

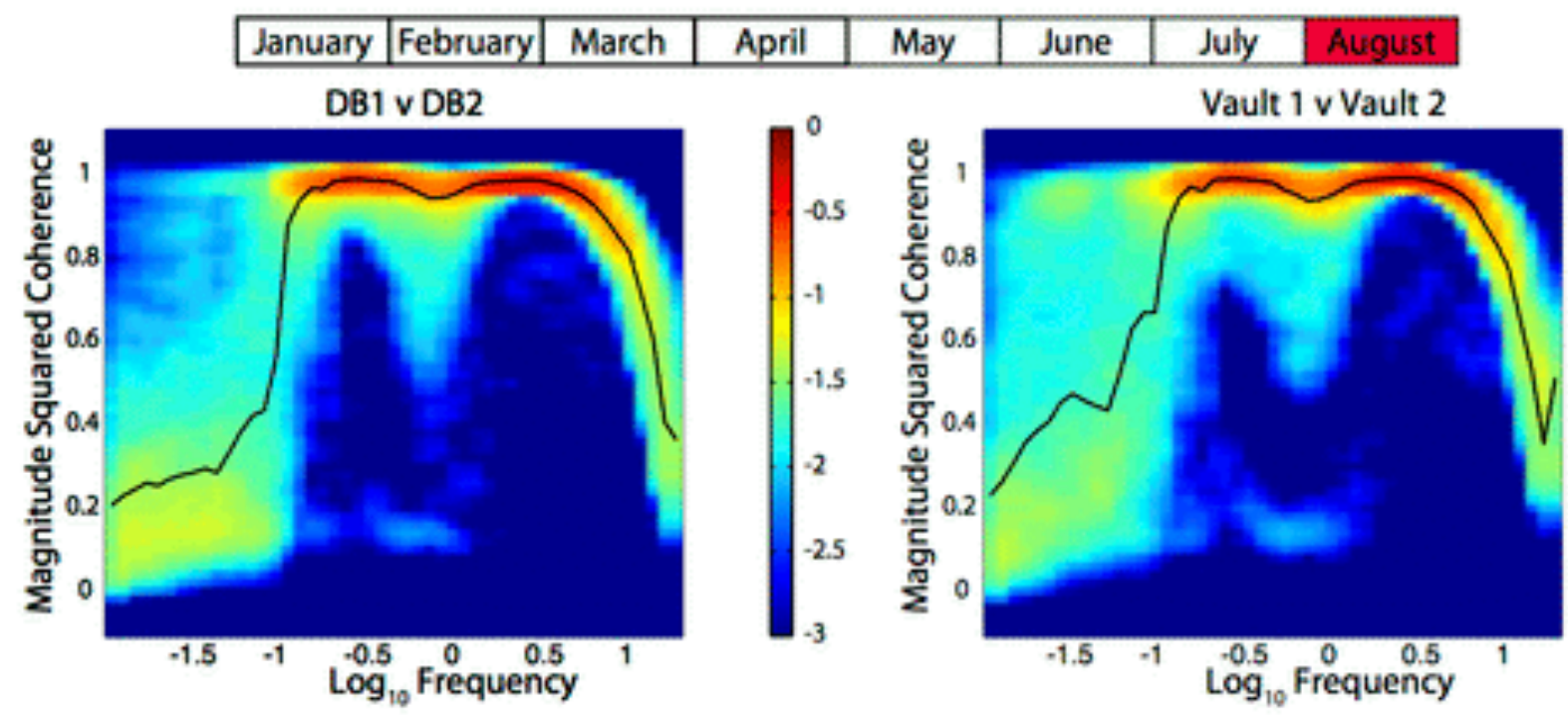

\section{$\mathrm{BHN}$}
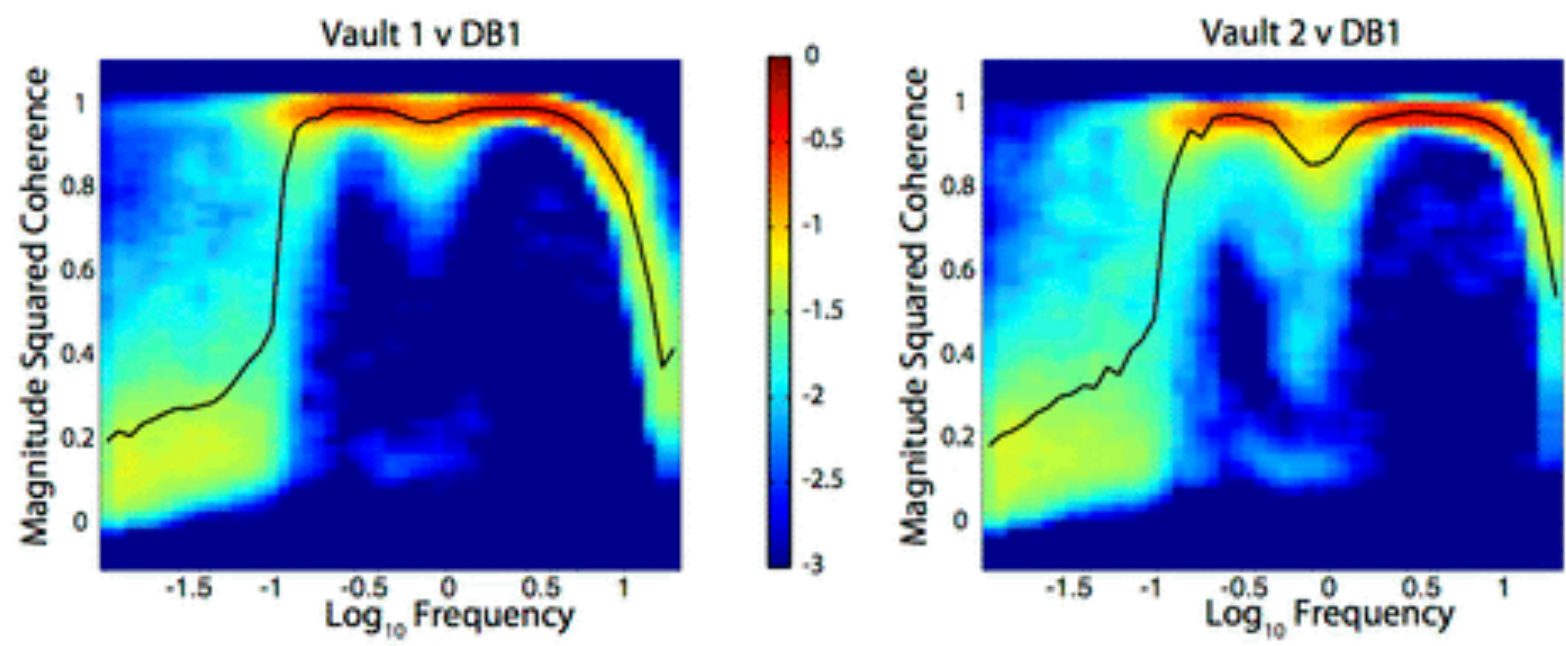

\section{$\mathrm{BHN}$}
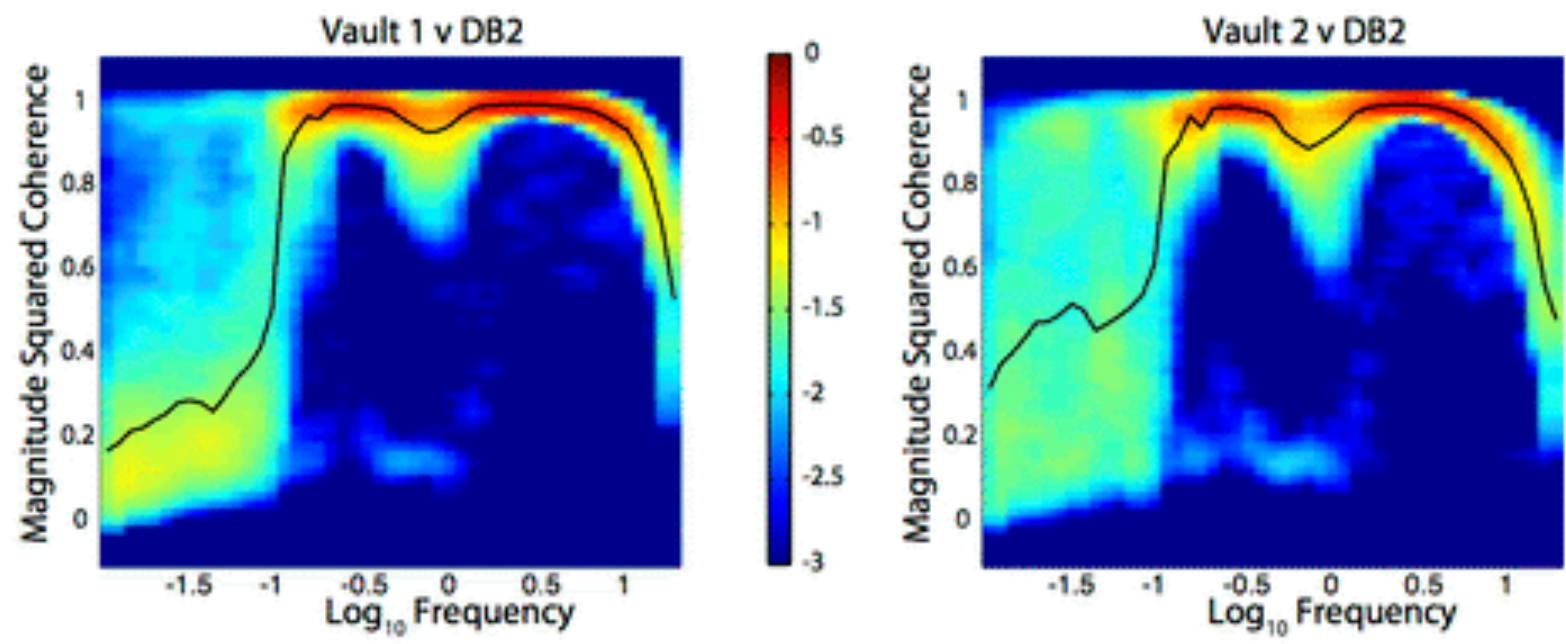